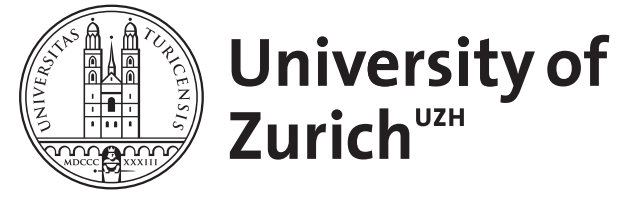

\title{
Römisches Erbrecht im Gnomon des Idios Logos
}

Babusiaux, Ulrike

DOI: https://doi.org/10.26498/zrgra-2018-1350107

Posted at the Zurich Open Repository and Archive, University of Zurich ZORA URL: https://doi.org/10.5167/uzh-161168

Journal Article

Published Version

Originally published at:

Babusiaux, Ulrike (2018). Römisches Erbrecht im Gnomon des Idios Logos. Zeitschrift der SavignyStiftung für Rechtsgeschichte. Romanistische Abteilung, 135(1):108-177.

DOI: https://doi.org/10.26498/zrgra-2018-1350107 


\title{
ZEITSCHRIFT \\ DER SAVIGNY-STIFTUNG \\ FÜR \\ RECHTSGESCHICHTE
}

\author{
135. B A N D
}

H E R A U S G E G E B E N V O N

U. BABUSIAUX, W. KAISER, M. SCHERMAIER, H.-P. HAFERKAMP, P. OESTMANN, J. RÜCKERT,

H. DE WALL, M. SCHMOECKEL, A. THIER

\author{
ROMANISTISCHE ABTEILUNG
}

\section{ELEKTRONISCHER SONDERDRUCK}

SAVIGNY VERLAGSGESELLSCHAFT MBH, WIEN 
Die Zeitschrift der Savigny-Stiftung für Rechtsgeschichte [ZRG] erscheint jährlich in drei selbständigen Abteilungen. Sie veröffentlicht Beiträge zur rechtshistorischen Forschung und berichtet über das einschlägige wissenschaftliche Schrifttum. Richtlinien zur Manuskriptgestaltung und vieles mehr unter www.savigny-zeitschrift.com. Redaktion der ZRG: DDr. Reingard Rauch, Waldheimatweg 33, A-8010 Graz, r.rauch@Savigny-Zeitschrift.com, www.savignyzeitschrift.com

Die Herausgeber und ihre Anschriften seit Januar 2017:

\section{Romanistische Abteilung}

Prof. Dr. Ulrike Babusiaux, Lehrstuhl für Römisches Recht, Privatrecht und Rechtsvergleichung, Rechtswissenschaftliches Institut, Universität Zürich, Rämistrasse 74/41, CH-8001 Zürich, ulrike.babusiaux@uzh.ch (Rezensionen)

Prof. Dr. Wolfgang Kaiser, Institut für Rechtsgeschichte und geschichtliche Rechtsvergleichung - Romanistische Abteilung, Albert-Ludwigs-Universität, Platz der Alten Synagoge, D-79085 Freiburg, wolfgang.kaiser@jura.uni-freiburg.de (Aufsätze und Miszellen zum altorientalischen, griechischen und byzantinischen Recht sowie zum römischen Recht der Spätantike und des Mittelalters)

Prof. Dr. Martin J. Schermaier, Institut für Römisches Recht und Vergleichende Rechtsgeschichte, Rheinische Friedrich-Wilhelms-Universität, Adenauerallee 24-42, D-53113 Bonn, schermaier@jura.uni-bonn.de (Aufsätze und Miszellen zum römischen Recht der Republik und des Prinzipats sowie zur Rezeptions- und Wirkungsgeschichte des römischen Rechts)

\section{Germanistische Abteilung}

Prof. Dr. Peter Oestmann, Institut für Rechtsgeschichte, Westfälische Wilhelms-Universität, Universitätsstraße 14-16, D-48143 Münster, oestmann@uni-muenster.de (Aufsätze, Miszellen und Besprechungen für die Zeit bis 1800)

Prof. Dr. Dr. h.c. Joachim Rückert, Neuere Rechtsgeschichte, Juristische Zeitgeschichte, Zivilrecht und Rechtsphilosophie, Goethe-Universität FB 01 Fach 13, Postfach 1119 32, D-60054 Frankfurt, rueckert@jur.uni-frankfurt.de (Aufsätze und Miszellen für die Zeit ab 1800 sowie Gastbeiträge)

Prof. Dr. Hans-Peter Haferkamp, Direktor des Instituts für Neuere Privatrechtsgeschichte, Deutsche und Rheinische Rechtsgeschichte, Universität zu Köln, Albertus-Magnus-Platz, D-50923 Köln, hans-peter.haferkamp@uni-koeln.de (Aufsätze, Miszellen und Besprechungen für die Zeit ab 1800)

\section{Kanonistische Abteilung}

Prof. Dr. Andreas Thier, Rechtswissenschaftliches Institut, Universität Zürich, Rämistrasse 74, CH-8001 Zürich, Ist.thier@rwi.uzh.ch (Aufsätze und Miszellen zum kanonischen Recht)

Prof. Dr. Heinrich de Wall, Hans-Liermann-Institut, Hindenburgstraße 34, D-91054 Erlangen, hli@fau.de (Aufsätze und Miszellen zum Evangelischen Kirchenrecht und Staatskirchenrecht)

Prof. Dr. Mathias Schmoeckel, Institut für Deutsche und Rheinische Rechtsgeschichte, Universität Bonn, Adenauerallee 24-42, D-53113 Bonn, rgesch@jura.uni-bonn.de (Literatur)

\section{ISSN 0323-4096}

ISBN 978-3-903195-05-9 (Einzelband)

(c) 2018 Savigny Verlagsgesellschaft mbH, A-1010 Wien. Alle Rechte vorbehalten.

Satz: Vogelmedia GmbH, A-2102 Bisamberg, www.vogelmedia.at

Druck und Herstellung in der EU 


\section{ZEITSCHRIFT DER SAVIGNY-STIFT U NG F ÜR RECHTSGESCHICHTE ROMANISTISCHE ABTEILUNG}

\section{Inhalt des 135. Bands}

\section{Aufsätze:}

Albers, Gregor, Zum Versprechen als Verpflichtungsgrund in der Spätantike: Urkundenpraxis, Kirchenlehrer und der westgotische Gaius . . . 334

Babusiaux, Ulrike, Römisches Erbrecht im Gnomon des Idios Logos . . 108

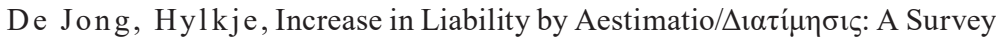
from Classical Roman Law to Byzantine Law . . . . . . . . . . . . . 364

Finkenauer, Thomas, Drittwirkende pacta im klassischen Recht . . . . . 178

Giglio, Francesco, The Concept of Ownership in Roman Law . . . . . . 76

Jakab, Éva, Prozess um eine entlaufene Sklavin (P.Cair.Preis. ${ }^{2}$ 1): Vertrag in der provinzialen Rechtskultur . . . . . . . . . . . . . . .

Jauß, Steffen M., Zur Konzeption des Vertrages zwischen Pharao Ramses II. und Großkönig Hattušili III. (1259 v.Chr.) . . . . . . . . . . . . . .

Liebs, Detlef, Wenn Fachliteratur Gesetz wird: Inwieweit wurden römische Juristenschriften im Lauf der Jahrhunderte überarbeitet? . . . . .

Pfeifer, Guido, Das Recht im Kontext normativer Ordnungen der Welt des Alten Orients . . . . . . . . . . . . . . . . . .

Wacke, Andreas, In pecuniam ludere: Die Rechtsfolgen verbotener Glücksspiele nach dem prätorischen Edikt - Rechtsschutzversagung als sozialpolitisches Programm . . . . . . . . . . . .

Zimmermann, Reinhard/Jakob Gleim, Überlebens- oder Kommorientenvermutung bei ,gemeinsamer Kalamität“? Schottland, England und die kontinentaleuropäische Rechtsentwicklung

\section{Miszellen:}

Beikircher, Hugo, Ad gladium (zu Coll. Mos. 11,7) . . . . . . . . . . 603

Kaiser, Wolfgang, Zur Textkritik von D. 38,10,1,6 (Gai. 8 [16] ed. prov.) . 633

Kaiser, Wolfgang, Zur Textkritik von Ulpianus (?), lib. sing. reg. 11,4 . .

Sotulenko, Eduard, ,Usu non capta' und ,morte Cincia removetur' in frg. Vat. $259 \ldots \ldots \ldots \ldots \ldots \ldots \ldots \ldots$ 


\section{IV}

Stag1, Jakob Fortunat, Caesars Koch oder das Schweigen der Quellen: Zur Kritik Varvaros am didaktischen System des Gaius . . . . . . . .

Trump, Dominik, Die Tironiana der Handschrift Paris, Bibliothèque Na-

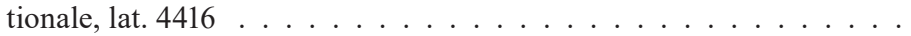

Varvaro, Mario, J.C. Maier - ein bereits bekannter Helfer Bluhmes bei der Transkription des Veroneser Codex Iustinianus . . . . . . . . . . .

\section{Dokumente:}

Beggio, Tommaso, Paul Koschaker und die Reform des romanistischen Rechtsstudiums in Deutschland. Ein unveröffentlichtes Dokument . .

B ock, Oliver, Fünf unveröffentlichte Briefe einer Korrespondenz zwischen Savigny und Charles Purton Cooper . . . . . . . . . . . . .

\section{Literatur:}

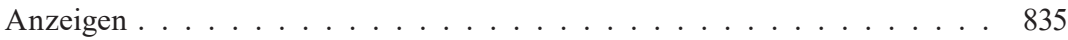

Rezensionen ........................... 681

Neuerscheinungen . . . . . . . . . . . . . . . . . . 877

Ancient Law, Ancient Society. Hg. von Dennis P. Kehoe/Thomas A.J.

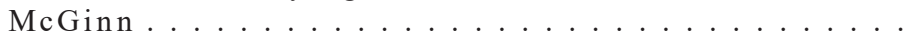

Anzeige von Ulrike Babusiaux

Außergerichtliche Konfliktlösung in der Antike, Beispiele aus drei Jahrtausenden. Hg. von Guido Pfeifer/Nadine Grotkamp . . . . . . . Anzeige von Ulrike Babusiaux

Cardilli, Riccardo, Damnatio e oportere nell'obbligazione . . . . . . . 764 Besprochen von Pascal Pichonnaz

Coffee, Neil, Gift and Gain. How Money Transformed Ancient Rome . . Besprochen von Wolfgang Ernst

Corpus der römischen Rechtsquellen zur antiken Sklaverei (CRRS), Teil IV: Stellung des Sklaven im Privatrecht. 3: Erbrecht. Aktive Stellung, Personeneigenschaft und Ansätze zur Anerkennung von Rechten, bearbeitet von Martin Avenarius . . . . . . . . . . . . . . . .

Besprochen von Jakob Fortunat Stagl

Czajkowski, Kimberley, Localized Law. The Babatha and Salome Komaise Archives . . . . . . . . . . . . . . . . . . . .

Besprochen von Tiziana J. Chiusi

D'Alessio, Raffaele, Studii sulla capitis deminutio minima. Dodici tavole - giurisprudenza - editto 
Deli, Gergely, Salus rei publicae als Entscheidungsgrundlage des römischen Privatrechts

Anzeige von Jakob Fortunat Stagl

Deppenkemper, Gunter, Negotiorum gestio - Geschäftsführung ohne Auftrag. Zu Entstehung, Kontinuität und Wandel eines Gemeineuropäischen Rechtsinstituts

Besprochen von Franz-Stefan Meissel

Dursi, Domenico, Res communes omnium. Dalle necessità economiche alla disciplina giuridica . . . . . . . . . . . . . . Besprochen von Anna Plisecka

Erxleben, Friederike, Translatio iudicii. Der Parteiwechsel im römischen Formularprozess . . . . . . . . . . . . . . . . . Besprochen von Jörg Domisch

Furfaro, Federica, Recezione e traduzione della Pandettistica in Italia tra Otto e Novecento. Le note italiane al Lehrbuch des Pandektenrechts di B. Windscheid . . . . . . . . . . . . . . . . . . Besprochen von Martin Avenarius

Gagarin, Michael/Paula Perlman, The Laws of Ancient Crete, c. 650$400 \mathrm{BCE} \ldots \ldots \ldots \ldots \ldots \ldots$ Anzeige von Gerhard Thür

Harke, Jan Dirk, Precarium. Besitzvertrag im römischen Recht . . . . . . 861 Anzeige von Susanne Heinemeyer

Hillmann, Reinhard, Brautpreis und Mitgift. Gedanken zum Eherecht in Ugarit und seiner Umwelt mit einer Rekonstruktion des im Ritual verankerten „Schlangentext"-Mythos Anzeige von Guido Pfeifer

Inscriptiones Graecae [IG] II/III ${ }^{3}$ 1,4 ed. Michael J. Osborne/Sean G. Byrne; II/III ${ }^{3} 4,1$ ed. Jaime Curbera/Andronike K. Makres; II/III ${ }^{3}$ 4,2 ed. Jaime Curbera; IV $^{2} 3$ ed. Ericus Sironen; X 2,1s ed. Pantelis M. Nigdelis; XII 4,3 ed. Dimitris Bosnakis/

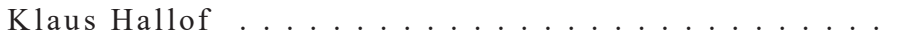

Anzeige von Gerhard Thür

Laborenz, Martin, Solutio als causa. Die Frage des Abstraktionsprinzips im römischen Recht . . . . . . . . . . . . . . . . . .

Besprochen von Martin J. Schermaier

Leão, Delfim F. / P. J. Rhodes, The Laws of Solon. A New Edition with Introduction, Translation and Commentary . . . . . . . . . . . 843 Anzeige von Gerhard Thür

Lukits, Rainer, Der Schiedsspruch des C. Helvidius Priscus . . . . . . . . Besprochen von Philipp Scheibelreiter 
Natalini, Cecilia, „Bonus iudex“. Saggi sulla tutela della giustizia tra Medioeveo e prima età moderna . . . . . . . . . . . . 808 Besprochen von Susanne Lepsius

Nowak, Maria, Wills in the Roman Empire. A Documentary Approach . . 800 Besprochen von Benedikt Strobel

Oath and State in Ancient Greece, hg. von Alan H. Sommerstein/Andew

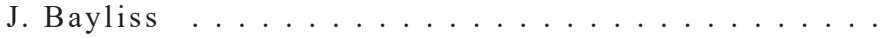

Anzeige von Nadine Grotkamp

Oath and Swearing in Ancient Greece, hg. von Alan H. Sommerstein/

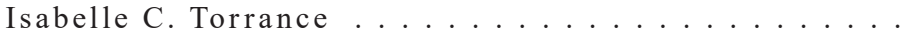
Anzeige von Nadine Grotkamp

Ogereau, Julien M., Paul's Koinonia with the Philippians. A Socio-Historical Investigation of a Pauline Economic Partnership . . . . . . . . Besprochen von Andreas M. Fleckner

Ownership and Exploitation of Land and Natural Resources in the Roman World. Hg. von P. Erdkamp/K. Verboven/A. Zuiderhoek . . 862 Anzeige von Paul J. du Plessis

The Oxford Handbook of Roman Law and Society, hg. von Paul J. du Plessis/Clifford Ando/Kaius Tuori

Besprochen von Franz-Stefan Meissel

Paulus, Christoph G., Der Prozess Jesu - aus römisch-rechtlicher Per-

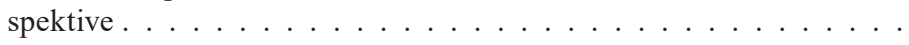
Besprochen von Detlef Liebs

Reassessing Legal Humanism and its Claims. Petere Fontes? Hg. von Paul J. du Plessis/John W. Cairns

Besprochen von Christoph Becker

Scharff, Sebastian, Eid und Außenpolitik. Studien zur religiösen Fundierung der Akzeptanz zwischenstaatlicher Vereinbarungen im vorrömischen Griechenland Besprochen von Nadine Grotkamp

Seelentag, Anna Margarete, Ius pontificium cum iure civili coniunctum. Das Recht der Arrogation in klassischer Zeit . . . . . . . . . . . . . Anzeige von Martin J. Schermaier

Tuori, Kaius, The Emperor of Law: The Emergence of Roman Imperial Adjudication . . . . . . . . . . . . . . . Besprochen von Wolfram Buchwitz

van Dongen, Emanuel G.D., Contributory Negligence: A Historical and Comparative Study . . . . . . . . . . . . . . Besprochen von Maria Floriana Cursi 


\section{VII}

Zanetti, Francesca, Gli Ebrei nella Roma antica - Storia e diritto nei secoli III-IV d.C. . . . . . . . . . . . . . . . . . . . . . . . 875 Anzeige von Matthias Armgardt

Zarro, Gianluca, Aspetti dell'autonomia negoziale dei Romani. Dalla fides ai nova negotia . . . . . . . . . . . . . . . 868 Anzeige von Martin J. Schermaier

\section{In memoriam:}

Hans-Peter Benöhr, 14.3.1937-22.7.2017. Von Jens Peter Meincke . . . . 933

Georg Klingenberg, 31.1.1942-31.7.2016. Von Markus Wimmer . . . . . . 920

Joseph Mélèze Modrzejewski, 8.3.1930-30.1.2017. Von Julie Velissaropoulos-Karakostas . . . . . . . . . . . . . . . . . 928

Peter Stein, 29.5.1929-7.8.2016. Von Richard Fentiman, Richard Helmholz, David Johnston und Reinhard Zimmermann . . . . . 921

\section{Chronik:}

Darstellung und Gebrauch der senatus consulta in der römischen Jurisprudenz der Kaiserzeit, 19.-20. Mai und 23.-24. Juni 2017, Münster. Von Gre-

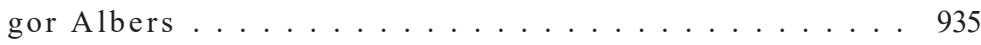

\section{Mitteilungen:}

XI. Internationaler Romanistischer Preis Gérard Boulvert . . . . . . . . . . . 943

Zum Tode Dieter Nörrs . . . . . . . . . . . . . . . . . . . . . . . 944

\section{Quellenverzeichnis}

erstellt von den Herausgebern . . . . . . . . . . . . . . . . . . . . . 945 


\section{VIII}

\section{Verzeichnis der Autorinnen und Autoren von ZRG RA 135 (2018)}

Dr. Gregor Albers, Bonn, S. 334, 935

Prof. Dr. Matthias Armgardt, Konstanz, S. 875

Prof. Dr. Martin Avenarius, Köln, S. 830

Prof. Dr. Ulrike Babusiaux, Zürich, S. 108, 850, 855, 877

Prof. Dr. Christoph Becker, Augsburg, S. 814

Dr. Tom maso Beggio, Helsinki - Trient, S. 645

Dr. Hugo Beikircher, München, S. 603

Dr. Oliver Bock, Jena, S. 637

Prof. Dr. Wolfram Buchwitz, Würzburg, S. 757

Prof. Dr. Tiziana J. Chiusi, Saarbrücken, S. 714

Prof. Dr. Maria Floriana Cursi, Teramo, S. 818

mr. dr. Hylkje De Jong, Amsterdam, S. 364

Dr. Jörg Domisch, Freiburg (Br.), S. 724

Prof. Dr. Paul J. du Plessis, Edinburgh, S. 862

Prof. Dr. Wolfgang Ernst LLM, Oxford, S. 748

Prof. Richard Fentiman MA BCL, Cambridge, S. 921

Prof. Dr. Thomas Finkenauer, Tübingen, S. 178

Dr. Andreas M. Fleckner LLM MPA, München, S. 685

Prof. Dr.Dr. France sco Giglio, Guildford (Surrey), S. 76

Jakob Gleim, Hamburg, S. 526

PD Dr. Dr. Nadine Grotkamp, Frankfurt (M.), S. 681, 849

PD Dr. Susanne Heinemeyer, Mainz, S. 861

Prof. Dr. Dr. h.c. Richard Helmholz, Chicago, S. 921

Prof. Dr. Éva Jakab, Szeged - Oxford, S. 474

Steffen Michael Jauß BA, Frankfurt (M.), S. 21

Hon. Prof. David Johnston PhD LLD, Edinburgh, S. 921

Prof. Dr. Wolfgang Kaiser, Freiburg (Br.), S. 629, 633, 877

Prof. Dr. Susanne Lepsius MA, München, S. 808

Prof. em. Dr. Dr. h.c. Detlef Liebs, Freiburg (Br.), S. 395, 743 


\section{IX}

Prof. em. Dr. Jens Peter Meincke, Köln, S. 932

Univ.-Prof. Dr. Franz-Stefan Meissel, Wien, S. 739, 779

Prof. Dr. Guido Pfeifer, Frankfurt (M.), S. 1, 835

Prof. Dr. Pascal Pichonnaz LLM., Fribourg - Washington (DC), S. 764

Dr. Anna Plisecka, Zürich, S. 752

Univ.-Prof. Dr. Philipp Scheibelreiter, Linz - Wien, S. 701

Prof. Dr. Martin J. Schermaier, Bonn, S. 786, 864, 868, 870, 943, 944

Eduard Sotulenko, Bochum, S. 592

Prof. Dr. Jakob Fortunat Stagl, Santiago (Chile), S. 582, 709, 859

Dr. Benedikt Strobel, München, S. 800

Prof. em. Dr. DDr. h.c. Gerhard Thür, Wien, S. 837, 843, 845

Dominik Trump MA, Köln, S. 607

Prof. Dr. Mario Varvaro, Palermo, S. 619

Prof. Dr. Julie Velissaropoulos-Karakostas, Athen, S. 928

Prof. Dr. Dr. h.c. mult. And reas Wacke, Köln, S. 261

ao. Univ.-Prof. Dr. Markus Wim mer, Linz, S. 920

Prof. Dr. Dr. h.c. mult. Rein hard Zimmerman n, Hamburg, S. 526, 921 

IV.

\title{
Römisches Erbrecht im Gnomon des Idios Logos*)
}

\author{
Von \\ Ulrike Babusiaux
}

Dieter Nörr zum Gedächtnis

\begin{abstract}
Roman law of succession in the Gnomon of the Idios Logos. The scholarship of the $19^{\text {th }}$ century has questioned that the rules stated in the so-called Gnomon of the idios logos (BGU $\mathrm{V}, 1210)$ had their origin in Roman law. However, a new and deepened discussion concerning the law of succession reveals extensive parallels between the Gnomon and the sources of Roman law. Additionally, the Gnomon provides a better insight into the development of the Roman law of succession; this historical perspective has been lost in the Justinianic transmission of the Roman legal texts, but is of importance for the fiscal dimension of the law of succession, the different functions of the fideicommissum familiae relictum, the rules on incapacity contained in the lex Iulia et Papia, as well as for the legal status of both women and soldiers in matters of inheritance.
\end{abstract}

Keywords: Law of Succession, Gnomon of the idios logos, Roman Egypt, Roman Fiscality, Provincial Practice

I. BGU V,1210 als Quelle des römischen Rechts; II. Wirkung von letztwilligen Veräußerungsverboten; III. Zum Heimfallrecht des Fiskus; IV. Regeln der Testamentserrichtung; V. Erbrechtliche Sanktionen der lex Iulia et Papia; VI. Zur Testierfähigkeit der Römerin; VII. Das Erbrecht der Soldaten; VIII. Ergebnisse und Ausblick')

*) Der Beitrag beruht auf einem Vortrag, den ich auf dem 41. Deutschen Rechtshistorikertag in Saarbrücken gehalten habe. Für die Einladung danke ich Frau Tiziana J. Chiusi, für weiterführende Diskussionsbeiträge Frau Éva Jakab und Herrn Gerhard Thür; für eine kritische Lektüre und vertiefende Anmerkungen bin ich Herrn José Luis Alonso zu großem Dank verpflichtet. Wichtige Unterstützung bei der Vorbereitung der Schriftfassung leisteten meine Mitarbeiterinnen Frau MLaw Elena Koch und Frau lic. phil. Thamar Xandry.

1) Zum Gnomon vgl. W. S chubart, Der Gnomon des Idios Logos, BGU V (1210), 1919; W. Uxkull-Gyllenband, Der Gnomon des Idios Logos, Berliner Griechische Urkunden [BGU] V, Bd. 2: Kommentar, 1934; O. Lenel/J. Partsch, Zum sog. Gnomon des Idios Logos, 1920; Th. Reinach, Un code fiscal de l'Egypte romaine: Le Gnomon de l'idiologue II, Nouvelle revue historique de droit français 


\section{BGU V,1210 als Quelle des römischen Rechts}

Auf dem Verso des 1912 gefundenen Papyrus Berliner Griechische Urkunden [BGU] V,1210, dessen Rekto eine Aktenrolle des Sitologen von Bernikis enthält²), finden sich 115 durchnummerierte Paragraphen des sogenannten „Gnomon des Idios Logos“3). Die der Aufstellung vorangehende Einleitung hebt hervor, dass der Gnomon auf Augustus selbst zurückgehe, nunmehr aber durch Anordnungen anderer Kaiser, des Senats, der Präfekten und der Idiologen ergänzt worden sei, wodurch die Zahl der Vorschriften angewachsen sei. Der Verfasser betont, dass er diese Regeln nur knapp zusammenfasse, um dem Rechtsanwender eine Erinnerungshilfe zu bieten, der die Lücken selbst auszufüllen habe. Aus dieser Selbsterklärung lässt sich schließen, dass der Papyrus nicht den Gnomon selbst, sondern Ergänzungen des bisher unbekannten Textes enthält ${ }^{4}$ ). Diese Fremdreferentialität des BGU V,1210 dürfte einer der Gründe für die äußerst knappe und teilweise schwer verständliche Ausdrucksweise des Dokumentes sein, welche offensichtlich nicht nur einen kundigen Leser, sondern auch einen anderweitig verfügbaren „Haupttext“ voraussetzt. Der Einfachheit halber soll im Folgenden bei Bezugnahme auf BGU V,1210 dennoch immer vom „Gnomon“ die Rede sein.

Die äußere Struktur des Textes ist aufgrund der Nummerierung der Vorschriften gut erkennbar. Als übergeordneter Gesichtspunkt ist die dem Amt des Idios logos in römischer Zeit zugewiesene „Fiskalverwaltung“ anzusehen'); diese umfasst verschiedene Tatbestände, die im Dokument in einer

et étranger 44 (1920) 5-134; S. Ric c ob ono, Il Gnomon dell'idios Logos, Palermo 1950; M. Vandoni, Testi per il corso di Papirologia, Il papiro B.G.U. 1210, Mailand 1972; M. La uria, Il gnomon dell'idios logos, Atti dell'Accademia di Scienze Morali e Politiche 74 (1963) 81-153; J. Mélèze-Modrzejews ki, Gnomon de l'idiologue, in: V. Giuffrè (Hg.), Les lois des Romains, Mailand 1977, 520-557.

2) Zur Analyse des Rekto vgl. Schubart (Fn. 1) 4f.; Beschreibung auch bei Riccobono, Gnomon (Fn. 1) 3-5.

3) Zur Beschreibung der Urkunde vgl. Schubart (Fn. 1) 2 f.

$\left.{ }^{4}\right)$ Die Interpretation der Einleitung ist umstritten: Von einem „Begleitschreiben" sprechen Lenel/Partsch (Fn. 1) 3f.; Riccobono, Gnomon (Fn. 1) 8f., meint, einen Teil des Gnomon vorliegen zu haben; weitere Deutungen bei MélèzeModrzejewski, Gnomon (Fn. 1) 521f.; vgl. auch E. Weiß, Die erbrechtliche Stellung des römischen Staatsschatzes und der Gnomon des Idios Logos, ZRG RA 53 (1933) 256-274, 258-263; ferner E. S eid l, Rechtsgeschichte Ägyptens als römischer Provinz, 1973, 14f., der von Anmerkungen (tituli) zu m Gnomon ausgeht.

${ }^{5}$ ) Vgl. Uxkull-Gyllenband (Fn. 1) 6-8; Riccobono, Gnomon (Fn. 1) 3-5.

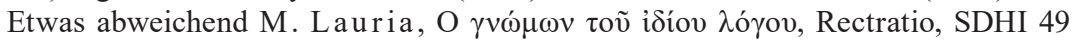
(1983) 1-17, der den Gnomon dem prätorischen Edikt annähern will. 
gewissen Ordnung zusammengefasst werden: Auf die in $\S \S 1-2$ geregelte Vollstreckung in das Vermögen/Erbe des (Fiskal-)Schuldners') folgen mit $\S \S 4-22$ und $\S \S 27-45$ Abschnitte zur Erbfolge $)$, $\S \S 23-26$ betreffen Ehe, Mitgift und Ehegattenschenkungen, §§46-53 Eheverbote ${ }^{8}$ ), während $\S \S 54-57$ statusrechtliche Fragen des Eherechts9) behandeln und §§ 58-69 die Durchführung des Zensus betreffen ${ }^{10}$ ); $\S 70$ ist dem crimen repetundarum ${ }^{11}$ ), $\S \S 71-99$ Rechtsfragen des Kultus und der Tempelverwaltung gewidmet ${ }^{12}$ ); $\S \S 100-111$ schließlich enthalten strafbewehrte Handels-, Kreditvergabe- und Registervorschriften, welche nach Ansicht von Lauria ,a tutela del patrimonium, del fisco imperiale ${ }^{\text {“13 }}$ ) erlassen worden sind, während die schwer leserlichen $\S \S 112-115$ die rechtliche Stellung von Kastraten und spadoni betreffen sollen ${ }^{14}$ ). Sowohl die Präambel als auch die behandelten Fragestellungen legen nahe, dass der Gnomon als ein Dokument der römischen Verwaltung Ägyptens anzusehen ist. Die 1974 erfolgte Publikation des P.Oxy. XLII 3014, der eine frühere Fassung des Dokumentes (für die §§35-41) enthältt's), zeigt zudem, dass die Anordnung tatsächlich überarbeitet und angepasst worden zu sein scheint, bestätigt also die im Vorwort des BGU V,1210 behauptete Aktualisierungsintention der Niederschrift.

Trotz der anerkannten und offensichtlichen Bezugnahmen des Dokuments auf römisches Recht $^{16}$ ) wird der Erkenntniswert für dessen Rekonstruktion von Teilen der Forschung bezweifelt. Diese Zweifel gründen auf zwei argu-

6) §3 könnte auch hierher gehören, vgl. Lauria, Gnomon (Fn. 1) 90.

${ }^{7}$ ) Lau ria ebenda 90-129, der in die successio mortis causa auch personenrechtliche Vorschriften einbezieht, welche sich auf die Erbfolge auswirken (§§ 38-45), hier aber außer Betracht bleiben sollen.

$\left.{ }^{8}\right)$ Lauria ebenda $129-131$.

9) La u ria ebenda 131-134, der $§ 54$ als Einzelvorschrift ansieht und $\S \S 55-56$ als Vorschriften für Veteranen ausgliedert.

$\left.{ }^{10}\right)$ Lauria ebenda 134-136.

${ }^{11)}$ Lauria ebenda $136 f$.

12) Lauria ebenda $137-140$.

13) Lauria ebenda 140-150; gleichsinnig Mélèze-Modrzejewski, Gnomon (Fn. 1) 524. Die Kennzeichnung ist vor dem Hintergrund der allgemeinen fiskalschützenden Tendenz der Vorschriften nicht weiterführend.

${ }^{14}$ ) Lauria, Gnomon (Fn. 1) 150f.

${ }^{15}$ ) Einzelheiten hierzu bei Mélèze-Modrzejewski, Gnomon (Fn. 1) 522f.; ferner E. Jakab, Testamente, Soldaten und der Idios logos, in: K. Harter-Uibopuu/ Th. Kruse (Hgg.), Dienst nach Vorschrift, 2017 (in Vorbereitung).

${ }^{16}$ ) Lauria, Gnomon (Fn. 1) 82: „Il gn[onom] riproduce massime di diritto romano, le desume da rescritti imperiali e da altri iura imprecisati, le adatta ai rapporti egiziani: la constazione è sicura ed ovvia“; Weiß (Fn. 4) 263f.: „Die Rechtsquellen, 
mentativen Topoi: Der erste betrifft die (angebliche) Unfähigkeit oder Uneinsichtigkeit des Schreibers oder Verfassers des Schriftstücks, dem Missverständnisse mit Blick auf das römische Recht oder Fehler bei der Übersetzung der lateinischen Vorlage oder Abschrift eines früheren Textes unterlaufen sein sollen ${ }^{17}$ ); das zweite wiederkehrende Argument greift Widersprüche, Auslassungen oder Abweichungen des Gnomon zu den juristischen Texten, vorrangig zu den Institutionen des Gaius heraus, um zu behaupten, dass der Gnomon einen lokalen Rechtszustand schildere, der von der stadtrömischen Rechtslage mehr oder weniger tiefgreifend verschieden und eher ptolemäischen ${ }^{18}$ ) oder sogar griechisch-alexandrinischen Vorbildern ${ }^{19}$ ) verpflichtet sei.

Gegenüber dem ersten Argument ist vorrangig auf die differenzierte Beschreibung und Würdigung der Urkunde durch den Erstherausgeber Wilhelm Schubart zu verweisen, der zunächst betont, dass es sich um ,eine sorgfältige Buchschrift, keineswegs frei von kursiven Zügen, aber doch auf einer Stufe, die vielen literarischen Texten eigentümlich ist ${ }^{\text {" }}{ }^{20}$ ) handele; weiter sei der Schreiber bestrebt, die Leserlichkeit durch das Nachziehen von Buchstaben zu erhöhen ${ }^{21}$ ). Selbst die häufigen Schreibfehler, die vom Schreiber selbst korrigiert werden ${ }^{22}$ ), sind nach Schubart ,in der Mehrzahl einfache Versehen,

über die die Einleitung zur Urkunde einen Überblick gibt, sind lediglich Quellen des römischen Rechtes (...)“; emphatischer Ric cob ono, Gnomon (Fn. 1) 40.

${ }^{17}$ ) Dies ist vor allem der Tenor bei Lenel/Partsch (Fn. 1) 11: ,juristische Kenntnisse nicht über jeden Zweifel erhaben“; 15: Missverständnis des griechischen Übersetzers; 17: Übersetzer oder lateinischer Urtext fehlerhaft, „,denkbar (...) ex iure Quiritium (...) ungeschickt wiedergegeben“; 21: „Irrtum unserer Quelle oder ihrer Vorlage“; 23 (zu §33): „Dieser Passus zeigt wieder deutlich, mit wie wenig Sorgfalt und Sachkenntnis unser Auszug hergestellt ist“; 26: Verfasser sei im Unklaren; 28: „Hier stand sehr wahrscheinlich im Urtext eine lateinische Wendung, die der Grieche nicht wiedergeben konnte“; 29: „Nähte der Flickarbeit noch deutlich zu sehen".

${ }^{18)}$ Vgl. unten zu $\S 4$ und $\S 7$ in Fn. 107, Fn. 108 und Fn. 117.

$\left.{ }^{19}\right)$ Gezwungen und in Methode und Ergebnis wenig überzeugend erweist sich heute der von H. Kaupper, Das griechisch-alexandrinische Recht im Gnomon des Idioslogos als Quelle athenischen Rechts, Diss. Erlangen 1954, unternommene Versuch, den ,alexandrinischen“ Charakter verschiedener Vorschriften „zu beweisen“. (Ich danke Herrn H.-D. Spengler für die Zugänglichmachung des in der UB Erlangen befindlichen Manuskripts.)

${ }^{20}$ ) Schubart (Fn. 1) 4.

${ }^{21)}$ Schubart (Fn. 1) 5 .

${ }^{22}$ ) Schubart (Fn. 1) 5: „Falsche Buchstaben, Silben oder Wörter werden z.T. sogleich gestrichen oder gelöscht (...); in andern Fällen wird das Richtige über die Zeile geschrieben." 
die beim Abschreiben entstehen können, übrigens fast durchweg Fehler, die ein gewisses Verständnis des Schreibers durchblicken lassen“淿3). Sinnentstellende Verschreibungen seien dagegen selten ${ }^{24}$ ); als nicht vom Schreiber korrigierte Rechtschreibfehler zählt Schubart ganze zehn ${ }^{25}$ ) in 115 Paragraphen. Auch sonst seien kaum sprachliche Fehler zu konstatieren ${ }^{26}$ ). Nach alldem kann die äußere Form des Dokumentes den Verdacht einer nachlässigen und kaum informierten Abfassung kaum erhärten; die vor allem von O. Lenel und J. Partsch gerügten Mängel des Gnomon ${ }^{27}$ ) erweisen sich bei näherem Hinsehen als Probleme der Terminologie, die sich aus der Verwendung des Griechischen für das römische Recht ergeben. Diese Schwierigkeiten beruhen einerseits auf der größeren Elastizität der griechischen Sprache, welche zu Mehrdeutigkeiten führt, andererseits darauf, dass sich eine eigentliche griechische Rechtsprache für römisches Recht erst langsam ausprägen musste ${ }^{28}$ ).

Im Zentrum stehen soll hier die Überprüfung des zweiten Argumentationsstranges, welcher das Verhältnis des Gnomon zu den Juristenschriften in und außerhalb der justinianischen Kompilation betrifft. Trotz der evidenten Anlehnung des Textes an Institute und Vorschriften des römischen Rechts ist die Forschung oftmals geneigt gewesen, BGU V,1210 nicht in Bezug auf die römische Rechtstradition zu verstehen, sondern - wie die Masse der in Ägypten gefundenen Dokumente - als Ausdruck der provinzialen Praxis zu interpretieren ${ }^{29}$ ). Zwar ist der Hinweis von Hans Julius Wolff zu beachten, dass der Gnomon nicht als Ausdruck einer bereits vor der Constitutio Antoniniana weit fortgeschrittenen Romanisierung des Rechtslebens in Ägypten missverstan-

23) Schubart (Fn. 1) 5f. mit einigen Beispielen (zu $§ 5, \S 18, \S 46, \S 58$ und $\S 61)$.

${ }^{24}$ ) Schubart (Fn. 1) 5 .

25) Schubart (Fn. 1) 6.

26) Schubart (Fn. 1) 6.

$\left.{ }^{27}\right)$ Vgl. oben Fn. 17.

${ }^{28}$ ) Einige wichtige Urkunden bei U. Laffi, In greco per i Greci, Ricerche sul lessico greco del processo civile e criminale romano nelle attestazioni di fonti documentarie romane, Pavia 2013; dazu G. Thür, ZRG RA 133 (2016) 480-483; zu administrativen Strukturen vgl. H. J. Ma s on, Greek Terms for Roman Institutions, Toronto 1974; zu (weiteren) epigraphischen Zeugnissen vgl. V.I. A nastasiad is / G.A. Souris, An index to Roman imperial constitutions from Greek inscriptions and papyri, Berlin 2000; A. Raggi/C. Slavich haben das Projekt eines Greek Lexicon for Roman Law (GLRL) lanciert: http://ciegl.classics.ox.ac.uk/html/webposters/75_SlavichRaggi.pdf (21.9.2017).

${ }^{29}$ ) Ein Überblick über die Deutungen der Eigengesetzlichkeit des römischen Ägyptens bei R. Haens ch, Die Provinz Aegyptus: Kontinuitäten und Brüche zum ptolemäischen Ägypten, Das Beispiel des administrativen Personals, in: I. P iso (Hg.), Die römischen Provinzen, Begriff und Gründung, Cluj 2008, 81-105. 
den werden dürfe, da Vorgaben für römische Bürger in einer Verwaltungsvorschrift in der Tat keinen Rückschluss auf das gelebte Recht erlaubten ${ }^{30}$ ). Übertrieben aber scheint es, wenn Lenel und Partsch, deren lateinische Übersetzung in der Romanistik mit besonderer Bereitschaft aufgenommen wurde, davon ausgehen, dass die Vorschriften des Gnomon stark durch lokale Vorstellungen geprägt seien, welche zu Fehldeutungen und Verfälschungen der römischrechtlichen Regelungen führten. Beide Stellungnahmen zeigen exemplarisch, dass die Reduktion der Frage auf die Dichotomie von „Reichsrecht“ und „Volksrecht“ angesichts der offenbar komplexen Realität nicht weiterführt, sondern lediglich die unfruchtbare fachliche Abgrenzung von juristischer Papyrologie und romanistischer Forschung befördert hat. Aus dieser perspektiven Verengung konnte sich auch die 1950 von S. Riccobono vorgelegte Summe der bisherigen Forschung offensichtlich nur teilweise lösen, da dieser zwar die Bedeutung des Gnomon für die römische Provinzialverwaltung betont ${ }^{31}$ ), den Text aber gleichzeitig als Ausdruck der Romanisierung Ägyptens deutete. Damit geriet die von Riccobono selbst in einem späteren Beitrag aufgeworfene Frage $^{32}$ ), ob sich der Text auch als Quelle des römischen Rechts lesen ließe, in Vergessenheit ${ }^{33}$ ), was sich auch daraus erklären mag, dass man die Besonderheiten des Gnomon im Verhältnis zu anderen dokumentarischen Funden Ägyptens offensichtlich unterschätzt hat. In jedem Fall hat der Gnomon in der romanistischen Forschung seit längerem keine Aufmerksamkeit mehr erfahren, wenngleich er zu Einzelfragen wiederholt konsultiert wurde ${ }^{34}$ ).

$\left.{ }^{30}\right)$ H.J. Wolff, Rez. zu S. Riccobono Jr., Reichsrecht und der Gnomon des Idios Logos, ZRG RA 76 (1959) 574f., 574: „Bedenklich ist es auch, wenn der Verfasser (...) den Gnomon als Zeugnis für eine angeblich schon vor der Const. Ant. weit vorgeschrittene Romanisierung des Lebens und des Rechts in Ägypten in Anspruch nimmt. Daß eine Reihe von Paragraphen der Quelle Rechtsverhältnisse römischer Bürger betreffen, besagt - gleichviel wie stark das römische Element, einschließlich der mehr oder weniger romanisierten Veteranen mit Zivität war - nichts für den Charakter des im Lande wirklich lebenden Rechts.“

31) Riccobono, Gnomon (Fn. 1) 20-27. Er spricht von einer „unità giuridica ed amministrativa dell'Impero di Roma“.

32) S. Riccobono Jr., Das römische Reichsrecht und der Gnomon des Idioslogos, 1957, $28 \mathrm{f}$.

33) Riccobono ist am 12.4.1958 verstorben, vgl. F. Wieacker, In memoriam Salvatore Riccobono, ZRG RA 76 (1959) 677-682, 679. Dezidiert in diesem Sinne E. Weiss, De nonnullis locis papyri illius, qui Gnomon inscribitur, praesertim de jure sepulcrorum in Aegypto, Aegyptus 13 (1933) 299-304, 299: ,ein über jeden Verdacht der Entstellung durch Interpolationen oder Glossen erhabenes Rechtsdenkmal“".

${ }^{34}$ ) Eine Ausnahme bieten die Beiträge auch von rechtshistorischer Seite im Sammelband von Harter-Uibopuu/Kruse (Fn. 15). 
Dennoch ist die Grundfrage, ob sich aus dem Gnomon über das Corpus iuris civilis hinausgehende Informationen zum römischen Recht entnehmen lassen, weiterhin als offen zu bezeichnen. An dieser Stelle soll sie für die in $\S \S 1,2,4,7,8,18,24-35$ enthaltenen Regelungen des Erbrechts untersucht werden ${ }^{35}$ ). Dieser sachlich beschränkte Ansatz rechtfertigt sich einerseits daraus, dass die für den Gnomon charakteristische fiskalische Dimension des römischen Erbrechts auch in der justinianischen Kompilation erkennbar ist und in die privatrechtliche Untersuchung des Erbrechts hineingenommen werden muss ${ }^{36}$ ); andererseits bietet sich gerade das Erbrecht für die Integration des Gnomon als Quelle an, da auch Justinians Digesten und Codex sowie Gaius' Institutionen und Ulpiani Epitome erkennen lassen, dass es sich um eine vielschichtige und geradezu widersprüchliche Materie handelt ${ }^{37}$ ). Beide Eigenschaften des römischen Erbrechts legen die in der bisherigen Literatur unterschätzte Möglichkeit nahe, den Gnomon, der auf die Zeit zwischen 150 und 180 n. Chr. datiert wird ${ }^{38}$ ), als Zeugnis einer weiteren Entwicklungsstufe dieses Rechtsbereichs zu verstehen und ihn so als Informationsquelle für in der justinianischen Kompilation verloren gegangene oder bewusst getilgte Normen des römischen Erbrechts zu nutzen ${ }^{39}$ ).

Aus der so skizzierten Fragestellung ergibt sich, dass die folgenden Ausführungen nicht darauf angelegt sind, Inhalt und Funktion des Gnomon einer Neudeutung zuzuführen ${ }^{40}$ ). Vielmehr ist die Untersuchung auf die Frage

${ }^{35}$ ) Außer Acht bleiben die Sondervorschriften des Erbrechts der liberti. Vgl. dazu C. Masi Doria, Bona libertorum: regimi giuridici e realtà sociali, Neapel 1996, die allerdings den Gnomon nicht berücksichtigt. Hier nicht behandelt werden kann zudem der vor allem für das gesetzliche Erbrecht inzident relevante Abschnitt über das Bürgerrecht und die Zuordnung von Kindern aus „Mischehen“.

${ }^{36)}$ Zur fiskalischen Dimension vgl. E. Bund, Erbrechtliche Geldquellen römischer Kaiser, in: O. Behrends et al. (Hgg.), Festschrift Wieacker, 1978, 50-65; ferner E. Champlin, Death and Taxes, The emperor and inheritance, Studi italiani di filologia classica 3, 10 (1992) 899-904.

${ }^{37}$ ) Zur Bewertung des römischen Erbrechts vgl. Nachweise bei U. Babusiaux, Römisches Erbrecht, 2015, 25f.

${ }^{38}$ ) Vgl. nur Mélèze-Modrzejew ski, Gnomon (Fn. 1) 522f. Die Epitome Ulpiani wird zitiert nach F. Schulz, Die Epitome Ulpiani des Codex Vaticanus Reginae 1128, 1926; für die Institutionen des Gaius wird zugrundegelegt M. David, Gai Institutiones secundum Codicis Veronensis ... ed. min., Leiden 21964.

${ }^{39}$ ) Zur Tilgung der leges publicae in der Kompilation vgl. grundlegend D. Mantovani, Legum multitudo e diritto privato, in: J. - L. Ferrary (Hg.), Leges publicae, Pavia 2011, 707-767, deutsche Übersetzung von U. Babusiaux: Legum multitudo, Die Bedeutung der Gesetze im römischen Privatrecht, 2018.

${ }^{40}$ ) $\mathrm{Zu}$ den Deutungsansätzen - liber mandatorum oder private Aufzeichnung 
beschränkt, ob und inwieweit sich aus dem Vergleich zwischen erbrechtlichen Regeln des Gnomon mit sachlich verwandten Texten der römischen Jurisprudenz neue Informationen zur Entwicklung einzelner Institute oder zur genaueren Ausgestaltung von Regelungen des römischen Erbrechts ergeben können (II-VII). Dabei folgt die Darstellung zunächst der Ordnung des Gnomon; allgemeine Schlüsse, insbesondere für das römische Erbrecht in Ägypten, sollen erst nach Durchsicht der einschlägigen Vorschriften gezogen werden (VIII).

\section{Wirkung von letztwilligen Veräußerungsverboten (§§ 1-2)}

Die ersten zwei Vorschriften des Dokumentes betreffen den Umfang des fiskalischen Beschlagnahmerechts.

BGU V,1210, 8-20:

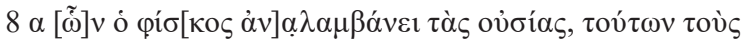

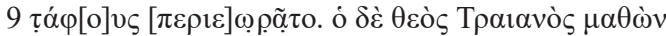

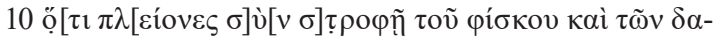

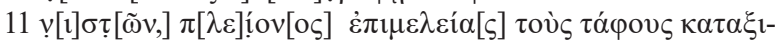

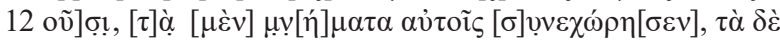

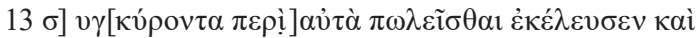

14 ...........] os $\mu$ ó

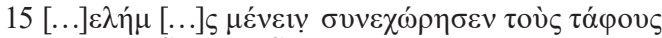

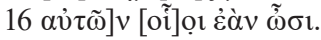

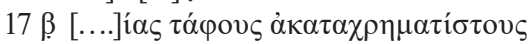

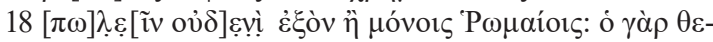

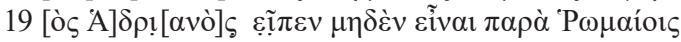

$20 \dot{\alpha} \kappa] \alpha[\tau] \alpha \chi[\rho \eta \mu] \alpha ́ \alpha \iota \sigma \tau o v$.

$\S 1$ : Der Fiskus hat bisher die Gräber von denen, deren Vermögen er einzieht, übergangen. Aber als der vergöttlichte Trajan erfuhr, dass mehrere unter Umgehung des Fiskus und der Gläubiger die Grabstätten größerer Sorgfalt für würdig erachteten, gestattete er ihnen zwar die Grabmäler, aber befahl, dass das [um die Grabstätten] herum angrenzende [Land] verkauft werde und (...); nur den alleinigen Schuldnern des Fiskus gestattete er, (...), dass die Gräber so beschaffen blieben, wie sie waren.

$\S 2:(.$.$) es ist niemandem außer den Römern allein gestattet, unveräußerliche$ Gräber zu verkaufen: Denn der vergöttlichte Hadrian sagte, dass bei den Römern nichts unverfügbar $\mathrm{se}^{\mathrm{il}}$ ).

- vgl. Riccobono, Gnomon (Fn. 1) 18-26; Mélèze-Modrzejewski, Gnomon (Fn. 1) 521f.; zuletzt Th. Kru se, Der Gnomon des Idios Logos im Lichte der Terminologie für Verwaltungsrichtlinien im Imperium Romanum, in: Harter-Uibopuu / Kruse (Fn. 15).

${ }^{41)}$ Abweichend die Übersetzung von Vandoni (Fn. 1) 15, die noch de Visschers These folgt, dazu gleich unten II.2. 
Die Formulierung des $§ 1$ lässt aufgrund der Frage, was dem Gegner des Fiskus verbleiben soll, darauf schließen, dass die Vorschrift die Einziehung verfallenen Vermögens (bona caduca) betraf ${ }^{42}$ ). Trotz der unsicheren Lesung des $\S 1$ ergibt sich nach bisherigem Kenntnisstand Folgendes: Bei jeglicher Einziehung der bona verblieben die Grabstätten bei den von der Einziehung Betroffenen; der Klagegegner des Fiskus musste also alles andere mit Ausnahme der Gräber herausgeben. Nachdem sich allerdings gezeigt hatte, dass die Grabstätten „mit größerer Sorgfalt bedacht wurden“

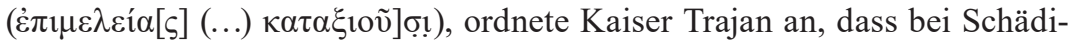
gungsabsicht gegenüber dem Fiskus oder den Gläubigern nur das eigentliche Grabmal zu belassen, das Umliegende aber zu verkaufen sei. §2 trifft sodann eine Unterscheidung zwischen Römern und Nichtrömern mit Blick auf unveräußerliche Gräber, wobei unter Berufung auf Hadrian ausgeführt wird, die Unveräußerlichkeit sei für Römer nicht verbindlich, während für Nichtrömer offenbar von einer entsprechenden Bindung ausgegangen wird. Es erscheint hilfreich, zunächst $\S 2$ genauer zu betrachten, um auch $\S 1$ weiterführend zu deuten.

1. Rechtsgeschäftliche Veräußerungsverbote:

$\S 2$ hat der Literatur zu Anfang des letzten Jahrhunderts Probleme bereitet, weil die Unwirksamkeit des Veräußerungsverbotes im Widerspruch zur gesetzlichen Unveräußerlichkeit der res religiosa zu stehen schien ${ }^{43}$ ). Entscheidend war die Einsicht von Fernand de Visscher, dass sich der Be-

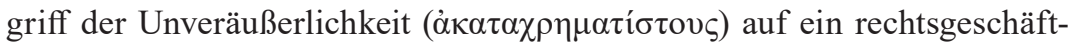
liches Veräußerungsverbot beziehen müsse ${ }^{44}$ ). Derartige Veräußerungsverbote können nach einem allerdings erst von den Kaisern Septimius Severus und Caracalla stammenden Reskript als Fideikommiss ausgelegt werden:

$\left.{ }^{42}\right) \mathrm{Zu}$ den bona vacantia vgl. unten S. 131-134 zu §4. Auch die Beschlagnahme von bona damnatorum ist im Gnomon vorgesehen, vgl. §36; dazu W. Waldstein, s. v. Bona damnatorum, in: RE Suppl. X, 1965, 96-119, bes. 108; nur von der republikanischen Zeit handelt F. Salerno, Dalla ,consecratio' alla ,publicatio bonorum', Neapel 1990.

43) Lenel/Partsch (Fn. 1) 10; ausführliche Diskussion der verschiedenen Erklärungsversuche bei Ric c obono, Gnomon (Fn. 1) 101-111; weitere Lit. bei F. de Visscher, Droit des tombeaux romains, Mailand 1963, 227-231.

44) De Visscher (Fn. 43) 233; ihm folgend Riccobono, Gnomon (Fn. 1)

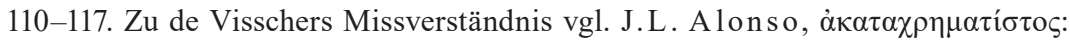
the aporia of Gnom. §2, vorgesehen für Journal of Juristic Papyrology (JJP) 48 (2018) m.w.N. 
D. 30,114,14 Marcian. 8 inst. ${ }^{45}$ ): Divi Severus et Antoninus rescripserunt eos, qui testamento vetant quid alienari nec causam exprimunt, propter quam id fieri velint, nisi invenitur persona, cuius respectu hoc a testatore dispositum est, nullius esse momenti scripturam, quasi nudum praeceptum reliquerint, quia talem legem testamento non possunt dicere: quod si liberis aut posteris aut libertis aut heredibus aut aliis quibusdam personis consulentes eiusmodi voluntatem significarent, eam servandam esse, sed haec neque creditoribus neque fisco fraudi esse: (...)

Voraussetzung für eine derartige Auslegung ist nach dem Reskript, dass sich das Verbot als Begünstigung eines bestimmten Personenkreises erkennen lässt; Veräußerungsverbote ohne erkennbare Begünstigungsabsicht sollen dagegen als nudum praeceptum keine Wirkungen entfalten ${ }^{46}$ ). Dabei nehmen die severischen Kaiser erkennbar an, dass ein als Fideikommiss ausgelegtes Veräußerungsverbot grundsätzlich jedem familienfremden Erwerber und auch dem Fiskus (als Erben oder Erwerber der Erbschaft) bis zur Grenze der vorsätzlichen Schädigung (fraus) entgegengesetzt werden kann ${ }^{47}$ ). Für das Verständnis von $\S 2$ lässt sich aus der severischen Differenzierung zunächst ableiten, dass die posthumen Veräußerungsverbote nach römischem Recht nicht generell (nudum praeceptum), sondern nur dann Wirksamkeit entfalten, wenn sie sich als (Familien-)fideikommiss auslegen lassen ${ }^{48}$ ).

Damit kommt es für die Wirksamkeit solcher Verbote darauf an, ob ein geschützter Personenkreis identifizierbar ist. Sofern der Erblasser nicht selbst den oder die Begünstigten genannt hat, ist damit auf den erkennbaren Willen oder den Zweck des Veräußerungsverbotes abzustellen. Dabei genügt es offensichtlich, wenn der Erblasser zugunsten der Familie hinterlässt (ad fami-

${ }^{45}$ ) Zum Text vgl. M. Ka ser, Rechtsgeschäftliche Verfügungsbeschränkungen im römischen Recht, aus: Festgabe Sontis, 1977, 11-31, jetzt in: ders. (Hg.), Römische Rechtsquellen und angewandte Juristenmethode [RRQ], 1986, 173-196, 187-191; D. Johnston, Prohibitions and perpetuities: family settlements in Roman law, ZRG RA 102 (1985) 220-290, bes. 272-281 (mit übertriebener Textkritik); L. Desanti, Restitutionis post mortem onus, Mailand 2003, 269-273.

$\left.{ }^{46}\right)$ Der früheste Beleg ist D. 32,38,4 Scaev. 19 dig., dazu ausführlich U. Babusiaux, Il valore della terra e il ,fideicommissum familiae relictum', Una configurazione giuridica motivata da fattori economici? in: Atti dell' Accademia Romanistica Costantiniana 22 (2017) 405-435, 414-419; ferner Alon so (Fn. 44).

${ }^{47}$ ) Zur Wirkung gegenüber dem Fiskus vgl. Babusiaux, Il valore (Fn. 46) 426-429.

${ }^{48}$ ) Fehlgehend de Vis scher (Fn. 43) 234: „Nuls n'aura le droit de saisir et faire vendre de tels dispositifs funéraires, à l'exception des seuls romains (...).“ Erst recht nicht zielführend sind die Überlegungen zum Pfandrecht (von denen aber noch die Übersetzung von Vandoni (Fn. 1) ausgeht), vgl. ausführlich A lon s o (Fn. 44): „de Visscher's extension of the Gnomon's $\dot{\alpha} \kappa \alpha \tau \alpha \chi \rho \eta \mu \alpha \tau i \sigma \tau o \varsigma$ to the realm of real securities is untenable.“ 
liam relinquere ${ }^{49}$ ), denn dies wird von der Jurisprudenz dahingehend ausgelegt, dass die aus der Familie Verbliebenen das Fideikommiss abstufend nach ihrer Verwandtschaftsnähe geltend machen können, wenn der Erbe gegen den Willen des Erblasser verstößt und die Sache einem Dritten veräußert oder hinterlässt ${ }^{50}$ ). Bei der Auslegung des Begriffs der familia war allerdings zu beachten, dass seit einem Senatsbeschluss unter Hadrian das aus dem Legatsrecht stammende Verbot, ad incertas personas zu verfügen, auch auf Fideikommisse Anwendung fand ${ }^{51}$ ). Zwar konnten Fideikommisse nach wie vor auch auf den Tod des Erben ausgesetzt werden; der Erblasser musste aber die Begünstigten seiner Anordnung jedenfalls als Personenkreis vor Augen haben ${ }^{52}$ ), womit das Veräußerungsverbot automatisch auf eine für den Erblasser vorhersehbare Zeitspanne begrenzt wurde ${ }^{53}$ ). Aufgrund der Formfreiheit des

$\left.{ }^{49}\right)$ Vgl. z. B. D. 31,69,3 Pap. 19 quaest. Fratre herede instituto petit ne domus alienaretur sed ut in familia relinqueretur (...); D. 35,2,54 Marcell. 15 dig., zu beiden vgl. D. Johnston, The Roman Law of Trusts, Oxford 1988, 77f.; weitere Beispiele bei dem s., Prohibitions (Fn. 45) 223-227.

$\left.{ }^{50}\right)$ D. 31,69,3 Pap. 19 quaest. (...) si non paruerit heres voluntati, sed domum alienaverit vel extero herede instituto decesserit, omnes fideicommissum petent qui in familia fuerunt. quid ergo si non sint eiusdem gradus? ita res temperari debet, ut proximus quisque primo loco videatur invitatus. nec tamen ideo sequentium causa propter superiores in posterum laedi debet, sed ita proximus quisque admittendus est, si paratus sit cavere se familiae domum restituturum. (...); D. 31,69,4 Pap. 19 quaest. Si quidam sint postea emancipati, tractari potest, an hi quoque recte fideicommissum petant. et puto recte petituros, quoniam familiae appellatione personae quoque hae demonstratae intelleguntur.

${ }^{51)}$ So zuerst Alonso (Fn. 44), XX. Gai. 2,287 Item olim incertae personae vel postumo alieno per fideicommissum relinqui poterat, quamvis neque heres instituti neque legari ei posset; sed senatusconsulto, quod auctore divo Hadriano factum est, idem in fideicommissis quod in legatis hereditatibusque constitutum est. Eine ausführliche Würdigung des Verbots zuletzt bei C. Corbo, Incertae personae e capacità successoria, Neapel 2012, bes. 21-106; vgl. ferner Ulpiani Epitome [UE] 24,18 Incertae personae legari non potest, veluti, quicumque filio meo filiam suam in matrimonio conlocaverit, ei heres meus tot milia dato ' (...); UE 25,13 (...) incertae personae ne quidem fideicommissa dari possunt.

${ }^{52}$ ) Hierzu fügt sich die Interpretation des Familienfideikommisses durch Papinian, vgl. D. 31,67 pr.-3 Pap. 9 quaest. Unum ex familia propter fideicommissum a se cum moreretur relictum heres eligere debet: ei quem elegit frustra testamento suo legat quod, posteaquam electus est, ex alio testamento petere potest (...), dazu Einzelheiten bei U. Babusiaux, Papinians Quaestiones, 2011, 141-152.

$\left.{ }^{53}\right) \mathrm{Zu}$ dieser natürlichen Grenze des Familienfideikommisses im römischen Recht vgl. Des anti (Fn. 45) 331-362 (v. a. zu Justinians Reform). Zu einer Rekonstruktion des kaiserzeitlichen Rechts vgl. zuletzt Babusiaux, Il valore (Fn. 46) 416-418 m. W. N. 
Fideikommisses kann das Verbot ad incertas personas allerdings gegenüber der gleichnamigen Regel für Legate wesentlich flexibler gehandhabt werden:

D. 31,32,6 Mod. 9 reg.: In fideicommisso quod familiae relinquitur hi ad petitionem eius admitti possunt, qui nominati sunt, aut post omnes eos exstinctos qui ex nomine defuncti fuerint eo tempore, quo testator moreretur, et qui ex his primo gradu procreati sint, nisi specialiter defunctus ad ulteriores voluntatem suam extenderit.

Nach Modestinus werden nicht nur diejenigen zur Geltendmachung des Familienfideikommisses zugelassen, die unter den Begriff der familia fallen, sondern auch die im ersten Grad erzeugten Abkömmlinge derjenigen, die zum Zeitpunkt des Todes des Verfügenden Angehörige der Familie waren ${ }^{54}$ ). Diese Auslegung, die durch das Abstellen auf den letztmöglichen Willen des Erblassers den Kreis der Begünstigten weit fasst, genügt zwar dem hadrianischen Bestimmtheitsgebot, optimiert aber gleichzeitig die Reichweite des erblasserischen Verbots ${ }^{55}$ ). Auszuscheiden sind weitere zukünftige Generationen, deren Existenz und Identität vom Erblasser nicht vorhergesehen werden kann, was zur Folge hat, dass das Veräußerungsverbot in der Regel spätestens nach drei Generationen unwirksam sein wird ${ }^{56}$ ). Unter diesen Prämissen lässt sich das römische Familienfideikommiss seit der hadrianischen Reform als temporale Verfügungsbeschränkung deuten, was aber-genau wie von $\S 2$ hervorgehoben - gleichzeitig bedeutet, dass es keine dauerhaft „unveräußerlichen“ Sachen geben kann ${ }^{57}$ ). Die Betonung des Zeitmoments liegt für $\S 2$ gerade aufgrund eines impliziten Vergleichs zur autochthonen

${ }^{54}$ ) Diese Auslegung folgt aus der Kombination der Sachverhaltsbeschreibung quod familiae relinquitur mit der Kennzeichnung der Begünstigten qui nominati sunt sowie ihrer weiteren Beschreibung qui ex nomine defuncti fuerint; in dieser Verwendung des nomen für Familienangehörige liegt im Übrigen die Verbindung zu den von Johnston, Roman Law (Fn. 49) 88-97, behandelten Fälle der „settlements within the nomen", die Freigelassene betreffen.

${ }^{55}$ ) Gegen die Interpolationsverdächtigungen zur Stelle bereits zutreffend Johnston, Roman Law (Fn. 49) 79-81; ausführlich auch Babusiaux, Il valore (Fn. 46) 418.

${ }^{56}$ ) Die Rechnung ergibt sich mit Modestinus' Formel daraus, dass zum Todeszeitpunkt des Erblassers wahrscheinlich Kinder und Enkel lebten, sodass sich allenfalls deren Abkömmlinge ersten Grades, also die Urenkel, auf das Fideikommiss zugunsten der Familie berufen können. Gleichsinnig John ston, Roman Law (Fn. 49) 86f., der einen Zeitraum von 50 Jahren als Maximum annimmt.

${ }^{57}$ ) Gleichsinnig Alons o (Fn. 44). Zu den gesellschaftlichen Implikationen der Frage vgl. J. Hill ner, Domus, Family, and Inheritance: The Senatorial Family House in Late Antique Rome, JRS 93 (2003) 129-145, die zeigt, dass es keine Intention der Erblasser zur dauerhaften Bewahrung von städtischen Häusern in der Familie gab. 
Rechtslage nahe: Während die Papyri zeigen, dass die nichtrömische Bevölkerung an weitreichende und zeitlich unbeschränkte Verfügungsverbote gebunden ist ${ }^{58}$ ), sind sie für römische Bürger nur solange bindend, wie sie als Fideikommiss (ad certas personas) Wirkungen entfalten können ${ }^{59}$ ). In den Digesten ist dieser personenrechtliche Unterschied eingeebnet; dass allerdings auch die römischen Juristen mit derartigen Fragestellungen in Kontakt kamen, zeigt das von Scaevola nicht zufällig auf Griechisch mitgeteilte „ewige“ Veräußerungsverbot ${ }^{60}$ ).

\section{Rückschlusse aus $\S 2$ auf den Inhalt von $\S 1$ :}

Mit dieser Interpretation des $\S 2$ ergibt sich auch eine abweichende Deutungsmöglichkeit für den sachlich nahen $\S 1$. Die Vorschrift wurde meist dahingehend verstanden, dass sich Kaiser Trajan gegen Grabluxus gewandt habe $\left.{ }^{61}\right)$, durch welchen der Erblasser hoffte, die Rechte des Fiskus oder anderer Gläubiger zu verkürzen. Eine besonders anschauliche Variante dieser Deutung stammt von Schubart, der auf „Gartengräber“"62) verweist, also auf Grabstätten, die durch Hinzunahme des Umlandes oder angrenzender Grundstücke eine besondere Größe erreichen und damit als Luxus anzusehen sein könnten. Aufgrund des Zusammenhangs zu §2 könnte man al-

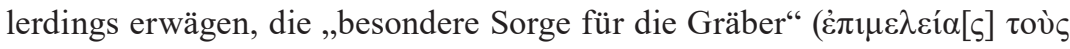

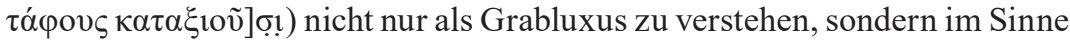

${ }^{58}$ ) Einzelheiten bei Alons o (Fn. 44).

${ }^{59}$ ) Zur grundsätzlichen Unverbindlichkeit rechtsgeschäftlicher Verfügungsbeschränkungen im römischen Recht vgl. Kaser, RRQ (Fn. 45) 173-196.

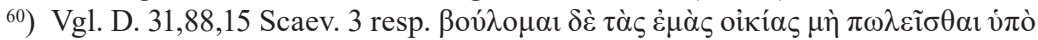

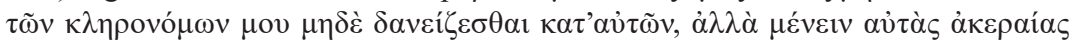

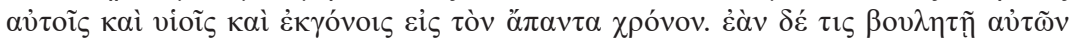

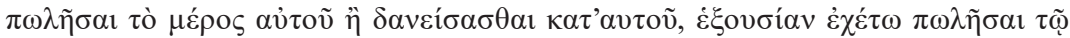

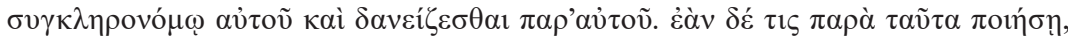

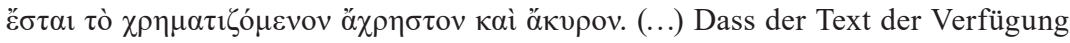
dennoch mitgeteilt wird, dürfte darauf zurückzuführen sein, dass ihm mangels einer dinglichen Verfügung durch den gebundenen Erben keine Wirkung zukommt. Somit ist das für die Kompilatoren interessante Thema des Fragmentes nicht die Wirkungsdauer, sondern der Wirkungsanlass. Zur Textinterpretation vgl. Joh n st on, Prohibitions (Fn. 45) 259f.; A. S pina, Ricerche sulla successione testamentaria nei responsa di Cervidio Scevola, Mailand 2012, 460-480; zuletzt A. Häusler, Letztwillige Verfügungen in griechischer Sprache bei Q.C. Scaevola, Paulus und Modestinus, ZRG 133 (2016) 420-444, 436-438.

${ }^{61)}$ Vgl. de Visscher (Fn. 43) 226f., gleichsinnig Ric cobono, Gnomon (Fn. 1) 95f. m. w. N.

${ }^{62}$ ) Schubart (Fn. 1) 11. Zur Ausgestaltung des Grabes vgl. allgemein M. Kaser, Zum römischen Grabrecht, ZRG RA 95 (1978) 15-92, $66 f$. 
einer besonderen kautelarjuristischen Vorsorge des Erblassers. Hier ist - wie in $\S 2$ - an ein Veräußerungsverbot zu denken, durch welches der Erblasser versucht, auch das Umland der Grabstätte vor dem Zugriff des Fiskus zu schützen. Dass derartige Gestaltungen im provinzialen Umfeld vorkamen, belegt erneut ein Auszug aus Scaevolas Digesten:

D. 32,38,4 Scaev. 19 dig. ${ }^{63}$ ): Iulius Agrippa primipilaris testamento suo cavit, ne ullo modo reliquias eius et praedium suburbanum aut domum maiorem heres eius pigneraret aut ullo modo alienaret: filia eius heres scripta heredem reliquit filiam suam neptem primipilaris, quae easdem res diu possedit et decedens extraneos instituit heredes. quaesitum est, an ea praedia extraneus heres haberet an vero ad Iuliam Domnam, quae habuit patruum maiorem Iulium Agrippam, pertinerent. respondi, cum hoc nudum praeceptum est, nihil proponi contra voluntatem defuncti factum, quo minus ad heredes pertinerent.

In diesem Fall hat der Primipilarier Iulius Agrippa seiner Erbin testamentarisch auferlegt, dass sie weder seine Grabstätte (eius reliquiae) ${ }^{64}$ ), noch das vor der Stadt liegende Grundstück oder ein größeres Haus veräußern dürfe. Dabei fällt auf, dass Scaevola die Grabstätte offenbar nur der Vollständigkeit halber erwähnt, da diese in der rechtlichen Würdigung fehlt: Während nämlich die Frage gestellt wird, ob Iulia Domna als Familienangehörige die

63) Zum Text vgl. Johnston, Prohibitions (Fn. 45) 227-229; ders., Roman Law (Fn. 49) 97-99, der aber die Bedeutung des Zusatzes reliquae eius unterschätzt; zuletzt Spina (Fn. 60) 428-432.

${ }^{64)}$ In jedem Fall sollte reliquiae eius als „sterbliche Überreste“ gedeutet werden und nicht als „Hinterlassenschaft“, so aber B. Kupisch, in: R. Knütel/ B. Kupisch/T. Rüfner/H.H. Seiler (Hgg.), Corpus iuris civilis V, Text und Übersetzung: Digesten 28-34, 2012, 439, der in Fn. 2 die Deutung als „sterbliche Überreste" immerhin für möglich hält. Belege für diesen naheliegenden Sprachgebrauch in: D. 10,2,30 Mod. 6 resp. Fundus mihi communis est pupillae coheredi: in eo fundo reliquiae sunt conditae, quibus religio ab utriusque (...); D. 11,7,42 Flor. 7 inst. Monumentum generaliter res est memoriae causa in posterum prodita: in qua si corpus vel reliquiae inferantur, fiet sepulchrum, si vero nihil eo-

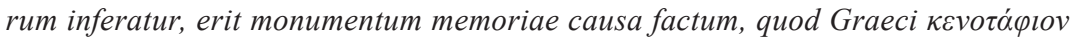
appellant; D. 11,7,44 Paul. 3 quaest. Cum in diversis locis sepultum est, uterque quidem locus religiosus non fit, quia una sepultura plura sepulchra efficere non potest: mihi autem videtur illum religiosum esse, ubi quod est principale conditum est, id est caput, cuius imago fit, inde cognoscimur. cum autem impetratur, ut reliquiae transferantur, desinit locus religiosus esse; D. 11,8,5 Ulp. 1 opin. Si in eo monumento, quod imperfectum esse dicitur, reliquiae hominis conditae sunt, nihil impedit quominus id perficiatur; D. 28,7,27 pr. Mod. 8 resp. Quidam in suo testamento heredem scripsit sub tali condicione "si reliquias eius in mare abiciat": quaerebatur, cum heres institutus condicioni non paruisset, an expellendus est ab hereditate. 
praedia von einem Dritten herausverlangen kann, bleibt das Grab des Iulius Agrippa unbeachtet. Dessen fehlende Relevanz erklärt sich zwanglos daraus, dass die Grabstätte als res religiosa weder eigentums- noch verkehrsfähig ist, sodass sie weder dem extraneus noch der Verwandten zustehen kann ${ }^{65}$ ). Es erscheint allerdings verfehlt, nur aus diesem Grund die Bezugnahme auf die reliquiae eius zu streichen $\left.{ }^{66}\right)$. Wie vielmehr schon Kaser gesehen hat, ist die Kautelarpraxis oftmals bestrebt, einen bereits bestehenden gesetzlichen Schutz rechtsgeschäftlich zu bekräftigen oder auszuweiten ${ }^{67}$ ). Daher ist es vorstellbar, dass der Schutz der Grabstätte dem Erblasser als Motiv diente, um sein weitergehendes Veräußerungsverbot zu rechtfertigen ${ }^{68}$ ). Bezieht man die aus D. 32,38,4 Scaev. 19 dig. ermittelte Fallgestaltung auf §1, so würde sich der Erlass Trajans gegen einen derartigen Missbrauch des an sich ehrenwerten Schutzes der Grabstätte richten. Dabei ist weiter zu beachten, dass die in $\S 2$ angesprochene Reform Hadrians, mit der das Bestimmtheitsgebot auch für Fideikommisse durchgesetzt wurde, unter seinem Vorgänger Trajan noch keine Geltung gehabt haben dürfte. Anders als Scaevola, der seine Entscheidung auf die Reform Hadrians stützt und dem Fideikommiss ohne Begünstigten als nudum praeceptum die Wirkung versagt ${ }^{69}$ ), ist es somit durchaus vorstellbar, dass sich Trajan lediglich gegen eine ausufernde Praxis mit Blick auf Grabstätten wandte. Mit dieser Prämisse wäre $\S 1$ ein weiterer Beleg für die auch sonst zu beobachtenden Bestrebungen der Kaiserzeit, Missbräuche durch Fideikommisse zu verhindern. Genauso wie Fideikommisse ad incertas personas (\$2) werden Fideikommisse zum Schutz von anderen Grundstücken als Gräbern (§1) nicht beachtet und verhindern die Beschlagnahme des Grundes als bona caduca nicht.

${ }^{65}$ ) Zur Grabstätte als res extra commercium vgl. Kas er, Grabrecht (Fn. 62) bes. 34-47 m.w. N.

${ }^{66}$ ) Dass das Detail in der Parallelstelle D. 32,93 pr. Scaev. 3 resp. weggefallen ist, kann eine Kürzung der Kompilatoren sein, anders D. Johns to n, Trusts and Tombs, ZPE 72 (1988) 81-87, 82: „,the presence of the tomb in the land is chance.“ Für die hier vertretene Deutung spricht C. 3,44,9 Phil. (a. 245), dazu Ka ser, RRQ (Fn. 45) 195f.

${ }^{67}$ ) Die mögliche Kumulation von gesetzlicher und letztwilliger Verfügungsbeschränkung hat schon Kaser ebenda 193f., erwogen. Er erklärt dies aber aus der Notwendigkeit, die noch nicht mit einem Leichnam belegte Grabstätte zu schützen; ein Überblick über die entsprechenden Klauseln bei de Vis s cher (Fn. 43) 106-123.

${ }^{68}$ ) Nur insoweit besteht also eine Beziehung zwischen Grabstätte und Familienfideikommiss; der Skepsis von John ston, Trusts (Fn. 66), gegen eine Entstehung des Familienfideikommisses aus der Grabstätte ist unbedingt zu folgen.

${ }^{69}$ ) Es gibt keinen Anlass, mit Johnston, Prohibitions (Fn. 45) 228, nudum praeceptum für eine Glosse zu halten. 
3. Das Fideikommiss ad incertas personas als caducum: Obwohl sich somit $\S \S 1-2$ gerade aus der Perspektive des römischen Rechts erklären lassen, wird der „Fiskalismus“ der Vorschrift als Besonderheit Ägyptens angesehen ${ }^{70}$ ). Vor allem ist - wie zuletzt Alonso hervorgehoben hat - die fiskalische Beschlagnahme ( $\alpha v] \alpha \lambda \alpha \mu \beta \alpha ́ v \varepsilon t)$ als Sanktion des auf Fideikommisse erstreckten Verbots, ad incertas personas nicht anderweitig belegt und könnte daher auf lokalen Besonderheiten beruhen ${ }^{71}$ ). Das Argument übersieht zunächst, dass Gaius' Institutionen auch in anderer Hinsicht keine vollständigen Informationen zur Behandlung der bona caduca liefern, da er lediglich das Rechtsregime von Legaten und Fideikommissen vergleicht ${ }^{72}$ ):

Gai. 2,286/286a: (286) Caelibes quoque, qui per legem Iuliam hereditates legataque capere prohibentur, olim fideicommissa videbantur capere posse.

(286a) Item orbi, qui per legem Papiam ob id, quod liberos non habent, dimidias partes hereditatum legatorumque perdunt, olim solida fideicommissa videbantur capere posse. sed postea senatus consulto Pegasiano proinde fideicommissa quoque ac legata hereditatesque capere posse prohibiti sunt; eaque translata sunt ad eos, qui in eo testamento liberos habent, aut si nulli liberos habebunt, ad populum, sicuti iuris est in legatis et in hereditatibus, quae eadem aut simili ex causa caduca fiunt.

Diese Schilderung zeigt, dass Gaius von einem zweistufigen Verfahren ausgeht, wenn der Erbteil oder das ausgesetzte Legat verfällt, weil Unverheiratete oder Kinderlose als Erben oder Legatare eingesetzt sind: Auf ers-

${ }^{70}$ ) Vgl. Uxkull-Gyllenband (Fn. 1) 3 (allgemein); Lenel/Partsch (Fn. 1) 13; Desanti (Fn. 45) 228f. zu §16; zuletzt dezidiert Alonso (Fn. 44) am Ende: „More likely seems that the Gnomon, here as elsewhere, somewhat disingenuously misinterprets a Roman rule turning it into grounds for confiscation." Ganz anders J.L. Murga, Un posible régimen jurídico especial para los sepulcros romanos en Egipto, RIDA 1984, 233-281, der von einer Besonderheit römischer Gräber auf provinzialem Boden ausgeht.

71) Vgl. Alon so (Fn. 44) zu § 16 des Gnomon: „And just as a legatum in favour of a postumus or an incerta persona is simply ineffective (cf. Gai. 2.238, 2.241, inutiliter relinquitur, inutiliter legatur), that is, cannot be claimed, so that the property remains with the heirs, also when no descendant is left who can claim a fideicommissum, the fiduciaries should simply be treated as having recovered full freedom regarding the property. Confiscation could have been introduced by Hadrian in the same senatusconsultum or later as a supplementary measure, treating these fideicommissa as caduca: but in that case one would have expected Gaius to mention it; worse, if it had been so, Gaius', idem in fideicommissis quod in legatis hereditatibusque constitutum est " would be simply wrong."

$\left.{ }^{72}\right) \mathrm{Zu}$ den Lücken und Auslassungen in Gaius vgl. grundlegend R. Quadrato, Le institutiones nell'insegnamento di Gaio, Neapel 1979, bes. 53-60 zum Recht der Fideikommisse. 
ter Stufe soll das caducum den im Testament eingesetzten Erben mit Kindern anwachsen. Erst bei Fehlen solcher Erben falle es an den Staatsschatz (populus $)^{73}$ ). Die in $\S 1$ angeordnete Beschlagnahme zugunsten des fiscus scheint mit dem geschilderten Verfahren nicht vereinbar, weil von einer vorrangigen Zuweisung der caduca an andere testamentarische Erben vor dem fiscus keine Rede ist; zudem wird in $\S 1$ nicht das (republikanische) aerarium, sondern der (caesarische) fiscus begünstigt.

Schon die juristische Überlieferung zur Behandlung der bona caduca ist indes mehrdeutig, wie ein Blick in die Ulpiani Epitome ${ }^{74}$ ) zeigt:

UE 17,1-2: (1) Quid quis sibi testamento relictum, ita ut iure civili capere possit, aliqua ex causa non ceperit, ,caducum' appellatur, veluti cecidit ab eo: verbi gratia si caelibi vel Latino Iuniano legatum fuerit, nec intra dies centum vel caelebs legi paruerit, vel Latinus ius Quiritium consecutus sit; aut si ex parte heres scriptus vel legatarius ante apertas tabula decesserit vel peregrinus factus sit.

(2) Hodie ex constitutione imperatoris Antonini omnia caduca fisco vindicantur: sed servato iure antiquo liberis et parentibus.

Zwei wesentliche Unterschiede zu den Institutionen des Gaius fallen ins Auge: Zum einen verwendet UE 17,1 einen gegenüber Gai. 2,286/286a erweiterten Kaduzitätsbegriff, zum anderen hält UE 17,2 fest, dass seit einer Konstitution des Antoninus alle bona caduca für den fiscus beansprucht werden, und das frühere Recht lediglich mit Blick auf Kinder und Eltern Anwendung finde.

Zunächst zur Allzuständigkeit des fiscus nach UE 17,2: Dass die in UE 17,2 genannte Konstitution tatsächlich eine umfassende Zuständigkeit des fiscus für bona caduca angeordnet hat, wird in der Literatur allgemein angenommen ${ }^{75}$ ). Diese Deutung ergibt sich vor allem im Umkehrschluss aus der Formulierung servato iure antiquo liberis et parentibus, welche die aus der lex Iulia et Papia bekannte Schonung der Kinder und Eltern von der incapacitas betrifft: Auch andere Quellen lassen erkennen, dass Aszendenten

${ }^{73}$ ) $\mathrm{Zu}$ anderen Quellen, die den Anfall an das aerarium belegen, vgl. G. Boulvert, Domestique et fonctionnaire sous le Haut Empire romain, Paris 1974, $28 \mathrm{f}$. m.w. N.; T. Spagnuolo Vigorita, ,Bona caduca' e giurisdizione procuratoria agli inizi del terzo secolo D.C., Labeo 24 (1978) 131-168, 141 f.

74) Das Verhältnis der Ulpiani Epitome zu den Institutionen des Gaius ist zweifelhaft und kann hier nicht erörtert werden, vgl. F. Mercogliano, Tituli ex corpore Ulpiani, Neapel 1997, 13-35 m. w. N.

75) Vgl. P. Voci, Diritto ereditario romano [DER] I-II, 2. Aufl. Mailand 1967, 1963, hier I, 432; weitere Nachweise bei Spagnuolo Vigorita, Bona caduca (Fn. 73) 145 Fn. 71 „È senz’altro questo il significato principale del brano.“; P.A. Brunt, The ,Fiscus‘ and its Development, JRS 56 (1966) 75-91, $79 f$. 
und Deszenten einander selbst dann vollwirksam testamentarisch zuwenden konnten, wenn die Empfänger unverheiratet und kinderlos waren $\left.{ }^{7}\right)$. Obgleich - so lässt sich UE 17,2 paraphrasieren - nunmehr alle caduca dem fiscus anfallen, bleibt dieses Vorrecht der nächsten Verwandten gewahrt. Alle anderen Vorrechte oder Privilegien aber, insbesondere auch die in Gai. 2,286a noch vorausgesetzte vorrangige Berücksichtigung der erwerbsfähigen testamentarischen Erben, hat die Konstitution dagegen beseitigt ${ }^{77}$ ).

Fraglich ist lediglich, zu welchem Zeitpunkt die in UE 17,2 angesprochene Reform anzusetzen ist, und ob sie tatsächlich eine Ersetzung der von Gaius noch vorausgesetzten Zuständigkeit des aerarium durch den fiscus bedeutet. Die Datierung der Reform wird durch die Mehrdeutigkeit des Namens „Antoninus“ erschwert, da sich dieser sowohl auf Marc Aurel als auch auf Caracalla beziehen kann. Während die ältere Literatur mehrheitlich für eine Zuweisung an Caracalla plädierte ${ }^{78}$ ), spricht sowohl die Zitierweise in den Ulpiani Epitome ${ }^{79}$ ) als auch die sonst feststellbare Entwicklung des Fiskalrechts eher für Marc Aurel ${ }^{80}$ ). In der Tat gibt es keinen Grund, die auch in anderer Hinsicht offensichtliche Verwischung der Kompetenzen von fiscus und aerarium während der Kaiserzeit erst als Anzeichen eines angeblichen Niedergangs in der Severerzeit zu deuten ${ }^{81}$ ); vielmehr beruht die Ablö-

${ }^{76}$ ) Zur Frage der geschützten Verwandtschaftsgrade vgl. nur A. WallaceHadrill, Family and inheritance in the Augustan marriage-laws, Proceedings of the Cambridge Philological Society 207 (1981) 58-80, bes. 62-64, 73-76 m.w. N. Einzelfragen hierzu bleiben an dieser Stelle unberücksichtigt.

${ }^{77}$ ) Zutreffend O. Tellegen-Couperus, Dioclétien et les biens vacants, TR 54 (1986) 85-95, bes. 92-94.

${ }^{78}$ ) Vgl. Boulvert (Fn. 73) $47 f$.

${ }^{79}$ ) Wenn man aus der sonstigen Zitierpraxis der Ulpiani Epitome Rückschlüsse zieht, vgl. UE 8,5 (...) ex constitutione divi Antonini; UE 26,7 (...) sed postea imperatorum Antonini et Commodi oratione in senatu recitata id actum est, (...), ist Antoninus hier mit Marc Aurel zu identifizieren. So im Ergebnis auch M. Aven arius, Der Pseudo-Ulpianische liber singularis regularum, 2005, 76-69, 348f. m. w. N., der die Antoninenzeit allerdings nach m. E. unsicheren inhaltlichen Kriterien fixieren will.

${ }^{80}$ ) Vgl. O. Hirschfeld, Die kaiserlichen Verwaltungsbeamten bis auf Diocletian, 31905, 116; offengelassen von G. Provera, La vindicatio caducorum, Turin 1964, 125f. „tra l'epoca degli Antonini e quella di Caracalla“.

${ }^{81)}$ Schon unter Trajan gibt es offenbar eine Tendenz, die caduca dem fiscus zuzurechnen, vgl. D. 49,14,13 pr. Paul. 7 ad leg. Iul. et Pap. Edicto divi Traiani, quod proposui, significatur, ut, si quis, antequam causa eius ad aerarium deferatur, professus esset eam rem quam possideret capere sibi non licere, ex ea partem fisco inferret, partem ipse retineret, dazu Boulvert (Fn. 73) 45 Fn. 267; weiterführend Tellegen-Couperus, Dioclétien (Fn. 77) 91f. 
sung des aerarium durch den fiscus offenbar schon darauf, dass spätestens seit Claudius auch das aerarium durch kaiserliche Beamte organisiert und beaufsichtigt wird ${ }^{82}$ ). Die Einverleibung der dem Staatsschatz zustehenden Mittel scheint daher mit den Flaviern abgeschlossen zu sein ${ }^{83}$, was allerdings Anlehnungen an den republikanischen Wortschatz (aerarium) auch durch spätere Kaiser nicht ausschließ $\mathrm{t}^{84}$ ). Wenn der fiscus aber ohnehin mit der Einziehung von Geldern auch für das aerarium beauftragt war, gibt es keinen Grund, die durch UE 17,2 naheliegende Ersetzung des aerarium durch den fiscus in Zweifel zu ziehen; die Konstitution Marc Aurels hätte damit lediglich eine längst bestehende Praxis bestätigt und harmonisiert ${ }^{85}$ ). Es sei betont, dass die kaiserliche Anordnung keineswegs die Abschaffung des aerarium beinhalten muss, sondern nur einen Bedeutungswandel der beiden Kassen zum Ausdruck bringt. Wie nämlich auch die Juristenschriften zeigen, bleiben beide Bezeichnungen bis in die späte Kaiserzeit erhalten und werden bis auf Ausnahmefälle als Synonyme verwendet, was dafür spricht, dass das aerarium fortbestand und vom fiscus schrittweise aufgesogen wurde ${ }^{86}$ ). Berücksichtigt man, dass auch der in BGU V,1210 überlieferte Text aufgrund der äußeren Gestalt auf die Zeit zwischen 150 und

$\left.{ }^{82}\right)$ Vgl. R. Orestano, Il ,problema delle persone giuridiche“ in diritto romano, Turin 1968, 232-254; Boulvert (Fn. 73) 44-47; T. Spagnuolo Vigorita, La giurisdizione fiscale tra Augusto e Adriano, in: F. Milazzo (Hg.), Gli ordinamenti giudiziari di Roma imperiale, Copanello 5-8 giugnio 1996, Neapel 1999, 449-484, $450 f$.

${ }^{83}$ ) Belege bei Provera (Fn. 80) 111-161; Brunt, Fiscus (Fn. 75) 80f.; eine Teilung der bona caduca und vacantia soll seit Trajan gelten, vgl. Spagnuolo Vigorita, Bona caduca (Fn. 73) 142f. m.w. N.

${ }^{84)}$ Spagnuolo Vigorita, Giurisdizione fiscale (Fn. 82) 451f.; ders., Bona caduca (Fn. 73) 132-135; anders M. Alpers, Das nachrepublikanische Finanzsystem, 1995, bes. 248-307, der auf die Einhaltung der Trennung zwischen fiscus und aerarium beharrt. Richtig ist die Beobachtung Alpers, dass fiscus auch einfach den fiscus provinciae bezeichnen kann. Diese Mehrdeutigkeit scheint aber Teil der Entwicklung zu einem Gesamt-fiscus zu sein; vgl. E. Lo Cascio, Fiscus principis nostri (SC de Cn. Pisone patre, 11. 54-55): ancora sulla configurazione giuridica del fisco imperiale, in: ders. (Hg.), Il princeps e il suo impero, Bari 2000, 163-174, bes. 167, der betont, dass es keine Belege für einen Zufluss aus den Provinzen an das aerarium gibt.

${ }^{85}$ ) Für die Kompetenzen des fiscus hinsichtlich caduca bereits zur Zeit Marc Aurels sprechen auch D. 28,4,3; D. 34,9,12, dazu Brunt, Dioclétien (Fn. 75) 80f; zum Inhalt der Entscheidung vgl. V. Wa n kerl, Appello ad principem, 2009, 17-94.

${ }^{86}$ ) Zur synonymen Verbindung vgl. v. a. D. 49,14,13 pr. Paul. 7 ad leg. Iul. et Pap.; D. 49,14,15,5 Mauric. 3 ad leg. Iul. et Pap.; häufig die Verbindung von praefecti aerarii und fiscus, z. B. D. 2,15,8,19 Ulp. 5 de omn. trib.; D. 40,5,4,20 Ulp. 60 ad ed. 
180 n. Chr. ${ }^{87}$ ) zu datieren ist, ist es jedenfalls naheliegend, dass er nicht die Rechtslage, die Gaius für die Zeit des Antoninus Pius schildert ${ }^{88}$ ), sondern die späteren Anpassungen durch Marc Aurel, das heißt das Zugriffsrecht des fiscus, dokumentiert.

Aber auch dem Bedenken gegen die Rechtsnatur der Sanktion kann unter Hinweis auf die Epitome Ulpiani Rechnung getragen werden. Während Gaius nur die Kaduzität aufgrund der incapacitas des kinder- oder ehelosen Begünstigten behandelt, belegt UE 17,1 einen erweiterten Kaduzitätsbegriff: Als caducum gilt hier einerseits der Wegfall des nach ius civile wirksam eingesetzten Erben, andererseits die nach Testamentseröffnung eingetretene Handlungsunfähigkeit des Legatars. Nach den beispielhaft genannten Fällen scheint es sich dabei vorrangig um Einschränkungen der persönlichen Empfangsfähigkeit des Begünstigten zu handeln, welche - genau wie die incapacitas - die Entgegennahme des testamentarischen Vorteils verhindern. Dabei ist zu beachten, dass offenbar sowohl die fehlende Beseitigung von ursprünglich bestehenden Hindernissen (Status als Unverheirateter oder als Latinus Iunianus), als auch nachträglich eintretende Verhinderungen wie der Tod oder der Wegfall des Bürgerrechts ${ }^{89}$ ) zum Verfall der Zuwendung führen.

Nach UE 17,1 tritt Kaduzität in Situationen ein, in denen nach ius civile wirksam verfügt worden ist und sich nachträglich ein Wegfall des Begünstigten ergibt. Diese Vorgabe ist für ein Fideikommiss allerdings nicht passend, da sich seine Wirksamkeit allein nach dem ius novum beurteil $^{90}$ ). Maßgeblicher Zeitpunkt für die Wirksamkeitsprüfung ist dabei schon aufgrund seiner Formlosigkeit nicht die Testamentserrichtung, sondern allein der Tod des Verfügenden ${ }^{91}$ ). Dieser Unterschied ist auch bei

${ }^{87)}$ S.o. Fn. 38.

$\left.{ }^{88}\right)$ Zur Datierung der Institutionen des Gaius unter Antoninus Pius vgl. zuletzt die Nachweise bei U. Babusiaux, Die Institutiones im Rahmen der gaianischen Werke, in: dies./ D. Mantovani (Hgg.), Le Istituzioni di Gaio: avventure di un bestseller, Trasmissione, uso e trasformazione del testo, Pavia 2019 (in Vorbereitung).

${ }^{89}$ ) Zum Verfall durch Verschiebung des Anfallszeitpunkts auf die Eröffnung des Testaments vgl. auch C. 6,51,1c Iust. (a. 534).

${ }^{90}$ ) Vgl. Inst. 2,23,1 und Inst. 2,25 pr., dazu V. Giodice-Sabatelli, La tutela giuridica dei fedecommessi fra Augusto e Vespasiano, Bari 1993.

$\left.{ }^{91}\right)$ Oder sogar die Testamentseröffnung, vgl. C. 6,51,1c Iust. (a. 534) Cum igitur materiam et exordium caducorum lex Papia ab aditionibus, quae circa defunctorum hereditates procedebant, sumpsit et ideo non a morte testatoris, sed ab apertura tabularum dies cedere legatorum senatus consulta, quae circa legem Papiam introducta sunt, concesserunt, ut, quod in medio deficiat, hoc caducum fiat, primum hoc corrigentes et antiquum statum revocantes sancimus omnes habere licentiam a 
der Übertragung des Verbotes einer Verfügung ad incertas personas auf Fideikommisse zu beachten. Während Legate, die ad incertas personas zugewendet waren, von vornherein keine Wirksamkeit entfalten können ${ }^{92}$ ), ist die Unbestimmtheit für Fideikommisse - wie auch die Auslegungsregel des Modestinus gezeigt hat (D. 31,32,6 Mod. 9 reg., vgl. II.1) - ex post zu ermitteln: Gibt es nach dem Tod des Erblassers keinen Familienangehörigen, den dieser als familia in seinen Willen mit aufgenommen haben kann, ist das Fideikommiss „verfallen“; nur wenn eine zur Gruppe der Begünstigten zu zählende Person die Sache für sich beansprucht, ist ein tauglicher Fideikommissar vorhanden. Diese in den justinianischen Quellen nicht belegte Situation ist mit dem bedingten Legat vergleichbar, welches nach der Darlegung in Justinians Reformkonstitution de caducis tollendis unter dem alten Recht als caducum verfiel (in causa cadu$c i$ ), wenn die Bedingung nicht eintrat ${ }^{93}$ ). Justinian beseitigt diese als unbillig empfundene Rechtsfolge und ordnet an, dass das verfallene Legat an die Kollegatare fallen soll, die allerdings im Gegenzug auch die an dem Legat hängenden Lasten übernehmen müssten ${ }^{94}$ ). Hieraus folgt, dass der fehlende Beleg einer fiskalischen Beschlagnahme der ad incertas personas ausgesetzten Fideikommisse keinen Beweis für die Sonderbarkeit des Gnomon bilden kann. Vielmehr zeigt der Gnomon umgekehrt, welche Lücken sich in der justinianischen Überlieferung für das Recht der Kaiserzeit aufgrund der Abschaffung der Kadukargesetzgebung auftun. In

morte testatoris adire hereditates similique modo legatorum vel fideicommissorum pure vel in diem relictorum diem a morte testatoris cedere.

${ }^{92}$ ) Die Überlieferung zum Verbot ad incertas personas ist ebenfalls gering, weil auch dieses von Justinian abgeändert wurde, vgl. C. 6,48,1 (a. 528/9), dazu M. Kaser, Das römische Privatrecht II, 21976, 554 Fn. 44; zuletzt ausführlich Desanti (Fn. 45) 307-323.

${ }^{93}$ ) Zum Verfall des bedingten Legats, vgl. C. 6,51,2a Iust. (a. 534) (...) forte quadam condicione, sub qua relictum erat, deficiente, quod veteres appellabant in causa caduci: vel mortuo iam testatore hoc quod relictum est deficiebat, quod aperta voce caducum nuncupabatur.

${ }^{94)}$ Vgl. C. 6,51,4 Iust. (a. 534) Pro secundo vero ordine, in quo ea vertuntur, quae in causa caduci fieri contingebat, vetus ius corrigentes sancimus ea, quae ita evenerint, simili quidem modo manere apud eos, a quibus sunt derelicta, heredes forte vel legatarios vel alios, qui fideicommisso gravari possunt, nisi et in hunc casum vel substitutus vel coniunctus eos antecedat: sed omnes personas, quibus lucrum per hunc ordinem defertur, eas etiam gravamen quod ab initio fuerat complexum omnimodo sentire, sive in dando sit constitutum sive in quibusdam faciendis vel in modo vel condicionis implendae gratia vel alia quacumque via excogitatum. Neque enim ferendus est is, qui lucrum quidem amplectitur, onus autem ei adnexum contemnit. 
dieser Hinsicht bilden $\S \S 1-2$ eine wertvolle Ergänzung der aus der außerjustinianischen Überlieferung und Justinians Reformkonstitution ersichtlichen Indizien.

\section{Zur Rekonstruktion des unverstandenen Textteils}

$$
\text { (Z. 14-16): }
$$

Mit dieser Deutung kann man versuchen, den bislang unverstandenen

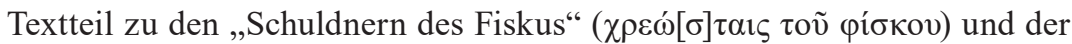

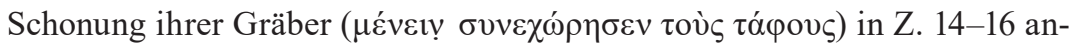
ders als die bisher herrschende Auffassung zu erklären:

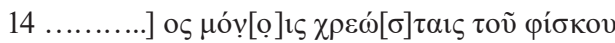

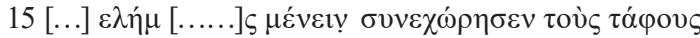

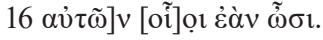

Anstelle der verschiedenen Ergänzungsvorschläge ${ }^{95}$ ) könnte nach dem Vorangehenden eher an eine Klarstellung mit Blick auf die Schuldner der Erbschaftssteuer zu denken sein. Dabei ist im Ausgangspunkt daran zu erinnern, dass die Begräbniskosten auch dem beschlagnahmenden Fiskus entgegengehalten werden können ${ }^{96}$ ). Sofern also der Erbe, dem die Erbschaft entzogen wird, Kosten für die Bestattung des Erblassers aufgewendet hat, kann er diese dem Fiskus entgegenhalten ${ }^{97}$ ). Für diese Kosten gilt eine Reihe von Privilegien ${ }^{98}$ ), da diese insbesondere vorrangig vor allen

${ }^{95}$ ) Unterschiedliche Ergänzungsvorschläge zu Z. 15 bei Schubart (Fn. 1) $11 \mathrm{Nr}$. 15; de Visscher (Fn. 43) 235f.; ferner Mélèze-Modrzejewski, Gnomon (Fn. 1) 526 Fn. 6; Vandoni (Fn. 1) 3; zuletzt B. Kramer, Zum Gnomon des Idios Logos $\S 1,15$, Archiv für Papyrusforschung 44 (1998) 253f.

${ }^{96}$ ) Dies ergibt sich aus D. 11,7,37 pr. Macer 1 ad leg. vic. her. Funeris sumptus accipitur, quidquid corporis causa veluti unguentorum erogatum est, et pretium loci in quo defunctus humatus est, et si qua vectigalia sunt, vel sarcophagi et vectura: et quidquid corporis causa antequam sepeliatur consumptum est, funeris impensam esse existimo, vgl. bereits O. Lene1, Palingenesia iuris civilis I, Leipzig 1889, Sp. 571 Fn. 3 In ratione vicensimae ponenda ante deducitur funeris impensa. Dem Erbunwürdigen verbleiben die iura sepulchrorum, vgl. auch D. 11,7,33 Ulp. 68 ad ed.

${ }^{97}$ ) Der Erblasser gilt als Primärschuldner, vgl. D. 11,7,1 pr. Ulp. 10 ad ed. Qui propter funus aliquid impendit, cum defuncto contrahere creditur, non cum herede. Die Geltung der im Edikt verheißenen Klage (D. 11,7,12,2 Ulp. 25 ad ed.) gegen den Rechtsnachfolger folgt aus D. 11,7,14,16-17 Ulp. 25 ad ed. 16. Si tamen quasi negotium heredis gerens funeravit, licet ratum non habeat, tamen funeraria eum agere posse Labeo scribit. 17. Datur autem haec actio adversus eos ad quos funus pertinet, ut puta adversus heredem bonorumve possessorem ceterosque successores.

${ }^{98}$ ) Grund für die Privilegien ist das öffentliche Interesse an der Bestattung, vgl. 
anderen Erbschaftsschulden sind ${ }^{99}$ ). Nach den Juristenschriften in den Digesten sind für die Begräbniskosten die Vermögensverhältnisse des Verstorbenen anzusetzen ${ }^{100}$ ); bei besonders wohlhabenden Erblassern können also auch größere Grabanlagen angemessen und damit abzugsfähig sein $\left.{ }^{101}\right)$. Kombiniert man diese Informationen und überträgt sie auf das Verhältnis zwischen dem Fiskus und dem herausgabepflichtigen Erben, könnte man Z. 14-16 wie folgt verstehen: Auch wenn der Erblasser die Herausgabepflicht nicht durch Einbezug anderer Grundstücke in die Grabstätte hindern kann (vgl. Z. 8-13), kann er die Begräbniskosten gegenüber dem Fiskus auch dann in Abzug bringen, wenn die Gräber mehr als die bloße Grabstätte umfassen. Man könnte den Fortgang also als Klarstellung verstehen, dass der Fiskus keinesfalls die trajanische Konstitution verwenden kann, um die Kostenübernahme zu verweigern. Auch wenn diese Rekonstruktion hypothetisch bleiben muss, fügt sie sich doch durchaus plausibel zum Kontext der beiden Vorschriften und ist zudem mit den lesbaren Worten des $\S 1$ vereinbar.

D. 11,7,12,3 Ulp. 25 ad ed. Hoc edictum iusta ex causa propositum erit, ut qui funeravit persequatur id quod impendit: sic enim fieri, ne insepulta corpora iacerent neve quis de alieno funderetur.

$\left.{ }^{99}\right)$ D. 11,7,45 Maec. 8 fideic. Impensa funeris semper ex hereditate deducitur, quae etiam omne creditum solet praecedere, cum bona solvendo non sint. Für das $\mathrm{Zu}-$ rückbehaltungsrecht gelten die Regeln der hereditatis petitio, vgl. D. 5,3,50,1 Pap. 6 quaest., dazu A. Bürge, Retentio im römischen Sachen- und Obligationenrecht, 1978, 43f.

$\left.{ }^{100}\right)$ Dies gilt jedenfalls für die Berechnung des Vermögenswertes der Erbschaft, wie er für die lex Falcidia zugrundegelegt wird, vgl. D. 35,2,1,19 Paul. 1. sing. ad leg. Falc.; dazu G. Klingenberg, Das modicum-Kriterium, ZRG RA 126 (2009) 187-283, 205-211 m.w. N. Grundlage ist das Ermessen des Richters in der actio funeraria vgl. D. 11,7,14,10 Ulp. 25 ad ed. Iudicem, qui de ea aequitate cognoscit, interdum sumptum omnino non debere admittere modicum factum, si forte in contumeliam defuncti hominis locupletis modicus factus sit: nam non debet huius rationem habere, cum contumeliam defuncto fecisse videatur ita eum funerando.

101) Vgl. D. 11,7,14,6 Ulp. 25 ad ed. Haec actio quae funeraria dicitur ex bono et aequo oritur: continet autem funeris causa tantum impensam, non etiam ceterorum sumptuum. Aequum autem accipitur ex dignitate eius qui funeratus est, ex causa, ex tempore et ex bona fide, ut neque plus imputetur sumptus nomine quam factum est neque tantum quantum factum est, si immodice factum est: deberet enim haberi ratio facultatium eius, in quem factum est, et ipsius rei, quae ultra modum sine causa consumitur. Quid ergo si ex voluntate testatoris impensum est? Sciendum est nec voluntatem sequendam, si res egrediatur iustam sumptus rationem, pro modo autem facultatium sumptum fieri. 


\section{Fazit:}

Insgesamt gibt es somit keinen Anlass, §§ 1-2 als ägyptisches Sonderrecht anzusehen. Vielmehr lassen sie sich als wertvolle Ergänzung der in den justinianischen Quellen fehlenden Informationen zur Kaduzität von Fideikommissen lesen.

\section{Zum Heimfallrecht des Fiskus (§ 4)}

Ebenfalls ein Vorrecht des fiscus betrifft:

BGU V,1210, 23-25

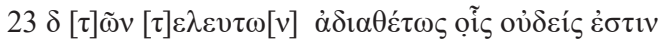

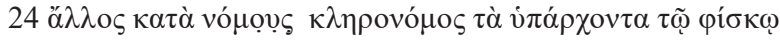

$25 \pi \rho \circ \sigma \kappa \rho \varepsilon i ́ v \varepsilon \tau \alpha 1$.

$\S 4$ : Von denen, die ohne Testament sterben, wird das Vermögen, soweit sie sonst keinen gesetzlichen Erben haben, dem Fiskus zugesprochen.

Nach dieser Vorschrift wird eine Erbschaft dem Fiskus zugesprochen, wenn es weder einen testamentarischen noch einen gesetzlichen Erben gibt. Diese Regelung entspricht der Sache nach der Rechtslage für bona vacantia $^{102}$ ) nach der lex Iulia caducaria $\left.{ }^{103}\right)$. Genau wie für $\S \S 1-2$ wird aber der fiscus als Begünstiger genannt, während Gaius das aerarium (populus) als Empfänger des vakanten Vermögens bezeichnet ${ }^{104}$ ). Erneut lässt sich der Widerspruch durch die Annahme einer sukzessiven Fiskalisierung des aerarium (vgl. II.3.) erklären, die bei Gaius, der sich ja auf elementare Lehren beschränkt, keine Erwähnung findet, während der auf die Praxis ausgerichtete Gnomon den tatsächlichen Zugriff des fiscus beschreibt ${ }^{105}$ ). Zu betonen ist zudem, dass auch die in den justinianischen Digesten überlieferte severische

102) Zum (unklaren) Verhältnis von bona vacantia und bona caducaria, vgl. R. Astolfi, I beni vacanti e la legislazione caducaria, BIDR 68 (1965) 323-336. Mit Ausweitung des Kaduzitätsbegriff (oben II.3) ist der Unterschied aufgehoben.

103) Zur lex Iulia caducaria vgl. S. Bolla, Zum römischen Heimfallrecht, ZRG RA 59 (1939) 546-554, 547f.; zur ägyptischen Praxis vgl. H. Kreller, Erbrechtliche Untersuchungen auf Grund der gräko-ägyptischen Papyrusurkunden, 1919, 126-129

$\left.{ }^{104}\right)$ Gai. 2,150 [...] ea lege bona caduca fiunt et ad populum deferri iubentur, si defuncto nemo heres vel bonorum possessor sit. Weitere Parallelen sind UE 28,7 und C. 10,10,1 Diocl./Maxim. (a. 292); zu allen Ric cobono, Gnomon (Fn. 1) 113f. Zur Verwendung von populus anstelle von aerarium vgl. bereits S. Bolla, Die Entwicklung des Fiskus zum Privatrechtssubjekt mit Beiträgen zur Lehre vom aerarium, Prag 1938, 3-7 m.w. N.

105) Besonders plastisch F. Millar, The Emperor in the Roman World, New York 1977, 153-174, der annimmt, das aerarium sei für die Auskünfte über bona vacantia zuständig gewesen, während derfiscus die Einnahmen verwaltet habe. 
Jurisprudenz von einem Letztzugriffsrecht des fiscus auszugehen scheint $\left.{ }^{106}\right)$. Erneut lässt sich also der Gnomon als Zeugnis eines anderweitig nicht belegten Zwischenschrittes zwischen der Situation unter Antoninus Pius und Caracalla heranziehen.

Umstritten ist allerdings weiterhin, ob $\S 4$ die römische Rechtslage zutreffend wiedergibt, selbst wenn man von einer Empfangszuständigkeit des fiscus ausgeht. So haben vor allem Lenel/Partsch hervorgehoben, dass die in $\S 4$ vorgesehene Rechtsfolge $\pi \rho \circ \sigma \kappa \rho \varepsilon i ́ v \varepsilon \tau \alpha 1$, die offenbar ein vorheriges Verfahren voraussetzte, kaum mit der Beschlagnahme, wie sie für das aerarium belegt ist, zu vereinbaren sei; als regelrecht fehlerhaft wurde angesehen, dass $\S 4$ den fiscus einem Erben gleichstelle (ó $\alpha \lambda$ os), obgleich in den Juristenschriften betont werde, dass der Staatsschatz gerade keine eigentliche Erbenstellung innehabe. Lenel/Partsch wollen $\S 4$ daher nicht als Beleg für das römische Recht, sondern allenfalls als Zeugnis alexandrinischen Sonderrechts ansehen $\left.{ }^{107}\right)$.

Diese Bedenken sind vor allem von Mélèze-Modrzejewski zurückgewiesen worden ${ }^{108}$ ), der zu recht betont, dass der fiscus (Caesaris) - anders als das aerarium $^{109}$ ) - auf die Geltendmachung der vindicatio caducorum und damit

${ }^{106)}$ Vgl. v. a. D. 38,9,1,6 Ulp. 49 ad ed. Qui semel noluit bonorum possessionem petere, perdidit ius eius, etsi tempora largiantur: ubi enim noluit, iam coepit ad alios pertinere bonorum possessio aut fiscum invitare; D. 40,4,50 pr. Pap. 9 resp. Quod divo Marco pro libertatibus conservandis placuit, locum habet irrito testamento facto, si bona venitura sint: alioquin vacantibus fisco vindicatis non habere constitutionem locum aperte cavetur, vgl. dazu Th. Fin ken a u er, Freilassung durch Nachlaßübernahme - zur addictio bonorum libertatis causa, in: ders . (Hg.), Symposion Wieling 2007, 19-58, 37-45.

${ }^{107}$ ) Lenel/Partsch (Fn. 1) 12 Fn. 1; vergleichbar auch Kaupper (Fn. 19) 29-38; ein weiteres Argument bildet die Nähe der explizit für Alexandriner geltenden Vorschriften $\S \S 5$ und 6; beide Vorschriften erklären sich jedoch ohne Weiteres daraus, dass das alexandrinische Bürgerrecht als Vorstufe für das römische galt, vgl. J. Mélèze-Modrzejewski, Loi et Coutume dans l'Égypte grecque et romaine, Warschau 2014, 273f.; zuletzt auch A. Dolg a nov, Imperialism and Social Engineering: Augustan Social Legislation in the Gnomon of the Idios Logos, in: HarterUibopuu/Kruse (Fn. 15) XX.

${ }^{108}$ ) J. Mélèze-Modrzejewski, La dévolution au fisc des biens vacants d'après le gnomon de l'idiologue (BGU 1210, §4), in: Studi Volterra VI, Mailand 1971, 91-125, bes. 92f. und 101f.; zustimmend Tellegen-Couperus, Dioclétien (Fn. 77) $87 \mathrm{zu} \S 4$.

${ }^{109}$ ) Den klarsten Beleg für die prozessualen Unterschiede zwischen fiscus und aerarium bildet D. 49,14,1 pr.-1 Call. 1 de iur. fisc. pr. Variae causae sunt, ex quibus nuntiatio ad fiscum fieri solet. Aut enim se quis, quod tacite relictum est, profitetur capere non posse vel ab alio praeventus defertur: vel quod mors ab heredibus non 
die Durchführung eines Verfahrens angewiesen gewesen sei $\left.{ }^{10}\right)$. Durch dieses Verfahren erlange der fiscus eine der Erbenstellung vergleichbare Po-

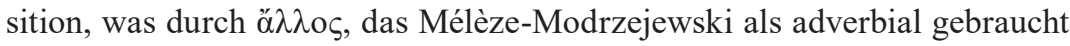
ansieht, auch klaren Ausdruck finde" ${ }^{111}$ ). Erbenähnlich - so ließe sich ergänzen - ist die Stellung vor allem deshalb, weil der fiscus die mit der Erbschaft verbundenen Lasten, insbesondere die Legate und Fideikommisse, auskehren muss, also keineswegs nur die Vorteile der Erbschaft erhält ${ }^{112}$ ). Damit aber ordnet $\S 4$ nichts anderes an als die zitierten Digestenstellen, die von einem Heimfallrecht für bona vacantia an den fiscus ausgehen und diesem gleichzeitig die Verpflichtungen des Erben auferlegen.

Mit diesem Ergebnis ist auch die für $\S 4$ häufig erörterte Frage eines Einflusses des lokalen Rechts eher skeptisch zu beurteilen ${ }^{113}$ ). Auch wenn belegt ist, dass vergleichbare Vorschriften für das ptolemäische Recht existierten, die insofern die Akzeptanz des $\S 4$ gefördert haben könnten ${ }^{114}$ ), sprechen die besseren Gründe für eine rein römische Regelung. Hierfür ist eine

vindicatur: vel quod indignus quis heres nuntiatur: (...) 1. An bona, quae solvendo non sint, ipso iure ad fiscum pertineant, quaesitum est. Labeo scribit etiam ea, quae solvendo non sint, ipso iure ad fiscum pertinere. Sed contra sententiam eius edictum perpetuum scriptum est, quod ita bona veneunt, si ex his fisco adquiri nihil possit., dazu Mélèze-Modrzejew ski, Dévolution (Fn. 108) 120f.; Provera (Fn. 80) 92-112; zuletzt S. Puliatti, Il ,de iure fisci“ de Callistrato. Il processo fiscale in età Severiana, Mailand 1992, bes. 195-200.

${ }^{110}$ ) Dies zeigt auch mit bes. Deutlichkeit Plin. Paneg. 36 (...) At fortasse non eadem severitate fiscum, qua aerarium, cohibes. Immo tanto maiore, quanto plus tibi licere de tuo, quam de publico credis. Dicitur actori, atque etiam procuratori tuo: In ius veni: sequere ad tribunal. Nam tribunal quoque excogitatum principatui est, par ceteris, nisi illud litigatoris amplitudine metiaris. Sors et urna fisco iudicem assignat: licet reiicere, licet exclamare: Hunc nolo, timidus est, et bona seculi parum intelligit: illum nolo, quia Caesarem fortiter amat. Eodem foro utuntur principatus et libertas. Quae praecipua tua gloria est, saepius vincitur fiscus; cuius mala caussa nunquam est, nisi sub bono principe. (...).

111) Vgl. Mélèze-Modrzejewski, Dévolution (Fn. 108) 106-108.

${ }^{112}$ ) Zum Grundsatz cum suo onere vgl. D. 30,96,1 Iul. 39 dig. Quotiens lege Iulia bona vacantia ad fiscum pertinent, et legata et fideicommissa praestantur, quae praestare cogeretur heres a quo relicta erant, dazu Fin ken a u er, Freilassung (Fn. 106) 45f., der den Text allerdings auf die bona caduca beschränken will; einen Sonderfall bildet D. 30,114,2 Marcian. 8 inst. Qui intestato decedit et scit bona sua ad fiscum perventura vacantia, fidei fisci committere potest.

113) Vgl. Bolla, Entwicklung (Fn. 104) 51-54, die von einer Übernahme aus dem ägyptischen Recht ausgeht; skeptisch dagegen D. Rathbone, Egypt, August and Roman Taxation, Cahiers Glotz 4 (1993) 81-112, $105 f$.

${ }^{114}$ ) Mélèze-Modrzejewski, Dévolution (Fn. 108) 110-113. 
Überlegung von O. Tellegen-Couperus nutzbar zu machen, die darauf verweist, dass schon für die Zeit des Augustus wie des Claudius Belege existieren, die eine kaiserliche Erteilung des Heimfallrechts an Stadtgemeinden bezeugen $\left.{ }^{115}\right)$. Tellegen-Couperus argumentiert, eine derartige Privilegierung von Stadtgemeinden durch den Kaiser setze das Zugriffsrecht des Kaisers und damit die Zuständigkeit des kaiserlichen fiscus voraus. Vor allem aber lässt sich aus diesen Stellen schließen, dass der Zugriff auf herrenlose Erbschaften als Ausdruck und Folge der römischen Herrschaft über die eroberte Provinz angesehen wurde ${ }^{116}$ ) und keineswegs als eine „privatrechtliche“ Regelung, in der Rechtsnormen verschiedener Provenienz Anwendung finden konnten.

\section{Regeln der Testamentserrichtung}

Aus der spezifischen Sicht des beschlagnahmenden Beamten sind auch die Regeln zur Testamentserrichtung formuliert, von denen hier $\S \S 7,8$ und 18 darzustellen sind.

\section{Zur Testamentsform (§7):}

\section{BGU V,1210, 33-34}

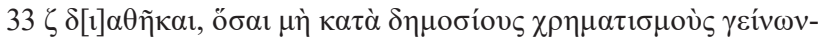

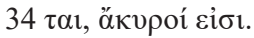

$\S 7$ : Testamente, die nicht nach öffentlichen Vorschriften errichtet werden, sind ungültig.

$\S 7$ ordnet die Ungültigkeit von Testamenten an, welche nicht entsprechend dem öffentlichen Recht errichtet worden sind. Diese Vorschrift scheint prima facie auf die besondere Form des griechischen Testaments

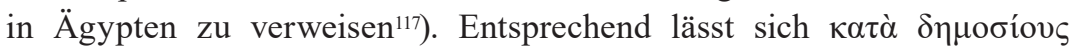

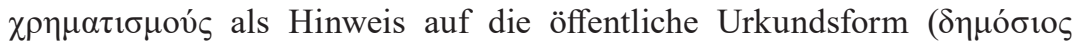

${ }^{115}$ ) Tellegen-Couperus, Dioclétien (Fn. 77) 88f.

${ }^{116)}$ Vgl. Reinach, Code fiscal II (Fn. 1) 51. Zu den Grundlagen der römischen Besteuerung siehe in diesem Zusammenhang Rathbone, Egypt (Fn. 113) 100-102, der allerdings betont, dass der Idios Logos sowohl für das aerarium als auch für den fiscus tätig gewesen sei. Zur Rechtsstellung als Provinz allgemein vgl. zuletzt den Überblick bei F. Herklotz, Aegypto capta, Augustus and the Annexation of Egypt, in: C. Rigg s (Hg.), The Oxford Handbook of Roman Egypt, Oxford 2012, 11-21.

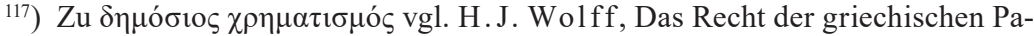
pyri Ägyptens II, 1978, 139-141 m. w. N.; aus Sicht des Testamentsrechts vgl. zuletzt B. Strobel, Römische Testamentsurkunden aus Ägypten vor und nach der Constitutio Antoniniana, 2014, 29f.; ausführlich M. Now a k, Wills in the Roman Empire, Warschau 2015, 74f. 
$\chi \rho \eta \mu \alpha \tau 1 \sigma \mu o ́ \varsigma)$ auffassen, welche Ausdruck des griechischen Notariatswesens in Ägypten ist und auch durch andere Urkunden belegt wird ${ }^{118}$ ). Ein erster Einwand gegen die Identifikation des $\S 7$ mit der für Ägypten typischen Registrierung und Archivierung ergibt sich allerdings daraus, dass das Fehlen einer entsprechenden öffentlichen Formalisierung allein die Wirkungen gegenüber Dritten betraf („opposabilité“) $)^{119}$ ). Insofern wäre

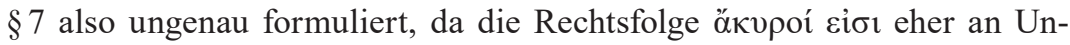
wirksamkeit als an Ausschluss einer Drittwirkung denken lässt. Auch verlangt $\S 7$ bei unvoreingenommener Betrachtung nicht die Errichtung einer „Staatsnotariatsurkunde“"120), sondern spricht schlicht davon, dass ein Testament „nach den öffentlichen Vorschriften“ zu errichten is $\left.{ }^{121}\right)$. In ihrer

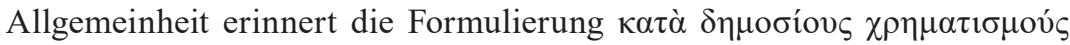
daher eher an die lateinische Formel secundum leges ${ }^{122}$ ) oder auch secundum legem publicam ${ }^{123}$ ), wie sie gerade auch für das römische Recht der Testamentserrichtung bezeugt ist.

${ }^{118}$ ) Die anderen Belege des Ausdrucks betreffen allerdings keine Testamente, sondern vorrangig Verkäufe von Grundstücken, vgl. P.Oxy. III,486 R; BGU I,50; P.Brem. 4; P.Mil. Vogl. 3; auch P.Tebt. II,335.

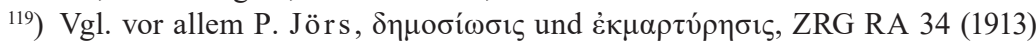
107-158, 152: „Öffentliche Urkunden haben die Vermutung der Echtheit und Unverfälschtheit für sich"; ähnlich L. Mitte is, Rez. zu A.B. Schwarz, Die öffentliche und private Urkunde im römischen Ägypten, Leipzig 1920, ZRG RA 41 (1920) 320-330, 329: ,So weit allerdings scheint die gräko-ägyptische Entwicklung nicht gelangt zu sein, daß die öffentliche Beurkundung als Voraussetzung der Gültigkeit irgendeines Rechtsgeschäfts in Frage gekommen wäre, vielmehr hat dieselbe den Rechtsgeschäften bloß eine stärkere Wirksamkeit gegeben, als es private Urkunden zu verschaffen fähig gewesen wären.“ Auf die Glaubwürdigkeit der Urkunde bezieht die Unterscheidung auch Wolff, Griechische Papyri II (Fn. 117) 144-166; die zwischen Mitteis und Wolff umstrittene Charakterisierung als „Wertpapier“ ist für die hier diskutierte Frage nicht von Relevanz.

${ }^{120}$ ) So F. Preisigke, Fachwörter des öffentlichen Verwaltungsdienstes Ägyptens in den griechischen Papyrusurkunden der ptolemäisch-römischen Zeit, 1915, s.v. $\chi \rho \eta \mu \alpha \tau \imath \sigma \mu o ́ \varsigma$ Ziff. 4; vgl. auch A.B. Schwarz, Die öffentliche und private Urkunde im römischen Ägypten, 1920, 14-29.

$\left.{ }^{121}\right)$ Vgl. H.G. Liddell/R. S cott/H.S. Jones, A Greek-English Lexicon, Ox-

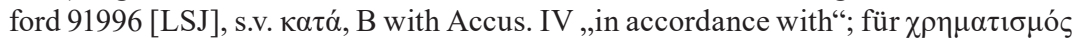
vgl. LSJ s.h.v. 2 ,decree or ordinance made by a sovereign or some public authority“.

${ }^{122}$ ) Der Plural ist allerdings selten und spät, vgl. C. 6,32,2 Valer./Gallien. (a. 256). Belegt ist allerdings auch die Verwendung für nichtrömische Gesetze, vgl. Gai. 1,92 (...) secundum leges moresque peregrinorum conceperit, (...); UE. 20,14 (...) ut secundum leges civitatis suae testetur.

$\left.{ }^{123}\right)$ Gai. 2,104; Gai. 3,174. 
Allerdings ist diese öffentlich-rechtliche Prägung des römischen Testaments in der romanistischen Literatur kaum beachtet worden ${ }^{124}$ ). Die Betonung des privaten, vor allem des privatschriftlichen Charakters des römischen Testaments geht dabei auf eine bereits bei Erman anzutreffende Idealisierung zurück, in der das „freie“, ,private“ Manzipationstestament römischer Prägung dem staatlich kontrollierten griechischen Testament entgegengestellt wird ${ }^{125}$ ). In dieser bis heute wirksamen Sichtweise sind die Vorgaben zur Testamentserrichtung primär Empfehlungen der Kautelarpraxis, welche erst sekundär auch gesetzliche Anerkennung finden $\left.{ }^{126}\right)$.

Betrachtet man die römischen Juristenschriften freilich ohne dieses Vorurteil, so ergibt sich, dass schon nach dem Elementarlehrbuch des Gaius die öffentlich-rechtliche Anbindung der römischen Testierfreiheit schlechterdings nicht bestritten werden kann. In der bekannten Schilderung des Manzipationstestaments ${ }^{127}$ ) wird die Funktion des familiae emptor wie folgt beschrieben: familiam pecuniamque tuam endo mandatela custodelaque mea esse aio, eaque, quo tu iure testamentum facere possis secundum legem publicam. Damit wird die Errichtung des Testaments explizit auf eine lex publica zurückgeführt. Eine entsprechende Vorstellung findet sich auch bei Pomponius:

124) Eine bemerkenswerte Ausnahme bildet G.G. Archi, Interesse privato ed interesse pubblico nell'apertura e pubblicazione del testamento romano, Iura 20 (1969) 337-430, der in vielen Details bereits die gesetzlichen Bindungen anerkannt.

125) Vgl. H. Erman, Zum antiken Urkundenwesen, ZRG RA 26 (1905) 456-478, 457: „Für Rom selbst dagegen ist hier hervorzuheben die späte und unvollkommene Ausbildung der ,amtsöffentlichen' Urkunde, man wirtschaftet so viel als möglich mit der testatio, also der ,Marktöffentlichkeit““; gleichsinnig Ka ser, RP II (Fn. 92) $\S 200 . I I I, 75 f . m . w . N$. Als öffentliche Testamente werden dann erst die spätantiken Fortentwicklungen bezeichnet, vgl. dazu F. Arcaria, Per la storia dei testamenti pubblici romani, in: Studi Nicosia I, Mailand 2007, 163-239.

$\left.{ }^{126}\right)$ Vgl. E. Ehrlich, Die Anfänge des testamentum per aes et libram, Zeitschrift für vergleichende Rechtswissenschaft 17 (1905) 99-109, der 103 wie folgt formuliert: „Die Entwickelung mag die römische Cautelarjurisprudenz vermittelt haben, deren Werk das römische testamentarische Erbrecht zum grössten Theil gewesen ist"; hierüber wisse man nichts, ,es mag jedoch gestattet sein, die Vermuthung auszusprechen, dass sie anfänglich nicht Rechtsregeln, sondern Formeln für die vorsichtige Abfassung von Testamenten gewesen sind"; vgl. Strobel (Fn. 117) 29.

${ }^{127}$ ) Gai. 2,104; dazu zuletzt F. Ter ra nova, Ricerche sul testamentum per aes et libram I, Turin 2011; zur Fortentwicklung M. Nowak, Mancipatio and its Life in Late-Roman Law, Journal of Juristic Papyrology [JJP] 41 (2011) 103-122. 
D. 50,16,120 Pomp. 5 ad Q. Muc. ${ }^{128}$ ): Verbis legis duodecim tabularum his ,uti legassit suae rei, ita ius esto" latissima potestas tributa videtur et heredis instituendi et legata et libertates dandi, tutelas quoque constituendi. sed id interpretatione coangustatum est vel legum vel auctoritate iura constituentium.

Im Kommentar zu Quintus Mucius erscheint die lex publica nicht in der Einzahl, sondern als vielschichtiges Konglomerat aus einer Bestimmung der XII-Tafeln, aus der Gesetzesinterpretation und sonstigem gesetzten Recht. Man kann die unterschiedliche Akzentuierung (lex bei Gaius; leges bei Pomponius) ungezwungen daraus erklären, dass sich die Manzipationsformel auf ein bestimmtes Gesetz bezieht ${ }^{129}$ ), während Pomponius eine von den XII-Tafeln ausgehende Entwicklung darzustellen sucht ${ }^{130}$ ). In jedem Fall zeigen diese Äußerungen das Bewusstsein der römischen Juristen für die gesetzlichen Bindungen des Erblassers bei der Testamentserrichtung ${ }^{131}$ ). Diese Beobachtung deckt sich damit, dass ein Manzipationstestament schon nach der knappen und unvollständigen Darstellung bei Gaius nur unter Einhaltung bestimmter Regeln Wirksamkeit entfaltet. Insbesondere muss der Erblasser (1) testierfähig $\operatorname{sein}^{132}$ ), (2) die Manzipation und Nunkupation ${ }^{133}$ ),

${ }^{128}$ ) Für eine Analyse des Textes vgl. zuletzt P. Arces, Studi sul disporre mortis causa, Mailand 2013, 78-90.

${ }^{129}$ ) Dies lässt sich aus der Übereinstimmung mit der solutio per aes et libram schließen, für die Gaius die Rechtsfolgen ebenfalls auf die lex publica zurückführt, vgl. Gai. 3,174. Zur dezemviralen Grundlage der testamentarischen Erbschaft vgl. F. Terranova, Riflessioni su D. 50,16,130 (Ulp. 2 ad leg. Iul. et Pap.), Annali del seminario giuridico dell'Università di Palermo [AUPA] 56 (2013) $159-179$, bes. $166 f$.

$\left.{ }^{130}\right)$ Vgl. D. Nörr, Pomponius oder zum Geschichtsverständnis eines römischen Juristen, aus: ANRW II.15, 1976, 497-604, jetzt in: T. J. Chiusi/H. - D. Spengler/ W. Kais er (Hgg.), Historiae iuris antiqui II, 2003 [HIA], 985-1092; weiterführend Mantovani, Legum multitudo (Fn. 39) 718-721. Üblicherweise wird der Text als Ausdruck der Entwicklung vom sog. LegatentHestament hin zum Erbeinsetzungstestament angesehen, vgl. M. Wurm, Apokeryxis, abdicatio und exheredatio, 1972, 70f. m. w. N.

$\left.{ }^{131}\right)$ Die Abhängigkeit von öffentlich-rechtlichen Vorgaben wird auch in der von Gaius skizzierte Entwicklung der Testamentsformen augenfällig: Nach einem Blick auf die evident öffentlich-rechtlichen Urformen des Testaments „,vor dem stehenden Heer“" (in procinctu) und ,vor der Volksversammlung“ (calatis comitiis) erörtert Gaius die für das Manzipationstestament (per aes et libram) geltenden Regeln; hierzu zuletzt Terranova, Riflessioni (Fn. 129) 309f.; Nachweise zur älteren Lit. bei E. Nis oli, Die Testamentseröffnung im römischen Recht, Diss. Bern 1949, 17-27.

${ }^{132}$ ) Vgl. Gai. 2,114. Dabei beschreibt Gaius insbesondere die besonderen Voraussetzungen für Testamente von Frauen, vgl. Gai. 2,111a/112.

133) Gai. 2,114-115. Auch Gai. 2,105-108 zum Status der Zeugen, des familiae 
(3) sowie eine Erbeinsetzung sollemni more ${ }^{134}$ ) stattgefunden haben; weiter müssen (4) der Haussohn und die postumi formgültig eingesetzt oder enterbt werden ${ }^{135}$ ). Zudem darf (5) das frühere Testament nicht durch ein späteres aufgehoben worden sein ${ }^{136}$ ). Auch wenn erkennbar wird, dass einige dieser Vorgaben eher aus der Gewohnheit (3) entstammten, ist doch sicher, dass die zentralen Vorgaben, vor allem zur Testierfähigkeit (1) $\left.{ }^{137}\right)$, zum Manzipationsritual (2) sowie zur Einsetzung von Hauskindern und postumi (4) ${ }^{138}$ ) durch leges publicae reglementiert wurden. Erst recht gilt dies für die bei Gaius nicht angesprochenen Vorgaben zur Schriftform und Urkundserrichtung, wie sie vor allem in der lex Cornelia $\left.{ }^{139}\right)$, der lex vicesima hereditatum $^{140}$ ) und dem SC Neronianum ${ }^{141}$ ) niedergelegt sind. Nach alldem kann

emptor, des libripens wie des Erben/Vermächtnisnehmers lassen allerdings weitere Vorgaben zur Durchführung des Rituals vermuten.

${ }^{134}$ ) Vgl. Gai. 2,116. und Gai. 2,118.

${ }^{135}$ ) Vgl. Gai. 2,123; für postumi, vgl. Gai. 2,130-134.

136) Vgl. Gai. 2,144. Zu beachten ist, dass Gaius in die hier nur skizzierte Darstellung der nach ius civile zu beachtenden Regeln immer wieder prätorische Anpassungen und Vorgaben einflicht; zudem fügt er exkursartig die für Legate und Fideikommisse geltenden Regeln an, was er aus der Sachnähe zu den Regeln der Testamentserrichtung rechtfertigt, vgl. Gai. 2,191 und Gai. 2,246 zum Fideikommissrecht.

${ }^{137}$ ) Vgl. D. 28,1,3 Pap. 14 quaest.; dazu C.F. v. Glück, Ausführliche Erläuterung der Pandecten nach Hellfeld, XXXIII,1, § 1403, Erlangen 1829, 341-347; H. Kr üger, Testamenti factio, ZRG RA 53 (1933) 505-508.

${ }^{138}$ ) Vgl. insbesondere die lex Iunia Velleia, vgl. P. Ste in, Lex Iunia Vellaea, in: M. Craw ford (Hg.), Roman Statutes II, London 1996, 811; zur Interpretation vgl. F. Lamberti, Studi sui ,postumi‘ nell esperienza giuridica romana II, Mailand 2001, 137-162.

${ }^{139}$ ) Vgl. zur lex Cornelia v.a. G.G. A rchi, Problemi in tema di falso nel diritto romano, aus: Pubblicazione dell'Università di Pavia n ${ }^{\circ}$ 91, 1941, jetzt in: ders ., Scritti III, Mailand 1981, 1487-1587; E.E. Kocher, Überlieferter und ursprünglicher Anwendungsbereich der „lex Cornelia de falsis“, Diss. München 1965, bes. 96-129 (mit Betrachtungen des SC Neronianum).

${ }^{140}$ ) Zur vicesima vgl. zuletzt bei S. Günther, Vectigalia nervos esse rei publicae, 2008, 40-94; zur Apertur vgl. Nisoli (Fn. 131); weiterführend Archi, Interesse (Fn. 124) 350-356 (zu D. 29,3,2 pr. Ulp. 50 ad ed.).

141) PS 5,25,6 Amplissimus ordo decrevit eas tabulas, quae publici vel privati contractus scripturam continent, adhibitis testibus ita signari, ut in summa marginis ad mediam partem perforatae triplici lino constringantur atque impositae supra linum cerae signa imprimantur, ut exteriori scripturae fidem interior servet. Aliter tabulae prolatae nihil momenti habent, dazu A. Macquéron, Le Sénatus-consulte Néronien et le caractère secret du testament romain, RHD 35 (1957) 459-476; weiterführend Archi, Interesse (Fn. 124) 379-383. Anders Erman (Fn. 125) 469, der 
von einer rein „privaten“ Form des römischen Testaments schlechterdings nicht gesprochen werden ${ }^{142}$ ), selbst wenn die Einzelheiten der genannten Regelungen aufgrund der justinianischen Tilgung der leges publicae nur schemenhaft erkennbar sind $\left.{ }^{143}\right)$. Allerdings zeigt sich die Anwendung und Bedeutung dieser Vorschriften auch in der dokumentarischen Praxis römischer Testamente aus Ägypten, welche sogar das umständliche und wahrscheinlich gar nicht immer durchgeführte Manzipationsritual ${ }^{144}$ ) skrupelhaft beurkunden, um dem Odium der Unwirksamkeit und damit dem möglichen Zugriff des Fiskus ${ }^{145}$ ) zu entgehen ${ }^{146}$ ).

2. Verbot der Umgehung der römischen Form durch Kodizille:

Aus dem Zusammenhang mit der römischen Testamentsform erklärt sich die unmittelbar anschließende Vorschrift:

BGU V,1210, 35-37

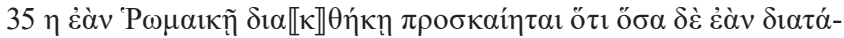

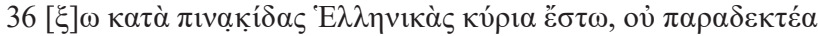

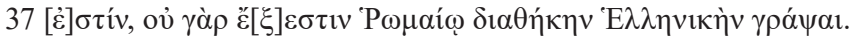

$\S$ 8: Wenn einem römischen Testament hinzugefügt wird: „Was ich auf Wachstafeln in griechischer Sprache hinterlasse, soll gelten", so darf es nicht angenommen werden, denn einem Römer ist es nicht erlaubt, ein griechisches Testament zu verfassen.

argumentiert, die Regelung habe nicht für Testamente gegolten. Ein Überblick zuletzt bei F. Marino, Il falso testamentario nel diritto romano, ZRG RA 105 (1988) 634-663.

${ }^{142}$ ) Anders Strobel (Fn. 117) 29. Fragen der „Privatheit“ der römischen Urkunde kommen nur ausnahmsweise (und illustrativ) im Zusammenhang mit dem fideicommissum tacitum vor, vgl. D. 30,103 Iul. 83 dig., wo von einer domestica cautio die Rede ist. $\mathrm{Zu}$ beachten sind auch die vielen gesetzlichen Regelungsversuche zu den Vermächtnissen, vgl. (im Zusammenhang mit der Testamentsform) S. Bolla, Zur Geschichte der römischen Vermächtsnisverfügungen, ZRG RA 68 (1951) 502-511, 509 f.

${ }^{143}$ ) Zur Negation des Einflusses der lex publica auf das römische Privatrecht vgl. Mantovani, Legum multitudo (Fn. 39) bes. 758-765 (zu Eugen Ehrlich).

${ }^{144}$ ) Vgl. M. A melotti, Il testamento romano attraverso la prassi documentale I, Mailand 1966, bes. 81-251.

${ }^{145}$ ) Zur fiskalischen Bedeutung der Testamentseröffnung vgl. bereits A r chi, Interesse (Fn. 124) 357-366.

${ }^{146}$ ) Irreführend Ric cobono, Gnomon (Fn. 1) 119f.: „Il nostro testo ci conferma così che erano non validi testamenti redatti in documenti privati“. Es geht nicht um den öffentlichen oder privaten Charakter des Dokuments, sondern um die Errichtung im Einklang mit ,öffentlich-rechtlichen' Vorgaben. 
Nach $\S 8$ werden Zusätze, die ein Römer auf Griechisch hinterlassen hat $\left.{ }^{147}\right)$, auch dann nicht als Teil des römischen Testaments angesehen, wenn dieses eine Kodizillarklausel enthält ${ }^{148}$ ). Zur Begründung wird darauf verwiesen, dass Römer kein griechisches Testament errichten könnten ${ }^{149}$ ). Die Regelung steht ersichtlich im Zusammenhang mit der Vorgabe, dass alle Rechtsinstitute des ius civile nur auf Lateinisch errichtet werden können ${ }^{150}$ ); allerdings gilt diese Regel gerade nicht für die Fideikommisse, welche auch von Römern auf Griechisch ausgesetzt werden können ${ }^{151}$ ). Wie schon die Begründung der Vorschrift zeigt, soll $\S 8$ damit weniger die Verwendung der griechischen Sprache durch Römer verhindern, als vielmehr die Einhaltung der römischen Testamentsförmlichkeiten garantieren. Auch die Digesten belegen, dass Kodizille, weil sie als Fideikommiss ohne jegliche Form Wirksamkeit entfalten können, zum Schutz der Testamentsform von den Testamenten abzugrenzen sind ${ }^{152}$ ). Diese Abgrenzung erfolgt typischerweise mit dem Argument, dass Kodizille nur Vermächtnisse und Fideikommisse, nicht aber Erbeinsetzungen als Herzstück des Testaments enthalten könnten ${ }^{153}$ ). Somit können zwar die im unwirksamen Testament ausgesetzten Legate als Fideikommisse auch dem Intestaterben auferlegt werden, die Erbeinsetzung selbst bleibt aber dem Testament vorbehalten ${ }^{154}$ ). Allerdings kann die Kautelarpraxis auch

${ }^{147}$ ) Zu eng Mélèze-Modrzejewski, Gnomon (Fn. 1) 528, der $\delta 1 \alpha \tau \alpha ́-[\xi] \omega$ mit „legs" wiedergibt; vgl. auch A.S. Hunt/ C.C. Edgar (Hgg.), Selected Papyri with an English translation II: Public Documents [Sel.Pap.], Cambridge (MA) 1934: „bequests“; wie hier: Lenel/Partsch (Fn. 1) 12: „cavero“.

${ }^{148}$ ) Zur Kodizillarklausel vgl. G. Negri, La clausola codicillare nel testamento inofficioso, Mailand 1974, 3-130; zuletzt auch Nowak, Wills (Fn. 117) 194-199.

${ }^{149}$ ) Zur testamenti factio in diesem Sinne vgl. Kr üger, Testamenti factio (Fn. 137) 505-508; gleichsinnig Ric c obono, Gnomon (Fn. 1) $120 \mathrm{f}$.

${ }^{150}$ ) Reinach, Code fiscal II (Fn. 1) 52-55; zur Sprachengesetzgebung für Testamente vgl. zuletzt Häusler (Fn. 60) 421-425.

$\left.{ }^{151}\right)$ Gai. 2,281 Item legata Graece scripta non valent; fideicommissa vero valent; dazu zuletzt Strobel (Fn. 117) 30f.

${ }^{152}$ ) Angedeutet (aber nicht weiter ausgeführt) bei Lenel/Partsch (Fn. 1) 12; zum ius singulare des Kodizillarrechts vgl. D. 29,7,2,2 Iul. 37 dig. Codicillorum ius singulare est, ut quaecumque in his scribentur perinde haberentur, ac si in testamento scripta essent. (...); weitere Nachweise bei Babusiaux, Erbrecht (Fn. 37) 179-183 und 339f.

$\left.{ }^{153}\right)$ Vgl. D. 29,7,10 Pap. 15 quaest. Quod per manus traditum est codicillis hereditatem dari non posse rationem illam habet, ne per codicillos, qui ex testamento valerent, ipsum testamentum, quod vires per institutionem heredum accipit, confirmari videretur.

${ }^{154}$ ) Unproblematisch ist dagegen der in der Literatur zum Gnomon - R i c c o b o no (Fn. 1) 121; Lenel/Partsch (Fn. 1) 12 - meist zum Vergleich zitierte Text D. 29,7,1 
diese Grenze aufweichen, indem die unwirksame Erbeinsetzung im Kodizill als Erbschaftsfideikommiss wiederholt wird, wie eine Entscheidung Julians zeigt:

D. 29,7,2,4 Iul. 37 dig.: Hereditas testamento inutiliter data non potest codicillis quasi hereditas confirmari, sed ex fideicommisso petitur salva ratione legis Falcidiae.

Der Jurist hält zunächst an der traditionellen Lehre fest, nach der das Kodizill keine Erbeinsetzung enthalten darf; allerdings erteilt er dem im Kodizill bestätigten Erben gleichzeitig die Klage aus einem Erbschaftsfideikommiss ${ }^{155}$ ). Letzteres unterscheidet sich nur noch dadurch von der Erbeinsetzung, dass der Fideikommissar gegenüber dem gesetzlichen Erben die falzidische Quart zu beachten hat, also nur Dreiviertel der Erbschaft erhält ${ }^{156}$ ).

Die hier skizzierte Situation erinnert an $\S 8$, da der Erblasser auch hier ein unwirksames Testament errichtet hat, dieses aber ausdrücklich als Kodizill gelten lassen will. Dass die in $\S 8$ verbotene Konstruktion - anders als das Kodizill in D. 29,7,2,4 Iul. 37 dig. - vollständig unwirksam ist, lässt sich daraus erklären, dass sie offensichtlich der Umgehung der römischen Testamentsform dient, da die letztwillige Verfügung als solche nicht im Testament, sondern im Kodizill enthalten ist ${ }^{157}$ ). Vor diesem Hintergrund erhellt auch, warum die in den Digesten enthaltenen Testamente mit griechischem Kodizill schon von dem unter Marc Aurel lebenden Juristen Scaevola offensichtlich viel großzügiger behandelt werden als in $\left.\S 8^{158}\right)$ : Es handelt sich hier nicht um Umgehungsversuche der Form, sondern um im Rahmen des

Ulp. 4 disp. Saepissime rescriptum et constitutum est eum, qui testamentum facere opinatus est nec voluit quasi codicillos id valere, videri nec codicillos fecisse: ideoque quod in illo testamento scriptum est, licet quasi in codicillis poterit valere, tamen non debetur; dazu A. Lovato, Studi sulle disputationes di Ulpiano, Bari 2003, 237 Fn. 87.

155) Vgl. auch Voci, DER II (Fn. 75) 331f. Ein weiterer zentraler Beleg ist D. 29,7,13,1 Pap. 19 quaest.; dazu C.A . Ma sch i, La solennità della heredis institutio nel diritto romano, Aegyptus 17 (1937) 197-232, $201 \mathrm{f}$.

${ }^{156}$ ) Zur Erstreckung der lex Falcidia (auf den Erbschaftsfideikommiss) auch bei Intestaterbschaft vgl. U. Manthe, Das senatus consultum Pegasianum, 1989, 45-47.

${ }^{157}$ ) Dies entspricht der Beobachtung aus der dokumentarischen Praxis, dass griechische Testamente in Kodizillarform errichtet werden, vgl. V. Arangio-Ruiz, La successione testamentaria secondo i papiri grecoegizii, Neapel 1906, 116f; B. Kübler, Griechische Tatbestände in den Werken der kasuistischen Literatur, ZRG RA 28 (1907) 174-210, bes. 196-199; zuletzt Nowak, Wills (Fn. 117) 196f.

${ }^{158}$ ) Zu Scaevola siehe Häusler (Fn. 60) 426-438 m.w.N. 
Fideikommissrechts zulässige griechischsprachige Ergänzungen und Zusätze durch den Erblasser ${ }^{159}$ ).

3. Verbot der fideikommissarischen Erbschaft zwischen Römern und Griechen:

Als nächstes sei die Regelung des $§ 18$ herausgegriffen, der sich einer vergleichbaren Strategie widmet $\left.{ }^{160}\right)$ :

\section{BGU V,1210, 56-58}

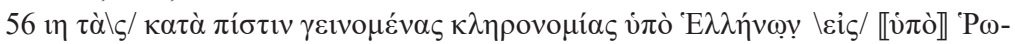

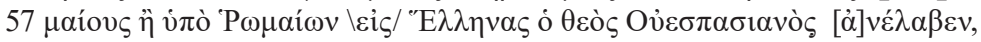

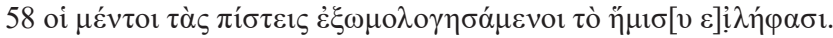

$\S 18$ : Die fideikommissarischen Erbschaften, die von Griechen an Römer oder von Römern an Griechen hinterlassen werden, hat der vergöttlichte Vespasian eingezogen; diejenigen jedoch, welche sich zu den Abreden bekannten, haben die Hälfte erhalten.

Nach diesem Abschnitt werden zwischen Römern und Griechen sowie Griechen und Römern ausgesetzte Universalfideikommisse eingezogen. Bei Selbstanzeige könnten die Begünstigten allerdings die Hälfte der zugedachten Erbschaft vom Fiskus herausverlangen ${ }^{161}$ ). In der Sache entspricht $§ 18$ dem Bericht in den Institutionen des Gaius, demzufolge Fideikommisse genutzt wurden, um letztwillige Verfügungen Peregrinen zuzuwenden, bis ein Senatsbeschluss unter Hadrian diese Praxis verbot ${ }^{162}$ ). Divergenzen zwischen den Institutionen und dem Gnomon bestehen allerdings mit Blick auf die Chronologie, da Gaius eine Maßnahme Kaiser Hadrians (117-138 n. Chr.) nennt, während der Gnomon bei Vespasian (69-79 n. Chr.) stehen geblieben zu sein scheint. In der Literatur ist hieraus teilweise geschlossen worden, dass der hadrianische Senatsbeschluss für Ägypten keine Geltung gehabt habe $\left.{ }^{163}\right)$.

Allerdings ist es nicht zwingend, dem Gnomon Unkenntnis der hadrianischen Anordnung zu unterstellen; vielmehr ist auf die unterschiedlichen Schwerpunkte der hadrianischen und der vespasianischen Regelung hinzu-

${ }^{159}$ ) Anders P.M. Meyer, Juristische Papyri, 1920, 319, nach dem schon ein einziger griechischer Satz zur Unwirksamkeit führen soll.

${ }^{160}$ ) Zur Auswahl der hier behandelten Stellen vgl. oben Fn. 36. § 17 steht ersichtlich im Zusammenhang mit Verfügungen zwischen patronus und libertus und soll hier daher außer Acht bleiben.

${ }^{161}$ ) So allgemein auch Mélèze-Modrzejewski, Gnomon (Fn. 1) 526: „ceux qui avouaient le fidécommis“.

${ }^{162}$ ) Gai. 2,285; dazu Johnston, Roman Law (Fn. 49) 19f.; zum Gnomon vgl. Lenel/Partsch (Fn. 1) 14f.; Riccobono, Gnomon (Fn. 1) 135.

${ }^{163)}$ So Uxkull-Gyllenband (Fn. 1) 33. 
weisen: Während $\S 18$ das Universalfideikommiss behandelt, das durch Vespasian im Rahmen des Senatusconsultum Pegasianum ${ }^{164}$ ) einer umfassenden Regelung zugeführt wurde, kommt der hadrianische Senatsbeschluss im Rahmen von Gaius' Vergleich zwischen Fideikommissen und Legaten zur Sprache und hat damit offenbar auch Einzelfideikommisse zum Gegenstand $\left.{ }^{165}\right)$. Soweit das Universalfideikommiss betroffen ist, liegt es daher durchaus nahe, die Regelung Vespasians als spezifische Einhegung einer Praxis anzuführen, die - anders als das Einzelfideikommiss - eine vollständige Umgehung der durch das Erfordernis der testamenti factio gezogenen Schranken erlauben würde ${ }^{160}$ ), zumal der Universalfideikommissar aufgrund des SC Pegasianum in eine erbenähnliche Position aufrückt $\left.{ }^{167}\right)$. Für diesen Erklärungsansatz lässt sich immerhin auch die im letzten Halbsatz von $§ 18$ angesprochene Möglichkeit der Selbstanzeige des Begünstigten nennen ${ }^{168}$ ). Derartige Denunziationen sind in den Digesten nur für tacita fideicommissa zugunsten von erwerbsunfähigen Personen bekannt ${ }^{169}$ ). Es ist allerdings gut vorstellbar, dass gleichfalls auch die in $\S 18$ behandelte Zuwendung an Personen, mit denen keine testamenti factio besteht, durch ein entsprechendes Anreizsystem aufgedeckt werden sollte, um Missbrauch zu unterbinden.

\section{Fazit:}

Die in $\S \S 7,8$ und 18 überlieferten Regeln zur Testamentserrichtung belegen den ergänzenden Charakter des Textes, der auch im Vorwort vom Verfasser selbst ausgesprochen wird. Während $§ 7$ als generelle Verweisnorm auf die bestehende Gesetzgebung fungiert, lassen sich $\S 8$ und $\S 18$ als besondere Ausprägungen von auch andernorts überlieferten Verbotsgesetzen ansehen. Ersichtlich zielen die in BGU V,1210 überlieferten Vorschriften auf die Regelung der Einziehungspraxis bei Verstößen gegen das römische Tes-

${ }^{164)}$ Einzelheiten v. a. bei Manthe (Fn. 156) 41-52.

${ }^{165}$ ) Einzelfideikommisse werden im Gnomon nicht gesondert behandelt.

${ }^{166}$ ) In den Digesten sind derartige Umgehungsversuche selten; einen singulären Beleg bildet D. 32,37,6 Scaev. 18 dig., dazu Häu sler (Fn. 60) 432f.

${ }^{167}$ ) Die Einsetzung eines Peregrinen wäre bereits von $\S 4$ erfasst, da diese unwirksam ist und der Erblasser somit keinen Erben hat.

${ }^{168}$ ) Lenel/Partsch (Fn. 1) 14f., meinen dagegen, $\tau \dot{\alpha} \varsigma \pi i ́ \sigma \tau \varepsilon 1 \varsigma \grave{\varepsilon} \xi \omega \mu о \lambda o \gamma \eta \sigma \alpha ́ \mu \varepsilon v o 1$ müsse sich auf den Belasteten beziehen. Hierfür besteht weder sprachlich noch sachlich Notwendigkeit, denn für die Beschwerten sind keine Prämien, sondern Strafen wie der Verlust der Quart vorgesehen, vgl. D. 35,2,59,1 Mod. 9 pandect.; zu Recht kritisch auch Uxkull-Gyllenband (Fn. 1) 34.

${ }^{169}$ ) Edictum Traianum, vgl. D. 49,14,13 pr.,1,7 Paul. 7 ad leg. Iul. et Pap. und D. 49,14,15,3 Maurician. 3 ad leg. Iul. et Pap., dazu bereits oben Fn. 82; zur Frage auch Riccobono, Gnomon (Fn. 1) 137. 
tamentsrecht, womit sich eine in der juristischen Überlieferung nahezu fehlende Perspektive eröffnet.

\section{Erbrechtliche Sanktionen der lex Iulia et Papia}

Eine besondere Bedeutung kommt dem Gnomon für die Rekonstruktion der augusteischen Ehegesetzgebung $\mathrm{zu}^{170}$ ), da die juristische Überlieferung große Lücken aufweist $\left.{ }^{171}\right)$. In der Tat haben schon die Vorgänger Justinians die lex Iulia et Papia in verschiedener Hinsicht eingeschränkt, Justinian hat sie gänzlich aufgehoben ${ }^{172}$ ). Um die Zuverlässigkeit der in $§ \S 24-32$ enthaltenen Informationen abzuschätzen, ist im Folgenden auch die Überlieferung in der Ulpiani Epitome in die Untersuchung einzubeziehen.

1. Die Einziehung der Mitgift von älteren Ehegatten, $\S \S 24-26$ :

Der erste Abschnitt des Komplexes betrifft die rechtlichen Konsequenzen der Ehe zwischen Personen, welche das von Augustus festgelegte Alter für die Heiratspflicht - der Mann ist über 60 Jahre, die Frau über 50 Jahre alt ${ }^{173}$ ) - überschritten haben:

\section{BGU V,1210, 73-78}

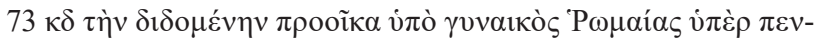

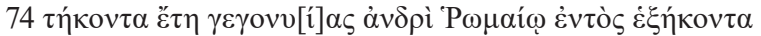

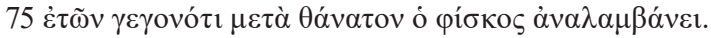

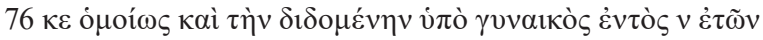

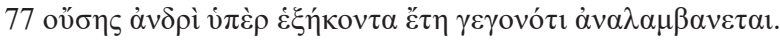

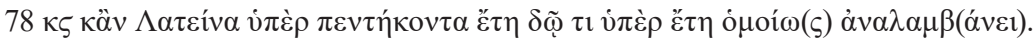

${ }^{170}$ ) Vgl. vor allem R. Besnier, L'application des lois caducaires d'Auguste d'après le Gnomon de l'idiologue, RIDA 2, Mélanges de Visscher 1 (1949) 93-118, 95-110.

${ }^{171}$ ) Die Spezialliteratur zur lex Iulia et Papia wird hier nur insoweit in den Blick genommen, als sie für die Interpretation der Regelungen des Gnomon von Bedeutung ist; Gesamtdarstellung bei J.E. Spruit, La lex Iulia et Papia Poppaea, Deventer 1969; L.F. Raditsa, Augustus' Legislation Concerning Marriage, Procreation, Love Affairs and Adultery, in: ANRW II.13, 1980, 278-339; R. Astolfi, La Lex Iulia et Papia, Padua 41996.

${ }^{172}$ ) C. 6,51,1 Iust. (a. 534); C. 5,4,27 Iust. (a. 531/2) Sancimus nuptias, quae inter masculos et feminas maiores vel minores sexagenariis vel quinquagenariis lege Iulia vel Papia prohibitae sunt, homines volentes contrahere et ex nullo modo vel ex nulla parte tales nuptias impediri; zu Reformen Konstantins und Theodosius, vgl. Astolfi, Iulia et Papia (Fn. 171) 43f.

${ }^{173}$ ) Zu den Wartefristen nach Eheauflösung vgl. D. Nörr, Planung in der Antike, Über die Ehegesetze des Augustus, aus: Festschrift Schelsky, 1977, 309-334, jetzt in: HIA (Fn. 130) 1093-1118, 1095f.; A s tolfi, Iulia et Papia (Fn. 171) 84f. 
§24: Die Mitgift, die von einer römischen Frau, die über 50 Jahre alt ist, einem römischen Mann, der unter 60 Jahre alt ist, gegeben wird, zieht nach dem Tod der Fiskus ein.

$\S 25:$ Desgleichen wird auch die eingezogen, die von einer Frau unter 50 Jahren einem Mann über 60 Jahren gegeben wird.

§26: Und wenn eine Latinerin über 50 Jahre einem über 60 Jahren Alten etwas gibt, so zieht er [der Fiskus] gleichermaßen ein.

Nach $§ \S 24-26$ wird die in einer solchen Ehe erteilte Mitgift vom Fiskus eingezogen, wobei $\S 25$ präzisiert, dass dies auch dann gilt, wenn die Frau noch im heiratsfähigen Alter ist und nur der Mann das Alter überschritten hat; nach $§ 26$ erfolgt die Einziehung der Mitgift auch im Fall der Ehe eines heiratsunfähigen Mannes mit einer unter 50-jährigen Latinerin. Elemente dieser Regelung finden sich auch in der Ulpiani Epitome:

UE 16,3: Qui intra sexagesimum vel quae intra quinquagesimum annum neutri legi paruerit, licet ipsis legibus post hanc aetatem liberatus esset, perpetuis tamen poenis tenebitur ex senatus consulto Persiciano. Sed Claudiano senatus consulto maior sexagenario si minorem quinquagenariam duxerit, perinde habebitur, ac si minor sexaginta annorum duxisset uxorem.

UE 16,4 Quod si maior quinquagenaria minori sexagenario nupserit, inpar matrimonium appellatur et senatus consulto Calvisiano iubetur non proficere ad capiendas hereditates et legata. Itaque mortua muliere dos caduca erit.

Anders als §§24-26 zitiert UE 16,3 allerdings drei Senatusconsulta, welche die erbrechtlichen Sanktionen der lex Iulia et Papia für Personen über dem Heiratsalter präzisieren: So bestimmt das um 34 n. Chr. ${ }^{174}$ ) ergangene SC Persicianum, dass das Erreichen der Altersgrenze nicht vom Eintritt der gesetzlichen Strafen befreie. Der Senatsbeschluss stellt damit klar, dass trotz Erlöschens der Ehepflicht die Strafsanktion für das frühere Verhalten erhalten bleibt. Eine Ausnahme soll nach dem in UE 16,3 genannten SC Claudianum für den über 60-jährigen Mann, der eine unter 50-Jährige heiratet, gelten, da er aufgrund dieser Ehe als ein unter 60-Jähriger behandelt wird. Heiratet dagegen umgekehrt eine über 50-jährige Frau einen unter 60-Jährigen, wird ihr die Strafe nach dem in UE 16,4 genannten SC Calvisianum nicht erlassen. Die Verbindung gilt als matrimonium inpar $\left.{ }^{175}\right)$, sodass die Ehegatten als unverheiratet und incapaces

174) Zur Datierung vgl. Radits a (Fn. 171) 324 ,under Tiberius“.

${ }^{175}$ ) Da auch nach antiker Vorstellung und medizinischem Wissen die Zeugung durch einen über 60-jährigen Mann möglich, die Empfängnis einer über 50-jährigen Frau hingegen nahezu ausgeschlossen war; entspricht die Schlechterstellung der Frau dem bevölkerungspolitischen Zweck der lex Iulia et Papia, wie er zum Beispiel in Dio. 56,1-10 thematisiert wird. Zu Zeugungstheorien in der hippokratischen Literatur vgl. S. Föllinger, Differenz und Gleichheit, Das Geschlechterverhältnis in der 
angesehen werden, so dass die in diese Ehe gegebene Mitgift als caducum verfällt ${ }^{176}$ ).

Immer wieder ist die Beweiskraft der $\S \S 24-26$ für das römische Recht in Frage gestellt worden, weil die differenzierenden Regelungen der $\mathrm{SCa}$ Claudianum und Calvisianum zu fehlen scheinen ${ }^{177}$ ). Demgegenüber ist zunächst darauf zu verweisen, dass $\S 24$ und UE 16,4 jedenfalls sachlich übereinstimmen, da beide Texte die im matrimonium impar (die Frau ist über 50 Jahre, der Mann unter 60 Jahre alt) gegebene Mitgift als verfallen ansehen, wenn die Frau verstirbt. Vor allem aber besteht bei näherem Hinsehen auch zwischen $\S 25$ und UE 16,3 kein Widerspruch: Vielmehr ist zu beachten, dass $\S 25$ allein die caducitas der Mitgift in einer Ehe zwischen einem über 60-jährigen Mann und einer unter 50-jährigen Frau betrifft ${ }^{178}$ ), während das in UE 16,3 genannte SC Claudianum lediglich die erbrechtliche incapacitas des über 60-Jährigen (teilweise) aufhebt, indem er als jüngerer Mann behandelt wird (perinde habebitur, ac si minor sexaginta annorum duxisset uxorem). Wie auch die Differenzierung der Strafsanktionen in UE 16,4 zeigt ${ }^{179}$ ), darf daraus noch nicht geschlossen werden, auch auf die Einziehung der Mitgift sei verzichtet worden ${ }^{180}$ ): Da UE 16,3 nur die incapacitas betrifft, während $\S 25$ die Kaduzität der Mitgift behandelt ${ }^{181}$ ), ist es unzulässig, beide

Sicht griechischer Philosophen des 4. bis 1. Jahrhunderts v. Chr., 1996, 34-42; zur Stoá vgl. ebd. 256-287.

${ }^{176}$ ) Zur Interpretation von UE 16,4 vgl. zuletzt Nachweise bei Avenarius (Fn. 79) 343f.

${ }^{177}$ ) Dies hat zu Spekulationen geführt, vgl. etwa Lenel/Partsch (Fn. 1) 20: „War in der Registratur des Idiologos das Senatusconsultum Claudianum gar nicht aufgezeichnet? Oder ist die Aufzeichnung bei der Abfassung unseres Auszugs übersehen und statt ihrer älteres ebenfalls aufgezeichnetes Recht wie es sich etwa nach dem caput a Tiberio additum gestaltet hätte, aufgenommen worden?“; Uxku11-Gyllenband (Fn. 1) 39f.: „Es bleibt nichts übrig als anzunehmen, dass sich die mildere Praxis des Claudianum nicht bewährt hat". Riccobono, Gnomon (Fn. 1) 151f. geht von einer verschärften Rechtslage in Ägypten aus; gleichsinnig Spruit (Fn. 171) 22, der von einem „meer genuanceerd regiem“ in Rom selbst spricht.

${ }^{178}$ ) So die gängige Interpretation, vgl. A s tolfi, Iulia et Papia (Fn. 171) 47: „Il § 24 corrisponde al contenuto del SC Calvisiano; il $\$ 25$ prova che il SC Claudiano non è conosciuto dal Gnomon.“

${ }^{179}$ ) UE 16,4 unterscheidet ausdrücklich zwischen der incapacitas zum Erwerb von Erbschaften und Legaten (,nach außen“) einerseits und der caducitas der Mitgift („nach innen“, zwischen den Ehegatten) andererseits.

${ }^{180}$ ) So aber Lenel/Partsch (Fn. 1) 19f.; zum matrimonium impar vgl. auch Astolfi, Iulia et Papia (Fn. 171) 43.

${ }^{181}$ ) Die incapacitas der Männer ist Gegenstand der Regelungen in $\S 27$ und $\S 32$. 
Quellen gegeneinander auszuspielen. Festzuhalten ist vielmehr nach beiden Werken, dass die verspätete Heirat keine taugliche Grundlage für den Erwerb der Mitgift bildet, und diese daher sowohl bei der Eheschließung eines über 60-jährigen Mannes als auch bei derjenigen einer über 50-jährigen Frau, dem Fiskus verfällt.

Keine Entsprechung in der Ulpiani Epitome hat die in $§ 26$ aufgenommene Klarstellung ${ }^{182}$ ), nach der auch die Latinerin, die als über 50-Jährige einen über 60-Jährigen heiratet, der Strafe der Ehegesetzgebung unterliegt ${ }^{183}$ ). Die Notwendigkeit zur Aufstellung einer derartigen Regelung folgt schon daraus, dass Latiner eherechtlich als peregrini angesehen werden ${ }^{184}$ ), während sich die lex Iulia et Papia an römische Bürger richtet ${ }^{185}$ ) und daher nicht automatisch auf Latiner Anwendung finden kann ${ }^{18}$ ). Dass nur die Ehe der Latinerin mit einem Römer und nicht umgekehrt einer Römerin mit einem Latiner behandelt wird, erklärt sich daraus, dass gemischte Ehen auch sonst generell nach dem für den Mann geltenden Recht beurteilt werden ${ }^{187}$ ). Zudem ist auch die lex Iulia et Papia vorrangig an römische Männer gerichtet $\left.{ }^{188}\right)$,

${ }^{182}$ ) Die Frage ist allerdings, inwieweit diese Vorschrift praktische Relevanz hatte: D. Kremer, Ius Latinum, Le concept de droit latin sous la république et l'empire, Paris 2006, spart Ägypten vollständig aus. Umgekehrt erwähnt A. Jörden s, Status and citizenship, in: Riggs (Fn. 116) 247-259, kein ius latinum. Fernliegend ist die Annahme, dass es sich um eine latina Iuniana handele, so aber Seidl (Fn. 4) 133.

183) Lenel/Partsch (Fn. 1) 20 erwägen, dass es sich um eine Schlechterstellung der Latinerin handele.

${ }^{184}$ ) Sie benötigen das conubium, vgl. Gai. 1,67-79. Zum Gesetzeskonflikt bei conubium und conubia vgl. Kremer (Fn. 182) bes. 29f. m.w. N.

${ }^{185}$ ) Dies folgt schon aus dem Bezug der lex Iulia et Papia auf die ordines und ergibt sich auch aus den Details der Regelung, die unterschiedliche Gesellschaftsschichten unterscheidet; ein Überblick bei A. Mette-Dittmann, Die Ehegesetze des Augustus, Eine Untersuchung im Rahmen der Gesellschaftspolitik des Princeps, 1991, 131-146 m.w. N. Zur generellen Beschränkung der lex auf cives Romani (und dem Ausschluss der Latiner) vgl. M. W lassak, Der Ausschluß der Latiner von der römischen Legisactio, ZRG RA 28 (1907) 114-129. Zu der dort hervorgehobenen Unterscheidung von Latinern und latini Iuniani vgl. zuletzt M. Humbert, Le status civitatis, Identité et identification du civis Romanus, in: A. Corbino/ M. Humbert/G. Negri (Hgg.), Homo, caput, persona, La costruzione giuridica dell'identità nell'esperienza romana, Pavia 2010, 139-173, bes. 156-172.

${ }^{186}$ ) Zur Anknüpfung an die republikanische Tradition bei Augustus (gerade in der Ehegesetzgebung) vgl. Mette-Dittmann (Fn. 185) 13f.; zur Gesellschaftspolitik hinsichtlich der ordines vgl. ebd. $26 \mathrm{f}$.

${ }^{187}$ ) Vgl. Kremer (Fn. 182) 30: „Ces mariages mixtes sont en pratique intégrés dans l'ordre juridique du mari.“"

${ }^{188}$ ) Zu den Belegen des SC Persicianum vgl. nur A. O’Brien Moore, Senatus- 
während die Frau als Ehefrau gedacht wird, die es dem Mann erlaubt, seiner gesetzlichen Verpflichtung zur Zeugung von Kindern nachzukommen ${ }^{189}$ ). Dabei ist - wie schon Cassius Dio dem Augustus in den Mund legt - auch die Wahl einer nichtrömischen Ehefrau eine Option, um dem gesetzlichen Gebot zu entsprechen ${ }^{190}$ ).

2. Einziehung der Erbschaft bei incapacitas, $\S \S 27-28$ :

Von der erbrechtlichen Erwerbsfähigkeit (capacitas) von Personen jenseits des Heiratsalters handelt der folgende Abschnitt:

\section{BGU V,1210, 79-83}

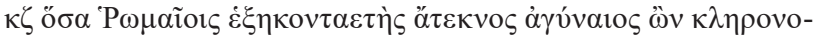

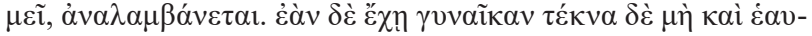
$\tau$

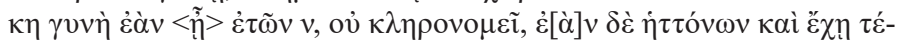

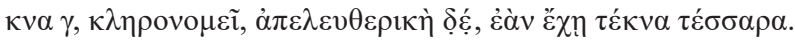

$\S 27$ : Was ein Römer im Alter von 60 Jahren, der weder Kind noch Frau hat, erbt, wird eingezogen. Wenn er aber eine Frau hat, jedoch keine Kinder, und wenn er sich selbst anzeigt, so wird ihm die Hälfte belassen.

$\S 28$ : Wenn eine Frau 50 Jahre alt ist, erbt sie nicht; wenn sie aber jünger ist und drei Kinder hat, erbt sie, eine Freigelassene aber, wenn sie vier Kinder hat.

Nach $\$ 27$ wird das dem über 60-jährigen Mann, der unverheiratet und kinderlos geblieben ist, Hinterlassene eingezogen. Ist er verheiratet, aber kinderlos kann er sich durch Selbstanzeige die Hälfte des Zugewandten erhalten. Für die Frau wird hingegen nicht unterschieden, ob sie ehe- oder kinderlos ist: Vielmehr bestimmt $\S 28$, dass sie der incapacitas nur entgeht, wenn sie als Freigeborene drei, als Freigelassene vier Kinder geboren hat ${ }^{191}$ ). Entsprechend des sonst bekannten Inhalts der lex Iulia et Papia ist für beide Vorschriften zu unterstellen ist, dass sie sich auf testamentarische Zuwendungen beziehen, weil nur der gewillkürte Erwerb von Todes wegen durch incapaci-

consultum, in: RE Suppl. VI, 1985, 800-812, 811. Zu beachten ist immerhin, dass die Bezeichnung SC Claudianum in zwei scheinbar unterschiedlichen Kontexten vorkommt, nämlich einerseits bei der Vermeidung der Folgen des Status als Unverheiratete, andererseits für die Rechtsfolgen der Ehe einer Bürgerin mit einem Sklaven.

${ }^{189}$ ) Zur Kontinuität dieser Betrachtungsweise bis zurück auf Plato vgl. Föllinger (Fn. 175) 107-114; bereits erkannt von Nör r, Planung (Fn. 173) 1104, der die fehlende Logik der Gesetzgebung gegenüber der Ehefrau hervorhebt.

$\left.{ }^{190}\right)$ Vgl. Dio. 56,5,5-6: In der Rede an die unverheirateten Römer erinnert Augustus an den Raub der Sabinerinnen, also an die Sitte, Frauen aus anderen Völkerschaften zu Ehefrauen zu nehmen, um dem Mangel an Nachkommen abzuhelfen.

${ }^{191}$ ) Einzelheiten zum ius liberorum bei B. Kübler, Über das Ius liberorum der Frauen und die Vormundschaft der Mutter, Ein Beitrag zur Geschichte der Rezeption des römischen Rechts in Ägypten, ZRG RA 30 (1909) 155-183. 
tas gehindert wird ${ }^{192}$ ). Ebenso ist zu unterstellen, dass die Altersgrenze von 50 Jahren in $\S 28$ nicht genannt wird, um die über 50-jährige Frau generell für erwerbsunfähig zu erklären, sondern um daran zu erinnern, dass die ehe- und kinderlos gebliebene Frau auch mit dem Ende des heiratspflichtigen Alters als incapax zu behandeln ist $\left.{ }^{193}\right)$.

Im Vergleich mit der sonstigen Überlieferung fallen zwei weitere Unterschiede ins Auge, die beide die Unterscheidung von kinderlosen Verheirateten (orbi) und Unverheirateten (caelibes) betreffen. So kennzeichnet Gaius als caelibes Personen, die durch die lex Iulia weder Erbschaften noch Legate erwerben können und stellt sie den orbi gegenüber, welche durch die lex Papia nur die Hälfte der Erbschaft oder des Legates verlieren würden ${ }^{194}$ ). $\$ 27$ lässt dagegen die Rechtsfolge der orbitas erst auf Anzeige des Mannes eintreten, während $\S 28$ zeigt, dass die Differenzierung zwischen orbitas und caelibatus für die incapacitas auch von heiratsfähigen Frauen (unter 50 Jahren) bedeutungslos ist ${ }^{195}$ ). In beiden Fällen verdient die größere Detailgenauigkeit des Gnomon Glauben: Hinsichtlich der Anzeigeobliegenheit in $\S 27$ ist darauf zu verweisen, dass das kaiserliche Fiskalrecht auch in anderen Zusammenhängen auf den Mechanismus der Selbstanzeige zurückgreiff ${ }^{196}$ ). Der Hauptanwendungsfall in den Digesten bildet das fideicommissum tacitum, bei dem einer erwerbsunfähigen Person durch geheime Absprache mit dem Erben etwas zugewendet werden soll ${ }^{197}$ ); zeigt sich der Begünstigte selbst an, kann er die Hälfte des Vor-

${ }^{192}$ ) Zum Anwendungsbereich der lex Iulia et Papia vgl. nur Mette-Dittmann (Fn. 185) 151-161.

193) Anders Lenel/Partsch (Fn. 1) 21, die meinen: „Die Behauptung, dass eine Fünfzigjährige nicht erben könne, ist eine Unmöglichkeit“", und daher von der besonderen Nachlässigkeit des Schreibers ausgehen; wie hier Astolfi, Iulia et Papia (Fn. 171), 47f.

$\left.{ }^{194}\right)$ Gai. 2,286 Caelibes quoque, qui per legem Iuliam hereditates legataque capere prohibentur, (...); 286a. Item orbi, qui per legem Papiam ob id, quod liberos non habent, dimidias partes hereditatum legatorumque perdunt, (...).

${ }^{195}$ ) Anders A stolfi, Iulia et Papia (Fn. 171) 358 Fn. 77, der $\$ 28$ nur auf die wechselseitige capacitas der Eheleute bezieht.

${ }^{196}$ ) Die Kritik an der lex Iulia et Papia in der nichtjuristischen Literatur entzündet sich gerade an der Denunziation und dem Delatorenunwesen, vgl. A. Giovannini, Pline et les délateurs de Domitien, in: O. Reverdin/B. Grange (Hgg.), Opposition et résistances à l'empire d'Auguste à Trajan, Genf 1987, 218-240 m. w. N. Auch das fragmentum de iure fisci kennt eine entsprechende Anzeigepflicht, vgl. fragmentum de iure fisci (ed. Krüger 1868) I, 1-4.

${ }^{197}$ ) Die beste Darstellung bei K.-P. Müller-Eis elt, Divus Pius constituit, 1982, 263-282; knapp Babusiaux, Erbrecht (Fn. 37) 290-292. 
teils erhalten ${ }^{198}$ ), während der Erbe die ihm zustehende Erbschaft oder die falzidische Quart an den Fiskus verliert ${ }^{199}$ ). Dass demgegenüber die Digesten Justinians keine Angaben zur Selbstanzeige des orbus enthalten, ist auf die Abschaffung der Kaduzitätsgesetzgebung durch Justinian zurückzuführen ${ }^{200}$ ); die unvollständige Auskunft durch die Institutiones des Gaius hingegen beruht auf seiner Stoffauswahl. So handelt die genannte Stelle allein von den Unterschieden zwischen Legaten und Fideikommissen und bezweckt keine umfassende Darstellung der lex Iulia et Papia oder auch nur der incapacitas ${ }^{201}$ ).

Auch die in $\S 28$ zum Ausdruck kommende fehlende Unterscheidung von caelibatus und orbitas bei Frauen passt zu dem sonst bekannten Inhalt der Gesetze $^{202}$ ) und lässt sich aus der bereits (V.1) erwähnten männlichen Perspektive des Gesetzgebers wie des Gesetzesadressaten erklären: Frauen sind nicht um ihrer selbst heirats- oder gebärpflichtig, sondern werden als Mittel für den Mann angesehen, seine gesetzliche Pflicht zu erfüllen ${ }^{203}$ ). Konsequenterweise werden die Frauen nur für die Geburt von (ehelichen) Kindern privilegiert ${ }^{204}$ ), nicht aber für die Eingehung der Ehe. Damit bietet der Gno-

$\left.{ }^{198}\right)$ Vgl. D. 49,14,13 pr. Paul. 7 ad leg. Iul. et Pap., pr. Edicto divi Traiani, quod proposui, significatur, ut, si quis, antequam causa eius ad aerarium deferatur, professus esset eam rem quam possideret capere sibi non licere, ex ea partem fisco inferret, partem ipse retineret. Zum Passus vgl. bereits oben Fn. 81. Für eine Interpolationsannahme, von der L. Mitteis, Römisches Privatrecht bis auf die Zeit Diokletians I, 1908, 353 n. 10; Voci, DER II (Fn. 75) 59 n. 3; G. Ürögdi, s.v. Fiscus, in: RE suppl. X, 1965, 227 ausgehen, gibt es keinen Anlass.

${ }^{199}$ ) Zum Wettlauf zwischen Erbe und Fideikommissar um die Anzeige vgl. D. 49,14,13,7 Paul. 7 ad leg. Iul. et Pap. Cum ante apertum testamentum tacitum fideicommissum nuntiatum esset ab his, qui fidem tacitam susceperunt, deinde post apertas a fideicommissario delatum esset, divus Antoninus recipi professionem eius iussit: neque enim dignam esse praemio tam praecipitem festinationem prioris, et cum quis se nuntiet non capere, potius confiteri de suo iure quam aliud deferre videtur; dazu Müller-Eis elt (Fn. 197) 276f. m. w. N.; weitere Nachteile in D. 22,1,17,2 Paul. 1. sing. de usur. und D. 35,2,59,1 Mod. 9 pandect.

$\left.{ }^{200}\right)$ Vgl. bereits Fn. 93.

${ }^{201}$ ) $\mathrm{Zu}$ den Lücken in Gaius vgl. Quadrato (Fn. 72); weitere Nachweise bei Babusiaux, Institutiones (Fn. 88).

202) Zutreffend Besnier (Fn. 170) 106f. „Le texte de Gaius ne parle que des hommes (orbi), rien ne permet de l'étendre aux femmes, aucun document ne fait la moindre allusion à une demi-incapacité des femmes orbae, ni aux droits des femmes qui n'auraient pas assez d'enfants pour obtenir le jus liberorum."

${ }^{203}$ ) Besonders eindrücklich ist diese Sichtweise in Dio. 56,3,1-8; Dio. 56,4,2; Dio. 56,5,4-7; Dio. 56,7,1-2; Dio. 56,8,3; Dio. 56,9,2.

${ }^{204}$ ) Zum ius liberorum vgl. Nörr, Planung (Fn. 173) 1110f. Aus diesem Grund ist 
mon nicht nur wichtige Details zur Gesetzgebung, sondern schärft auch den Blick für die in den Juristenschriften nicht reflektierte, aber offensichtliche Ungleichbehandlung von Mann und Frau.

3. Sanktionen der Ehelosigkeit für wohlhabende Römer (§ 29 und $\S 32$ ):

Abweichungen zwischen Männern und Frauen sind auch für die weiteren Sanktionen der Gesetzgebung zu beobachten, wie $§ 29$ im Vergleich mit $\S 32$ zeigt:

\section{BGU V 1210,84-86}

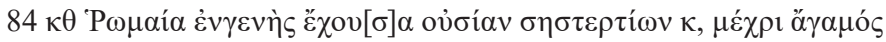

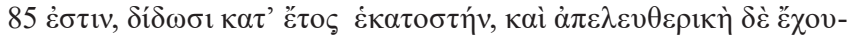

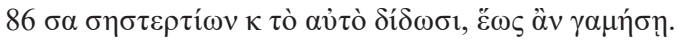

§29: Eine geborene Römerin, die ein Vermögen von 20'000 Sesterzen hat, zahlt, solange sie ehelos ist, jährlich 1/100 und eine Freigelassene, die ein Vermögen von 20 '000 Sesterzen hat, zahlt dasselbe, bis sie heiratet.

Nach $\S 29$ müssen unverheiratete Römerinnen - frei geborene wie freigelassene $^{205}$ ) -, die über ein Vermögen von 20'000 Sesterzen verfügen, 1/100 ihres Vermögens als Steuer zahlen, bis sie heiraten. Diese „Jungfrauensteuer“206) ist in anderen Quellen nicht belegt, als generelle Erscheinung aber durchaus glaubhaft, da sie den Druck zur Eheschließung erhöht und die auch in anderen Regelungen bekämpfte Ansammlung von Vermögen in den Händen von (unverheirateten) Frauen vorbeugt ${ }^{207}$ ). Beachtlich ist dabei, dass für die Vermeidung dieser Rechtsfolge die Eheschließung ausreicht; auch diese Anknüpfung ist aber nicht als Differenzierung zugunsten der Frau zu deuten, sondern lässt sich leicht daraus erklären, dass die Steuer andernfalls das für die Ehegatten zur Verfügung stehende Vermögen mindern würde, was dem Zweck der Mitgift widerspricht ${ }^{208}$ ).

auch das Argument von Mette-Dittmann (Fn. 185) 159f., die meint, die lex Iulia et Papia habe den Frauen durch das ius liberorum größere Freiheit gebracht, nicht valabel; wie hier Astolfi, Iulia et Papia (Fn. 171) $47 \mathrm{f}$.

${ }^{205}$ ) Lenel/Partsch (Fn. 1) 22 monieren die Gleichbehandlung beider Gruppen.

${ }^{206}$ ) Meyer (Fn. 159) 324 und Nörr, Planung (Fn. 173) 1094, die beide auch auf die Parallele in Val. Max. 2,9,1 verweisen; ferner A stolfi, Iulia et Papia (Fn. 171) $323 f$.

${ }^{207)}$ Anders Ux ku11-Gyllenband (Fn. 1) 41 der eine Spezialsteuer für Ägypten vermutet; wie hier bereits Astolfi, Iulia et Papia (Fn. 171) 82f.; vgl. auch Besnier (Fn. 170) 107f.

${ }^{208}$ ) Zur Versorgungsfunktion der Mitgift in der Ehe vgl. zuletzt J. F. St a g1, Favor dotis, Die Privilegierung der Mitgift im System des römischen Rechts, 2009, 22-25 m.w.N. 
Eine weitergehende Privilegierung der Männer offenbart:

\section{BGU V 1210,91-92}

$91 \lambda \beta$ P P

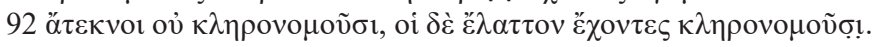

§32: Römer, die über 100’000 Sesterzen haben, ehelos und kinderlos sind, erben nicht; die weniger haben, erben.

Nach $\S 32$ sind unverheiratete und kinderlose Männer mit einem Vermögen über 100'000 Sesterzen nicht erwerbsfähig; nachdem mit § 27 eine Spezialvorschrift für die über 60-jährigen Männer besteht, kann sich § 32 nur auf die heiratspflichtigen Männer im Alter zwischen 25 und 60 Jahren beziehen. Für sie würde gegenüber der Schilderung bei Gaius, der von einer generellen incapacitas spricht, eine weitere Erleichterung gelten, da die Erwerbsunfähigkeit nicht allgemein, sondern nur bei größeren Vermögen einträte ${ }^{209}$ ). Auch diese Bestimmung ist als Detail der lex Iulia et Papia glaubhaft, da sie den aus der römischen Geschichtsschreibung bekannten Motiven des Augustus entspricht, gerade die besitzenden Stände zur Eheschließung und Kindererzeugung zu zwingen ${ }^{210}$ ).

4. Weitere Regeln der lex Iulia et Papia für Frauen, $\S \S 30-31$ :

Sonderregeln für die erbschaftlichen Zuwendungen an und von Frauen finden sich schließlich in $\S 30$ und $\S 31$ :

BGU V,1210, 87f.

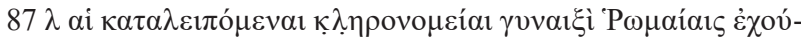

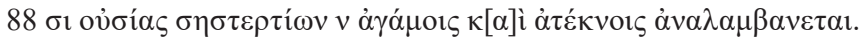

$\S 30$ : Die Erbschaften, welche römischen Frauen, die unverheiratet und kinderlos sind, von denen, welche ein Vermögen von 50’000 Sesterzen haben, hinterlassen werden, werden eingezogen.

$\S 30$ sieht die Einziehung von Erbschaften vor, welche unverheirateten und kinderlosen römischen Frauen von besonders wohlhabenden Erblassern (50’000 Sesterzen) hinterlassen worden sind. Üblicherweise wird diese Vorschrift - in Entsprechung zu $\S 32$ - als Regelung der incapacitas von besonders wohlhabenden kinderlosen und unverheirateten Frauen interpretiert $\left.{ }^{211}\right)$. Eine derartige Regelung wäre aber nicht nur ohne jegliches Vorbild;

${ }^{209}$ ) Für Männer wäre also 1. nach dem Vermögen und 2. nach dem Grad der Gesetzesuntreue (fehlende Verheiratung oder fehlende Kinderzeugung) zu unterscheiden.

${ }^{210}$ ) Gleichsinnig Riccobono, Gnomon (Fn. 1) 158; Astolfi, Iulia et Papia (Fn. 171) 82f.; Mette-Dittmann (Fn. 185) 177f.

211) Vgl. Lenel/Partsch (Fn. 1) 23, die von einer Milderung analog $§ 32$ sprechen; Reinach, Code fiscal II (Fn. 1) 69-71. 
sie ist auch sprachlich und sachlich nicht überzeugend: So spricht gegen die Auffassung, dass $§ 30$ die incapacitas betrifft, zunächst, dass die Vorschrift

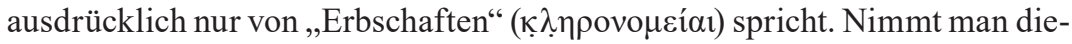
se Wortwahl ernst, so muss also die testamenti factio gemeint sein, die im Zusammenhang mit großen Vermögen und unverheirateten und kinderlosen Frauen eingeschränkt wird. Mit diesen Stichworten liegt sachlich ein Bezug zur lex Voconia nahe, nach der es Bürgern mit einem gewissen Vermögen nicht erlaubt war, Frauen zu Erben einzusetzen ${ }^{212}$ ).

Diese Hypothese stößt auf zwei Schwierigkeiten, die freilich beide überwunden werden können: Die erste Schwierigkeit betrifft die sprachliche $\mathrm{Zu}-$ ordnung der Vermögenssumme von 50’000 im Text der Vorschrift. Nach den

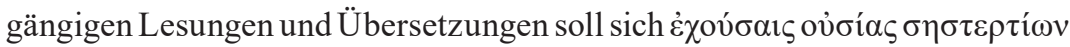
auf die eingesetzten Frauen beziehen ${ }^{213}$ ) und nicht auf den Erblasser. Allerdings ist es sprachlich ohne Weiteres möglich, die Partizipialkonstruktion

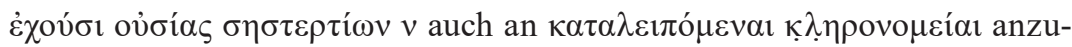
knüpfen. Voraussetzung ist allerdings, dass man die weithin akzeptierte Kor-

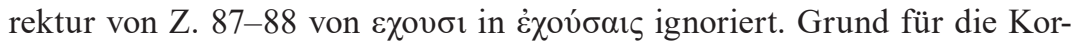

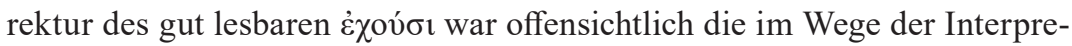
tation gewonnene Annahme, dass sich das Partizip auf die Frauen beziehen

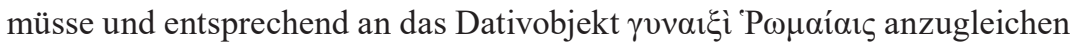

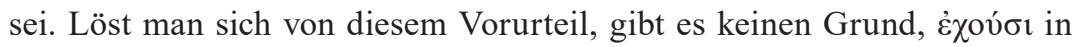

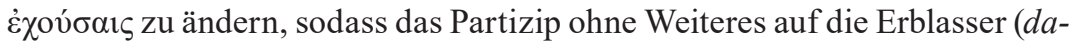
tivus auctoris) und nicht auf die Empfängerinnen zu beziehen ist.

Die zweite Schwierigkeit ergibt sich aus der Überlieferung der lex Voconia, die ursprünglich jegliche Einsetzung von Frauen ab einem bestimmten Vermögen des Erblassers untersagt haben soll ${ }^{214}$ ). Soweit $\S 30$ die Erbeinsetzung von Frauen durch besonders vermögende Erblasser nur verbietet, wenn die Empfängerinnen ehe- und kinderlos sind, ist daher von einer Modifikation des Gesetzes auszugehen. Dabei ist zu beachten, dass Cassius Dio berichtet, Augustus habe im Rahmen der Reform der lex Iulia durch die lex Papia

${ }^{212}$ ) Gai. 2,274, sonstige Belege bei A. Weishaupt, Die lex Voconia, 1999, 4f., 26f., $39 f$.

213) Vandoni (Fn. 1) S. 18 übersetzt: „Le eredità lasciate a donne romane nubili e senza figli, che possiedano 50'000 sesterzi, vengono confiscate"; Sel.Pap. (Fn. 147) 206: „Inheritances left to Roman women possessing 50,000 sestertii, if unmarried and childless, are confiscated.“

${ }^{214}$ ) Die ursprüngliche Fassung ist umstritten, vgl. Nachweise bei Weishaupt (Fn. 212) 39-71; ausführlicher J.A.J.M. van den Meer, Lex Voconia, Made for Men, Amsterdam 1996, 42-71. 
Poppaea den Frauen auch den Erwerb entgegen der lex Voconia erlaubt $\left.{ }^{215}\right)$. Zwar sind Einzelheiten nicht bekannt; da auch andere Reformen an das ius liberorum anknüpfen ${ }^{216}$ ), wäre aber durchaus zu erwägen, $§ 30$ als Ausdruck dieser Reform anzusehen, nach der nun nicht mehr jede Frau, sondern nur die unverheirateten und kinderlosen von der Erbenstellung ausgeschlossen gewesen wären. Mit dieser Annahme wäre $\S 30$ also kein Beleg für eine gemilderte incapacitas wohlhabender Frauen, sondern vielmehr der Überlieferung zur lex Voconia zuzuschlagen ${ }^{217}$ ).

Als Indiz für diese Annahme sei auf ein paralleles Problem bei der Deutung von UE 16,1a hingewiesen:

UE 16,1a: Libera inter eos testamenti factio est, si ius liberorum a principe inpetraverint (...)

Diese Stelle regelt die zivile testamenti factio zwischen Ehegatten und knüpft diese an das ius liberorum. Nachdem bereits UE 16,1 die volle capacitas der Ehegatten untereinander festhält, ist diese Rechtsfolge schwer verständlich und Schulz hat sie sogar als Fehler des Epitomators angesehen $\left.{ }^{218}\right)$. Geht man indes auch für UE 16,1a von einem Verweis auf die durch die lex Papia Poppaea modifizierte lex Voconia aus, ist es sachlich zutreffend, von der testamenti factio zu sprechen, da diese lex die „Erbeinsetzungsfähigkeit“ der Frau verhindert ${ }^{219}$ ). Mit diesen Überlegungen wären $\S 30$ und UE 16,1a in der Sache nicht verschieden; unterschiedlich wäre nur die von der Vorschrift

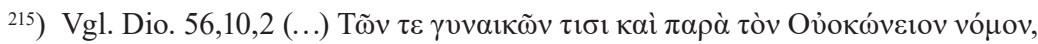

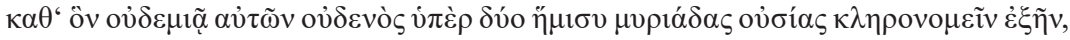

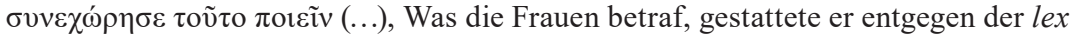
Voconia, wonach es keiner Frau erlaubt war, von jemandem Vermögen im Wert von mehr als 25'000 Drachmen zu erben, in einigen Fällen dies dennoch zu tun (...); dazu Weishaupt (Fn. 212) 29; zuletzt S. Hähnchen, Ratio Voconiana, Gedanken zur erbrechtlichen Benachteiligung von Frauen, in: J.D. Harke (Hg.), Facetten des römischen Erbrechts, 2012, 35-53, 43 m.w. N.

${ }^{216}$ ) Vgl. Mette-Dittmann (Fn. 185) 182f. Zu dieser Wirkung des ius liberorum vgl. Kübler, Ius liberorum (Fn. 191) bes. 164f.; ferner auch A. Steinwenter, Ius liberorum, in: RE X.2, 1919, 1281-1284, 1282.

${ }^{217}$ ) Dem entspricht, dass das ius liberorum allgemein als Anknüpfungspunkt der augusteischen Reform vermutet wird, vgl. Astolfi, Iulia et Papia (Fn. 171) 321f.; Mette-Dittmann (Fn. 185) 164.

${ }^{218}$ ) Vgl. Schulz (Fn. 38) 40 Fn. zu 1a: „Der Verf. wirft testamenti factio und capacitas durcheinander."

${ }^{219}$ ) Die Zuwendungen der Ehegatten untereinander hätten nach alldem zwei unterschiedliche Hürden zu überwinden: Zum einen müsste die Testierfreiheit, insbesondere zugunsten der Frau, bestehen (UE 16,1a); zum andern müssten beide Ehegatten nach Kaiserrecht erwerbsfähig sein (UE 16,1). 
gewählte Perspektive, da UE 16,1a die Befreiung der Ehegatten betont, während $\S 30$ aus Sicht des Fiskus die Folgen der fehlenden Privilegierung untersucht.

Auch $\S 31$ betrifft Zuwendungen zwischen Ehegatten:

\section{BGU V, 1210,89f.}

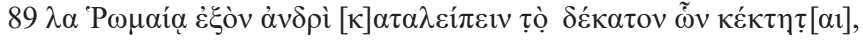

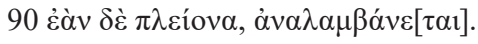

$\S 31$ : Einer Römerin ist es erlaubt, ihrem Mann den zehnten Teil dessen, was sie erworben hat, zu hinterlassen; ist es mehr, so wird es eingezogen.

Die Vorschrift bestimmt, dass die Frau dem Mann ein Zehntel zuwenden darf, wenn sie - wie zu unterstellen ist - keine Kinder haben. Aus UE 15,1 ist bekannt, dass eigene Kinder sowie Kinder aus früheren Ehen den Umfang der Zuwendungsmöglichkeiten zwischen den Ehegatten erhöhen ${ }^{220}$ ). Dass diese Privilegien im Gnomon nicht genannt werden, spricht nicht gegen den Beweiswert der Vorschrift für das römische Recht, sondern ist einerseits der Kürze, andererseits der fiskalischen Perspektive geschuldet, in der nur die wichtigsten Tatbestände Aufnahme finden ${ }^{221}$ ).

\section{Fazit:}

Nach alldem sind $\S \S 24-32$ mit Sicherheit als Ausdruck des Sanktionenregimes der lex Iulia et Papia anzusehen. Dabei ist auch festzuhalten, dass sich die Abweichungen zur sonstigen Überlieferung nicht aus lokalen Besonderheiten ergeben, sondern überwiegend der größeren Detailgenauigkeit des aus Anwenderperspektive verfassten Gnomon geschuldet sind.

Im Einzelnen ist festzuhalten, dass Mitgiften aus Ehen zwischen über 50-jährigen Frauen und über 60-jährigen Männern als caducum eingezogen wurden ( $\S 24-26)$, ohne dass diese Rechtsfolge durch das SC Claudianum gemildert wurde. Hinsichtlich der Rechtsfolge der incapacitas belegen §27-28 wichtige Unterschiede zwischen den Geschlechtern: Während für Männer zwischen Kinderlosigkeit (orbitas, Frist: 60 Jahre) und caelibatus unterschieden wird, wobei dem orbus durch Selbstanzeige immerhin die Hälfte des Hinterlassenen erhalten bleibt (\$27), können Frauen der incapacitas (bis zum 50. Lebensjahr) nur durch das ius liberorum entgehen. Zudem

$\left.{ }^{220}\right)$ UE 15,1 Vir et uxor inter se matrimonii nomine decimam capere possunt. quod si ex alio matrimonio liberos superstites habeant, praeter decimam, quam matrimonii nomine capiunt, totidem decimas pro numero liberorum accipiunt. Zur Interpretation vgl. zuletzt Avenarius (Fn. 79) 333; Einzelheiten zur Rechtslage bei Astolfi, Iulia et Papia (Fn. 171) 34-36.

${ }^{221}$ ) Erwogen werden kann auch, dass die Eheleute die in UE 15,2 genannten Ausnahmetatbestände aufgrund verstorbener Kinder selbst geltend machen mussten. 
werden wohlhabende unverheiratete Frauen (Vermögen: 20’000 Sesterzen) nach $§ 29$ mit einer „Jungfrauensteuer“ belegt, während sich Reichtum von Männern lediglich auf die Inkapazitätsfolgen auswirkt (§32). Das ius liberorum schließlich gilt nach der hier vertretenen Deutung des $\S 30$ auch für die Erbeinsetzungsfähigkeit von Frauen, die von wohlhabenden Männern nur dann wirksam eingesetzt werden können, wenn sie verheiratet sind und Kinder haben. Keine Neuerung bedeutet die Bestimmung, dass eine Frau ihrem Ehemann ein Zehntel hinterlassen kann, wenn sie keine Kinder haben (§31). Details zur Berücksichtigung verstorbener Kinder sind hier ausgespart.

Auch wenn somit der Gnomon niemals die Rechtsgrundlage der genannten Vorschriften nennt - was sich aber durchaus mit der in der Präambel genannten Ergänzungsfunktion des Textes in Einklang bringen lässt ${ }^{222}$ ) -, bildet er somit eine wichtige Informationsquelle für die Anwendungsfragen der von Justinian getilgten Ehegesetzgebung des Augustus.

\section{VI.Zur Testierfähigkeit der Römerin}

Besondere Schwierigkeiten hat die in $\S 33$ behandelte factio testamenti der Römerin bereitet; diese betreffen sowohl Z. 93 als auch die in Z. 93-95 getroffene Aussage zur Unwirksamkeit eines Legates:

BGU V,1210, 93-95

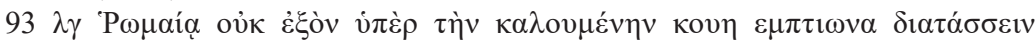
$\dot{\alpha} v \varepsilon \lambda \eta \dot{\eta} \mu \theta \eta \delta \dot{\varepsilon} \kappa \alpha \grave{~}$

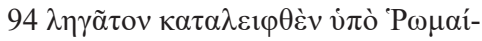

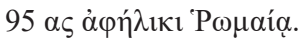

§33: Einer Römerin ist es nicht erlaubt, ohne die sogenannte coëmptio ein Testament zu errichten; es wurde aber auch ein Legat eingezogen, das von einer Römerin mit Wirkung für eine unmündige Römerin hinterlassen worden war.

Zunächst ist gegenüber überkritischen Bemerkungen in der Literatur zu Beginn des 20. Jhdts. ${ }^{223}$ ) darauf hinzuweisen, dass die griechische Verschreibung des lateinischen Wortes кovๆ $\varepsilon \mu \pi \tau 1 \omega v \alpha$ für quae emptionem noch kein Hinweis auf die fehlende Sachkunde des Schreibers darstellt224). Vielmehr

222) Vgl. oben I, bes. Fn. 4.

223) Vgl. Lenel/Partsch (Fn. 1) 23f.: „Dieser Passus zeigt wieder deutlich, mit wie wenig Sorgfalt und Sachkenntnis unser Auszug hergestellt ist. Der Übersetzer hat nämlich hier seine lateinische Vorlage offensichtlich nicht verstanden“; ihnen folgt noch Riccobono, Gnomon (Fn. 1) 162.

224) Vgl. B. Rochette, Le latin dans le monde grec, Brüssel 1997, 203-206 zum „bilinguisme imparfait“ griechischer Muttersprachler mit Blick auf das Lateinische. Zum Phänomen in Ägypten vgl. G. Nocchi Macedo/B. Rochette, Confusion de codes graphiques dans les papyrus latins, in: M. Capasso/M. De Nonno (Hgg.), 
legt die Forschung zur Zweisprachigkeit gerade im römischen Ägypten nahe, dass sich das Phänomen aus der „unvollständigen Bilingualität“ erklärt, bei welcher der Schreiber die andere Sprache (hier: Lateinisch) zwar versteht und spricht, ohne jedoch die Schriftsprache zu beherrschen, sodass er die fremdsprachigen Worte in der ihm vertrauten Schrift wiedergibt ${ }^{225}$ ). Ebenfalls zurückzuweisen sind die aus der Verwendung des Wortes í $\pi \dot{\varepsilon} \rho$ formulierten Bedenken; so bezeichnet vi $x \dot{\rho} \rho$ nicht nur eine zahlenmäßige Beschränkung ${ }^{226}$ ), welche im Zusammenhang mit der coëmptio nicht zielführend wäre, sondern kann auch im Sinne von Vorzeitigkeit verstanden werden ${ }^{227}$ ). Die zentrale erste Aussage des $\S 33$ lautet mithin, dass es einer Römerin nicht erlaubt ist, vor Durchführung bzw. ohne eine coëmptio ein Testament zu errichten.

1. Kein Testament ohne (vorherige) coëmptio:

Wenn damit allerdings generell von einer beschränkten Testierfähigkeit der Römerin ausgegangen wird, die vor Testamentserrichtung eine coëmptio durchzuführen habe, so scheint dies im Widerspruch zur Überlieferung bei Gaius zu stehen:

Gai. 1,115a: Olim etiam testamenti faciendi gratia fiduciaria fiebat coemptio: Tunc enim non aliter feminae testamenti faciendi ius habebant, exceptis quibusdam personis, quam si coemptionem fecissent remancipataeque et manumissae fuissent; sed hanc necessitatem coemptionis faciendae ex auctoritate divi Hadriani senatus remisit.

Gai. 2,112228): (...) ex auctoritate divi Hadriani senatus consultum factum est, quo permissum est sui iuris feminis etiam sine coemptione testamentum facere, si modo non minores essent annorum XII; scilicet ut quae tutela liberatae non essent, tutore auctore testari deberent.

Für den unter Antoninus Pius schreibenden Juristen bildet die Tatsache, dass Frauen ${ }^{229}$ ) die Testierfähigkeit nur durch die coëmptio fiduciaria er-

Studi paleografici e papirologici in ricordo di Paolo Radiciotti, Lecce 2015, 369-389, die 372 vor allem auf die rein mündliche Kenntnis einer zweiten Sprache verweisen: „Le bilinguisme n'entraîne pas nécessairement la maîtrise des deux alphabets.“

${ }^{225}$ ) So die Vermutung von J. Adams, Bilingualism and the Latin Language, Cambridge 2003, 599-623 speziell zur Situation in Ägypten; ein Überblick zuletzt bei T.E. Evans, Latin in Egypt, in: Rigg (Fn. 117) 517-525.

${ }^{226}$ ) Eine solche nimmt Uxkul1-Gyllenband (Fn. 1) 43 kaum glaubhaft an.

$\left.{ }^{227}\right)$ Lenel/Partsch (Fn. 1) 24 sehen dies als Fehlübersetzung von praeterquam an; zur Deutung im Sinne der Vorzeitigkeit vgl. LSJ (Fn. 121) s.v. vं $\pi \dot{\rho} \rho$ B with Accus. IV of time, ,,beyond, i.e. before, earlier than“.

$\left.{ }^{228}\right)$ Lesart nach David (Fn. 38) 49.

${ }^{229}$ ) Exceptis quibusdam personis bezieht sich auf die Vestalinnen, vgl. Gell. 
halten, eine rechtshistorische Reminiszenz (olim). Durch Hadrian nämlich sei die Bedingung der coëmptio für die Befreiung aus dem Hausverband aufgehoben worden ${ }^{230}$ ); erhalten bleibe - wie Gai. 2,112 zeigt - die grundsätzliche Notwendigkeit, einen Tutor bei der Testamentserrichtung hinzuzuziehen $^{231}$ ). Ohne Tutor könnten nur die von der Geschlechtsvormundschaft befreiten Frauen mit ius liberorum testieren ${ }^{232}$ ). Weiter verkompliziert wird diese Rechtslage dadurch, dass die coëmptio auch dazu dienen kann, Vormünder gegen einen tutor fiduciarius auszutauschen, wobei dieser gerade zu dem Zweck ernannt werden kann, ein Testament zu errichten ${ }^{233}$ ).

Auch unter Berücksichtigung dieser Verwerfungen innerhalb des ius civile besteht damit ein Widerspruch zwischen Gnomon und Gaius, insofern $\S 33$ die coëmptio zur Erlangung der Testierfähigkeit verlangt, während nach Gai. 1,115a und Gai. 1,112 seit Hadrian von diesem Erfordernis abgesehen wurde. Hieraus ist überwiegend geschlussfolgert worden, die Darstellung in $\S 33$ sei unzuverlässig oder veraltet $\left.{ }^{234}\right)$. Nachdem im Verlauf der bisherigen Untersuchung mehrfach zu beobachten war, dass die gaianische Darstellung aufgrund der didaktischen Schwerpunktsetzung verkürzt oder vereinfacht ist, während der Gnomon wichtige Details aus der Anwendungsperspektive anführt ${ }^{235}$ ), ist allerdings auch zu erwägen, dass sich der Widerspruch

1,12,9 Virgo autem vestalis simul est capta atque in atrium Vestae diducta et pontificibus tradita est, eo statim tempore sine emancipatione ac sine capitis minutione e patris potestate exit et ius testamenti faciundi adipiscitur, dazu zuletzt Y. González Roldán, Il diritto ereditario in età adrianea, Legislazione imperiale e senatus consulta, Bari 2014, 28f.

${ }^{230}$ ) Als ,nachgeformtes Rechtsgeschäft“ qualifizierte dies die klassische Darstellung bei E. Rabel, Nachgeformte Rechtsgeschäfte, ZRG RA 27 (1906) 290-335, 330 .

$\left.{ }^{231}\right)$ Vgl. Gai. 2,118 Observandum praeterea est, ut si mulier, quae in tutela est, faciat testamentum, tutore auctore facere debeat: alioquin inutiliter iure civili testabitur. $\mathrm{Zu}$ den beiden unterschiedlichen Reformen vgl. E. Volterra, Sulla capacità delle donne a far testamento, BIDR 48 (1941) 74-87; vgl. ferner die Nachweise bei L. Monaco, Hereditas e mulieres, Mailand 2000, 171-184.

${ }^{232}$ ) Vgl. auch González Roldán (Fn. 229) 29.

${ }^{233}$ ) Vgl. Gai. 1,115 Quod est tale: Si qua velit quos habet tutores deponere et alium nancisci, illis auctoribus coemptionem facit; deinde a coemptionatore remancipata ei, cui ipsa velit, et ab eo vindicta manumissa incipit eum habere tutorem, a quo manumissa est; qui tutor fiduciarius dicitur, sicut inferius apparebit. Zur coëmptio als Eheschließungsakt vgl. R. Köstler, Raub- und Kaufehe bei den Römern, ZRG RA 65 (1947) 43-68, bes. 47-49.

${ }^{234}$ ) Lenel/Partsch (Fn. 1) 24f.; anders Reinach, Code fiscal II (Fn. 1) 57-59, der die Aussage auf die uxor in manu bezieht.

${ }^{235}$ ) Vgl. II.3 zu $§ 2$; IV.2 zu $\S 8$, IV.3 zu $§ 18$ und vor allem V.3 zu $\S 27-28$. 
zwischen beiden Texten mit besserer Kenntnis der hadrianischen Reform auflösen ließe. Dies ergibt sich schon daraus, dass Gaius offenbar nur das Ergebnis - Befreiung von der coëmptio - berichtet, während $\S 33$ den Ausgangspunkt - Verlangen der coëmptio entsprechend dem ursprünglichem ius civile - hervorhebt. Nimmt man zum Beispiel an, dass die Befreiung von dem Erfordernis an ein Verfahren oder eine kaiserliche Anordnung geknüpft war, wären beide Schilderungen durchaus zu vereinbaren; ohne weitere Zeugnisse kann es derzeit aber nur bei einem non liquet bleiben.

\section{Zum Verständnis von Z. 93-95:}

Weitaus problematischer ist die Deutung der zweiten in $\S 33$ getroffenen

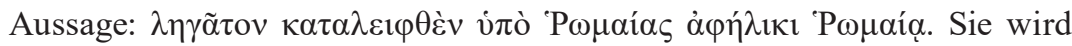
meist als Anordnung der Einziehung eines Legates verstanden, welches eine Römerin zugunsten einer unmündigen Römerin ausgesetzt habe ${ }^{236}$ ). Ausgehend von der Unmündigkeit der Person, die im Zusammenhang mit dem legatum zitiert wird, ist allerdings weniger an ein Legat zu ihren Gunsten als vielmehr an ein Pupillartestament, also ein Legat mit Wirkung für die Erbschaft der unmündigen Römerin zu denken. Der dativus commodi, mit dem ein Interesse oder Vorteil der Person angesprochen wird, könnte also auf den vergeblichen Versuch einer römischen Frau weisen ${ }^{237}$ ), ein Testament nicht nur für sich selbst, sondern auch für ihre unmündige Tochter zu errichten. Gerade die Tatsache, dass die Einziehung nicht die Erbschaft als solche, sondern nur das Legat betrifft, lässt sich für diese Deutung anführen: So ist zunächst daran zu erinnern, dass Frauen nach römischem Recht nicht im Wege der Pupillarsubstitution testieren können, da die Befugnis, ein Testament für einen Unmündigen zu errichten, moribus introductum nur den Hausvätern zusteht ${ }^{238}$ ). Erlaubt ist es den Frauen allerdings, für den Fall des Versterbens des unmündigen Kindes einen Ersatzerben vorzusehen. Ein Beispiel hierfür bildet:

${ }^{236}$ ) Ric cobono, Gnomon (Fn. 1) 162; zur Bedeutungsvariante $\alpha \dot{\varphi} \tilde{\eta} \lambda \jmath \xi$ „,unmündig“vgl. LSJ (Fn. 121) II. „minor, infant, in law“.

${ }^{237}$ ) Dass es sich um einen Präzedenzfall handelt, betont zu Recht Uxkul1Gyllenband (Fn. 1) 43.

${ }^{238}$ ) Vgl. die Voraussetzungen in D. 28,6,2 pr. Ulp. 6 ad Sab. Moribus introductum est, ut quis liberis impuberibus testamentum facere possit, donec masculi ad quattuordecim annos perveniant, feminae ad duodecim. Quod sic erit accipiendum, si sint in potestate: ceterum emancipatis non possumus. Postumis plane possumus. Nepotibus etiam possumus et deinceps, si qui non recasuri sunt in patris potestate (...); dazu zuletzt G. Finazzi, La sostituzione pupillare, Neapel 1997, 19-22 sowie $117-120$ m.w. N. 
D. $28,6,33$ pr. Afr. 2 quaest. ${ }^{239}$ ): Si mater ita testetur, ut filium impuberem, cum erit annorum quattuordecim, heredem instituat eique pupillaribus tabulis, si sibi heres non erit, alium substituat, valet substitutio.

In der Erörterung des Africanus hat die Mutter den Sohn als Erben unter der Bedingung eingesetzt, dass er bei ihrem Tod mündig sei; gleichzeitig hat sie in einem separaten, vom Juristen als „Pupillartestament“ bezeichneten Dokument, einen Ersatzerben für den Fall bestimmt, dass der Sohn vor Erreichen der Mündigkeit verstorben sei. Diese Substitution wird, obgleich sie in einem separaten Dokument vorgenommen wird, von Africanus als $s u b$ stitutio vulgaris und damit als wirksam behandelt. Diese Entscheidung lässt sich auch auch daraus rechtfertigen, dass die Ersatzerbenbestellung nur den eigenen Erben der Mutter betrifft, also trotz der Errichtung zweier separater Testamente gerade keine Erbfolge nach dem Kind vorliegt ${ }^{240}$ ). Dagegen wäre es als rechtlich unzulässig anzusehen, wenn die Mutter dem unmündig verstorbenen Kind einen Ersatzerben einsetzte.

Das Beispiel aus den Quaestiones des Africanus führt vor Augen, dass die Unterscheidung zwischen der substitutio vulgaris und der Pupillarsubstitution in der Praxis schwierig sein konnte ${ }^{241}$ ), woraus sich die Nachsicht der römischen Juristen erklärt, die spätestens seit Julian die Umdeutung der beiden Ersatzerbenbestellungen in die jeweils andere Form für zulässig erachteten $^{242}$ ). D. $28,6,33$ pr. Afr. 2 quaest. spricht dabei dafür, dass man die

${ }^{239}$ ) Zum Text vgl. zuletzt Finazzi (Fn. 238) 157 Fn. 41, der allerdings das Problem des Textes umgeht, indem er annimmt, dass die Formulierung pupillaribus tabulis nur auf die Ersatzerbenbestellung für den pupillus verweise.

${ }^{240}$ ) Sie findet sich auch in Testamenten von Frauen aus Ägypten; vgl. P.Köln II,100; P.Oxy. III,490, P.Oxy. III,492. Hier wird jeweils für den Fall des Versterbens der beerbten Kinder eine Substitution der Enkel angeordnet. H. J. Wolff, Die Pupillarsubstitution, Eine Untersuchung zur Geschichte des ,Heres'-Begriffs und der römischen Rechtswissenschaft, in: Studi Riccobono III, Palermo 1936, 436-470, 457f., weist allerdings zu recht daraufhin, dass die Einsetzung des unmündigen Kindes (durch die Mutter) unter der Bedingung des Erreichens der Volljährigkeit steht (auch zu D. 28,6,39 pr. Iav. 1 ex post. Lab.).

${ }^{241}$ ) Vgl. bereits J. Vážný, Note critiche ed esegetiche alla sostituzione pupillare, BIDR 47 (1940) 31-62, 36f. zu D. 28.6.46 Paul. 13 resp. Zur eigentlichen Pupillarsubstitution liefern die Juristenschriften meistens Beispiele, welche die Berechnung der lex Falcidia betreffen, vgl. etwa D. 28,6,41,6 Pap. 6 resp. Coheres impuberi $f$ ilio datus eidemque substitutus legata e secundis tabulis relicta perinde praestabit, ac si pure partem et sub condicione partem alteram accepisset (...); dazu Finazzi (Fn. 238) 285-290; ausführlich D. Schanbacher, Ratio legis Falcidiae, 1999, $148-154$.

${ }^{242}$ ) Autoritativ entschieden durch die divi fratres, vgl. D. 28,6,4 pr. Mod. 1. sing. 
günstige Auslegung nicht nur bei väterlichen, sondern auch bei mütterlichen Testamenten zur Anwendung brachte, indem man eine von einer Frau angeordnete und damit eigentlich unwirksame Pupillarsubstitution als Vulgarsubstitution auslegte und damit als wirksam erachtete. Mit dieser Hypothese ließe sich der in Z. 93-95 angesprochene Fall sinnvoll erklären: Man könnte annehmen, dass von der Mutter (vं ò 'P $\omega \mu \alpha i ́ \alpha \varsigma)$ versucht worden war, ein Pupillartestament für die unmündige Tochter ( $\left.\alpha \varphi \eta^{\prime} \lambda \iota \kappa \iota ~ P \omega \mu \alpha i ́ \alpha\right)$ zu errichten. Während die darin liegende Ersatzerbenbestellung nach D. 28,6,33 pr. Afr. 2 quaest. als Vulgarsubstitution aufrechterhalten werden konnte, waren die weiteren Anordnungen aus dem Pupillartestament unwirksam, da der Mutter insoweit die testamenti factio fehlte: Zwar kann auch einem gewöhnlichen Ersatzerben ein Legat für den Ersatzerbfall auferlegt werden ${ }^{243}$ ); als unzulässige Bedingung muss es aber angesehen werden, wenn die Mutter nicht für den eigenen Erbfall, sondern „für den Erben der Tochter“ oder „nach der Tochter" Vermächtnisse aussetzt, weil der Frau die Befugnis fehlt, für einen anderen zu testieren ${ }^{244}$ ). Weiter ist anzunehmen, dass der Fiskus entsprechend der auch sonst anzunehmenden Praxis der Einziehung von caduca (s. o. II.3) das „nach der Tochter“ ausgesetzte Legat beanspruchen konnte. Mit aller Vorsicht könnte man daher Z. 93-95 dahingehend deuten, dass hier die sachlich eingeschränkte testamenti factio der Frau thematisiert werden sollte. Mit dieser Annahme wäre jedenfalls eine grammatikalisch mögliche und sachlich sinnvolle Interpretation gefunden, die sich auch zur ersten Aussage des $\S 33$ gut fügen würde ${ }^{245}$ ): Die Vorschrift würde damit erstens aussagen, dass Römerinnen grundsätzlich nur testierfähig sind, wenn eine coëmptio stattgefunden hat und zweitens würde festgehalten dass die Testier-

de heurematic. Iam hoc iure utimur ex divi Marci et Veri constitutione, ut, cum pater impuberi filio in alterum casum substituisset, in utrumque casum substituisse intellegatur, sive filius heres non exstiterit sive exstiterit et impubes decesserit, dazu Mü1ler-Eis elt (Fn. 197) 39-42; weitere Literatur bei Schanbacher (Fn. 241) 63 Fn. 32 .

243) Beispiele für Legate nach dem Ersatzerben in D. 30,104,6 Iul. 1 ad Urs. Feroc.; D. 31,82,1 Paul. 10 quaest.; D. 36,2,7,3 Ulp. 20 ad Sab.

${ }^{244}$ ) Für die väterlichen Testamente war die Stellung des Substituten (als Vatersoder Pupillarerbe) bekanntlich äußerst umstritten, vgl. Vážný (Fn. 241) 41-51; ein Überblick über die Literatur bei Schanbacher (Fn. 241) 62-80.

${ }^{245}$ ) Auch für die Ersatzerbenbestellungen in Testamenten von Männern ist umstritten, ob sie eher dem Schema der Pupillarsubstitution oder substitutio vulgaris zuzuordnen sind, vgl. A rangio-Ruiz, Successione testamentaria (Fn. 157) 90-94; zuletzt M. Nowak, The Substitution of Heirs in Wills of Roman Egypt, Zeszyty Prawnicze 12.1 (2012) 173-179. 
freiheit für Frauen nicht die Befugnis umfasste, Testamente für ihre Kinder zu verfassen ${ }^{24}$ ), weshalb von der Mutter angeordnete Vermächtnisse aus der Erbschaft des Kindes zu konfiszieren seien.

\section{Fazit:}

Der schwer verständliche $\S 33$ lässt sich mit der Annahme, dass er grundsätzlich die Einschränkungen der Testierfähigkeit der römischen Frau betrifft, einer sinnvollen Deutung zuführen. Dabei ist hervorzuheben, dass die Vorschrift nur die Abweichungen zur griechischen Rechtslage benennt, also namentlich die Notwendigkeit, unter Beiziehung eines Tutors zu testieren, nicht erwähnt wird, weil insoweit Übereinstimmung zwischen griechischem und römischem Recht besteht.

\section{Das Erbrecht der Soldaten $(\S \S 34-35)$}

Auch die Kenntnis des Sonderrechts, das für Soldaten im Erbrecht gilt, wird durch den Gnomon um wichtige Einzelheiten bereichert. Dabei sind das sog. Soldatentestament (testamentum militis) und die Intestaterbfolge zu unterscheiden.

1. Soldatentestament $(\S 34)$ :

\section{BGU V,1210, 96-98}

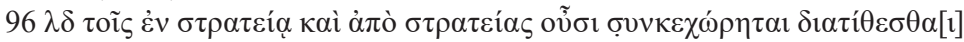

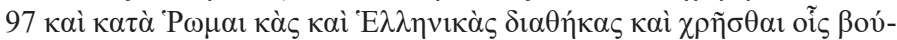

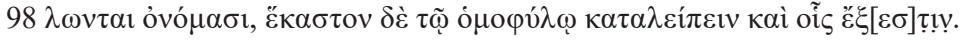

$\S 34$ : Denen, die im Heeresdienst sind, und denen, die außerhalb des Heeresdienstes sind, ist es zugestanden worden, sowohl in Gemäßheit der römischen wie der griechischen Testamente zu testieren und die Namen zu gebrauchen, die sie wollen, [und] dass ein jeder aber dem Stammesgenossen hinterlässt und denen, welchen es erlaubt ist.

$\S 34$ ordnet ein Testierprivileg zugunsten von Militärpersonen an, welche gegenüber den Formalitäten des römischen Testaments vereinfacht testieren können. Dieses Sonderrecht des Soldaten ist auch in der juristischen Überlieferung beleg $\mathrm{t}^{247}$ ). Unklar und umstritten sind allerdings die in $\S 34$ angeordneten Details, da diese nicht in allen Punkten mit der Darstellung des Privi-

${ }^{246}$ ) Zur materna potestas in Ägypten, die hierzu in einem Gegensatz steht, vgl. R. Taubenschlag, The Law of Greco-Roman Egypt in the Light of the Papyri, Warschau 21955, 149-155.

${ }^{247}$ ) Zu Einzelheiten vgl. die umfangreichen Nachweise bei B. Kübler, s.v. Testament (juristisch), in: RE 5.A, 1934, 966-1016, bes. 1000-1002; zuletzt zur Entwicklung A. Lovato, Testamentum militis, Sul ,consolidamento' giuridico di un privilegio, in: M. Chelotti et al. (Hgg.), Scritti Pani, Bari 2011, 257-266; J.F. Stag1, 
legs in den Juristenschriften übereinstimmen. Die Unklarheiten beginnen mit

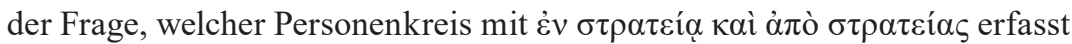
ist; sodann ist der Inhalt des Privilegs, insbesondere das Zugeständnis des

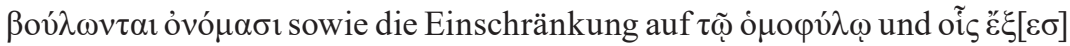
ז!̣y, zweifelhaft.

Hinsichtlich des Personenkreises scheint die Gegenüberstellung \&̇v $\sigma \tau \rho \alpha \tau \varepsilon i ́ \alpha$ und $\alpha$ đò $\sigma \tau \rho \alpha \tau \varepsilon i ́ \alpha \varsigma$ zunächst für eine Unterscheidung von Soldaten im aktiven Dienst und aus dem Dienst entlassenen Veteranen zu sprechen ${ }^{248}$ ). Mit dieser Annahme ergibt sich allerdings ein Widerspruch zu der in den Digesten ersichtlichen Rechtslage, nach der das Privileg des Soldatentestaments nur aktiven Soldaten bis zu einem Jahr nach ihrer ehrenwerten Entlassung gewährt wird ${ }^{249}$ ), während in $\S 34$ auch Veteranen einbezogen wären. Es hat verschiedene Versuche gegeben, den Widerspruch auf interpretativem Wege zu beseitigen. So ist vermutet worden, der Schreiber habe die Jahresfrist ausgelassen ${ }^{250}$ ) oder den Begriff veteranus falsch verstanden ${ }^{251}$ ). Da diese Konstruktionen wenig überzeugen, haben schon W. Schubart und S. v. Bolla $\sigma \tau \rho \alpha \tau \varepsilon i ́ \alpha$ nicht als Hinweis auf die Soldateneigenschaft, sondern unmittelbarer als Hinweis auf den Feldzuge25) oder Waffendienst ${ }^{253}$ ) angesehen. Für diese Deutung spricht zunächst, dass

Das testamentum militare in seiner Eigenschaft als ius singulare, Revista de estudios histórico-jurídicos 36 (2014) 129-157.

${ }^{248}$ ) So die gängige Deutung; vgl. Nachweise bei Riccobono, Gnomon (Fn. 1) 163; zuletzt J. Meyer-Herrmann, Testamentum militis, Das römische Recht des Soldatentestaments, 2012, 114-118, der ả $\pi$ ò $\sigma \tau \rho \alpha \tau \varepsilon i ́ \alpha \varsigma$ als Synonym für Veteran ansieht; offengelassen von Strobel (Fn. 117) 118f.

${ }^{249}$ ) Vgl. D. 29,1,38 Paul. 8 quaest. Quod dicitur, si miles intra annum quam missus est decesserit, valere eius testamentum quod iure militari fecerat, verum est, etiamsi post annum condicio institutionis exstiterit, mortuo eo intra annum. Et ideo si heredi filio substituerit, nihil interest, quando filius moriatur: sufficit enim patrem intra annum obisse; D. 29,1,26 Macer 2 milit. Testamenta eorum, qui ignominiae causa missi sunt, statim desinunt militari iure valere, quod anni spatium testamentis eorum, qui honestam vel causariam missionem meruerunt, tribuitur. Ius testandi de castrensi, quod filiis familias militantibus concessum est, ad eos, qui ignominiae causa missi sunt, non pertinet, quod hoc praemii loco merentibus tributum est.

${ }^{250}$ ) Vgl. J. Maquéron, Le testament d'Antonius Silvanus (Tablettes Keimer), RHD 23 (1945) 123-170, 145.

251) Meyer-Herrmann (Fn. 248) 132.

${ }^{252}$ ) Schubart (Fn. 1) 19: „denen, die auf dem Feldzuge sind und vom Feldzuge kommen".

$\left.{ }^{253}\right)$ S. B olla, Das römische Soldatenerbrecht in der Zeit der klassischen Juristen, in: dies. (Hg.), Aus römischem und bürgerlichem Erbrecht, 1950, 1-24. 


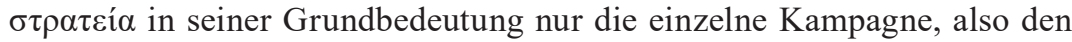
Feldzug, bezeichnet ${ }^{254}$ ); zudem leuchtet nicht recht ein, warum der Status des Veteranen, der in vielen Urkunden aus Ägypten mit dem Lehnwort

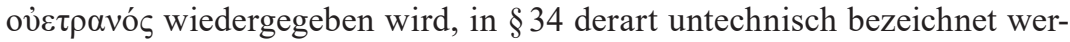
den sollte ${ }^{255}$ ). Aber auch die Annahme, der àjò $\sigma \tau \rho \alpha \tau \varepsilon i ́ a \varsigma$ sei ein (ehrenhaft) entlassener Soldat vor der Bestätigung des Veteranenstatus mittels $\dot{\varepsilon} \pi i ́ \kappa \rho ı\left(\varsigma^{256}\right.$ ), ist nicht zielführend, da der Gnomon selbst die missio (honesta) an anderen Stellen mit نं ò $\mu 1 \sigma \sigma ı \kappa i ́ \omega v$ und ähnlichen Ausdrücken wiedergibt $\left.{ }^{257}\right)$.

Da $\alpha$ đò $\sigma \tau \rho \alpha \tau \varepsilon i ́ a \varsigma$ weder den entlassenen noch den als Veteran anerkannten Soldaten bezeichnet, hat W. Schubart als Adressatenkreis des Privilegs die an der Kampfhandlung Beteiligten während und nach dem Feldzug angesehen; allerdings wirft auch dieser Vorschlag ein Problem der Frist auf, da unklar ist, wie lange der Feldzug zurückliegen darf, um das Privileg zu gebrauchen ${ }^{258}$ ). Zudem leuchtet nicht recht ein, warum die in Ägypten dauerhaft stationierten Truppen nur für einzelne Feldzüge privilegiert werden soll$\operatorname{ten}^{259}$ ). Abweichend hat S. v. Bolla daher vorgeschlagen, den Befund im Sinne

${ }^{254}$ ) Vgl. LSJ (Fn. 121) s.v. $\sigma \tau \rho \alpha \tau \varepsilon i ́ \alpha$ 1. „expedition, campaign“.

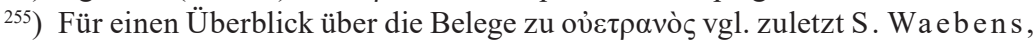
Reflecting on the ,Change in A.D. 140', The Veteran Categories of the EPIKRISIS Documents revisited, ZPE 180 (2012) 267-277; C. Sánchez-Moreno Ellart, Ipsis liberis posterisque eorum, Die Bedeutung der Geburtsurkunden von Soldaten der Auxiliareinheiten und der Wandel im Formular von diplomata militaría im Jahre 140 n. Chr. ausweislich RMD I 39 und RMD IV 266, ZRG RA 125 (2008) 348-374.

${ }^{256}$ ) In der Sache bereits Bolla, Soldatenerbrecht (Fn. 253) 17f., zur Unterscheidung vgl. J.C. Mann/M.M. Roxan, Discharge Certificates of the Roman Army, Britannia 19 (1988) 341-347; zur غ̇ंíkpıøıৎ vgl. zuletzt Wa eben s, ZPE 180 (Fn. 255) 267-277; zur Aufzeichnung und Dokumentation der Dienstzeiten vgl. Hartmut Wolff, Bemerkungen zum Verwaltungsgang und zur Verwaltungsdauer der Bürgerrechtsschenkungen an Auxiliare, ZPE 43 (1981) 403-425 m. w. N.

${ }^{257}$ ) So wird zur Kennzeichnung von Frauen, die entlassene Soldaten geheiratet haben, der Terminus vं

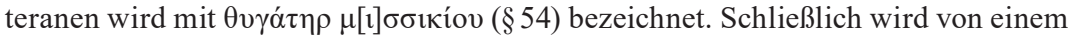
Ägypter, der unbemerkt in der Legion gedient hat, gesagt, dass er nach seiner Entlassung (§55) Ägypter bleibe und dass dies auch für die entlassenen Ruderer der Flotte gelte $(\S 55)$. $§ 56$ enthält sodann eine Strafbestimmung für diejenigen, die im Heer gedient haben, aber keine ehrenvolle Entlassung erhalten haben (oi $\sigma \tau \rho \alpha \tau \varepsilon v ̣$ ó $\varepsilon v o$ เ

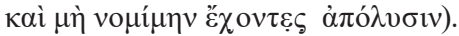

${ }^{258)}$ Lenel/Partsch (Fn. 1) 26.

${ }^{259}$ ) So schon Riccobono, Gnomon (Fn. 1) 163 Fn. 2; Einzelheiten bei P.A. Brunt, The Administration of Roman Egypt, JRS 65 (1975) 124-147, 131f.; R. Haensch, The Roman Army in Egypt, in: Riggs (Fn. 117) 68-82. 
von Inst. 2,11,3 aufzulösen ${ }^{260}$ ) und die von $§ 34$ erfassten beiden Gruppen als Soldaten von innerhalb und außerhalb des Lagers (in castris vs. extra castra) aufzufassen ${ }^{261}$ ). Zur zweiten Gruppe sollen beurlaubte oder sich aus anderen Gründen fern der Truppe aufhaltende Soldaten gehören ${ }^{262}$ ). Zwar findet sich auch in den Digesten ein Beleg, in dem das Soldatentestament ausdrücklich auch Soldaten zugestanden wird, die ihr Lager verlassen haben, um von einem Standort an einen anderen transferiert zu werden ${ }^{263}$ ); hierfür wird aber nicht der Begriff extra castra, sondern in numeris non esse verwendet ${ }^{264}$ ); zudem steht die Soldateneigenschaft der Betroffenen offensichtlich nicht in Zweifel (est enim miles), sodass die Gleichsetzung mit den ảंò $\sigma \tau \rho \alpha \tau \varepsilon i ́ \alpha \varsigma$ in $\S 34$ sprachlich nicht überzeugt.

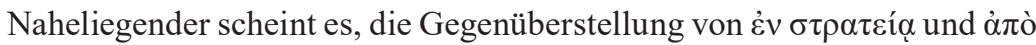
$\sigma \tau \rho \alpha \tau \varepsilon^{\prime} \alpha \varsigma$ als Abgrenzung zwischen den Kernaufgaben des Soldaten, also dem Waffendienst einerseits, und anderen für das Militär nützlichen Tätigkeiten andererseits, anzusehen ${ }^{265}$ ). Diese letzteren, nicht unmittelbar militärischen Aufgaben werden nicht von Soldaten im eigentlichen Sinne erfüllt,

${ }^{260}$ ) Inst. 2,11,3 Sed hactenus hoc illis a principalibus constitutionibus conceditur, quatenus militant et in castris degunt: post missionem vero veterani vel extra castra si faciant adhuc militantes testamentum, communi omnium civium Romanorum iure facere debent. et quod in castris fecerint testamentum non communi iure, sed quomodo voluerint, post missionem intra annum tantum valebit. quid igitur, si intra annum quidem decesserit, condicio autem heredi adscripta post annum extiterit? an quasi militis testamentum valeat? et placet, valere quasi militis; ferner auch C. 6,21,17 Iust. (a. 529).

${ }^{261)}$ Vgl. Bolla, Soldatenerbrecht (Fn. 253) bes. 16-18, die غ̇v $\sigma \tau \rho \alpha \tau \varepsilon i ́ \alpha$ mit „qui

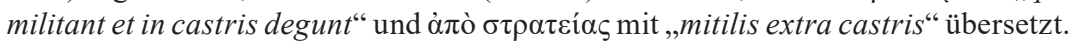

${ }^{262}$ ) Bolla ebenda 18, die durchaus erkennt, dass Personen, die sich eigenmächtig entfernt haben, sicherlich nicht auf das Privileg berufen konnten.

${ }^{263}$ ) Eine Ausnahme bildet D. 37,13,1,2 Ulp. 45 ad ed. Si quis militum ex alio numero translatus sit in alium, quamvis et hinc sit exemptus et illo nondum pervenerit, tamen poterit iure militari testari: est enim miles, quamvis in numeris non sit. Diese Parallele hat von Bolla nicht gesehen.

${ }^{264}$ ) Vgl. z.B. D. 29,1,17,1 Gai. 15 ad ed. prov. Iulianus etiam ait, si quis alium castrensium rerum, alium ceterarum scripsisset, quasi duorum hominum duas hereditates intellegi, ut etiam in aes alienum, quod in castris contractum esset, solus is teneatur, qui castrensium rerum heres institutus esset, extra castra contracto aere alieno is solus obligetur, qui ceterarum rerum heres scriptus esset. cui scilicet conveniens videtur respondisse, ut ex quaqua causa debeatur militi, vel huic heredi vel illi ipso iure debeatur. (...).

${ }^{265}$ ) Eine Übersicht über die Tätigkeiten bei Fr.Chr. Glück/Chr.Fr. Mühlenbruch, Ausführliche Erläuterung der Pandecten nach Hellfeld, Ein Commentar, XLII, Erlangen 1841, 53f. 
sondern von Zivilpersonen im Umfeld des Militärs, wobei zum Beispiel die Soldatenfrauen, aber auch Händler und Handwerker als ständige Begleiter des Heeres gehören ${ }^{266}$ ). Auch für diesen Personenkreis gilt nach den Juristenschriften ein Testierprivileg:

D. $37,13,1$ pr. Ulp. 45 ad ed. ${ }^{267}$ ): Non dubium est, quin debeant ratae voluntates esse eorum, qui in hosticolo suprema iudicia sua quoquo modo ordinassent ibidemque diem suum obissententiarum quamquam enim distet condicio militum ab his personis constitutiones principales separent, tamen qui in procinctu versantur cum eadem pericula experiantur, iura quoque eadem merito sibi vindicant. Omnes igitur omnino, qui eius sunt condicionis, ut iure militari testari non possint, si in hosticolo deprehendantur et illic decedant, quomodo velint et quomodo possint, testabuntur, sive praeses quis sit provinciae sive legatus sive quis alius, qui iure militari testari non potest.

Ulpian hält fest, dass nach verschiedenen Kaiserkonstitutionen auch die Testamente von Nichtsoldaten nach den Regeln des ius militare beurteilt werden könnten, wenn diese im Feindesland (hosticum) verstorben seien ${ }^{268}$ ). Begünstigt sind also - wie der zweite Satz (omnes ...) nochmals klarstellt auch Personen außerhalb des Waffendienstes (àmò $\sigma \tau \rho \alpha \tau \varepsilon i ́ \alpha \varsigma)$, wobei Ulpian zunächst den Provinzstatthalter und Legaten nennt, dann aber explizit jeden einschließt, der sich der besonderen Gefahrenlage im Feindesland ähnlich einem Soldaten ausgesetzt hat. Der Grund für diese über die Soldateneigenschaft hinausgehende Privilegierung dürfte darin liegen, dass die Armee für Versorgung und Unterhalt auf Zivilpersonen angewiesen war $\left.{ }^{269}\right)$. Die für das

$\left.{ }^{266}\right)$ Der Status der sog. lixae ist noch nicht vollständig aufgeklärt; dazu grundlegend R. Feig Vishnia, The Shadow Army: The Lixae and the Roman Legions, ZPE 139 (2002) 265-272, dort 268: ,We know that the lixae were unarmed and that they did not constitute part of the fighting personnel.“ In den juristischen Quellen erscheinen sie nur am Rande, vgl. Cth. 7,1,10: Valentinian/Valens (a. 367) Plerique milites secum homines condicionis ingenuae propinquitate simulata vel condicione lixarum frequenter abducunt: (...). G. Wesch-Klein, Soziale Aspekte des römischen Heerwesens in der Kaiserzeit, 1998, bezieht diese Stelle ausschließlich auf Sklaven, die im Heer dienen, was nicht überzeugt; anders (,free servants") A.H.M. Jones, The Later Roman Army II, 284-602, Baltimore 1964, 1270 Fn. 91 zum Text.

${ }^{267}$ ) Der Text ist wenig behandelt. Vgl. die knappe Bemerkung von J.F. Stag1, Das Soldatentestament unter den Soldatenkaisern, in: U. Babusiaux/A. Kolb (Hgg.), Das Recht der Soldatenkaiser, 2015, 109-126, 110 Fn. 3; eine Variante des Textes in D. 29,1,44 Ulp. 45 ad ed. Rescripta principum ostendunt omnes omnino, qui eius sunt gradus, ut iure militari testari non possint, si in hostico deprehendantur et illic decedant, quomodo velint et quomodo possint, testari, sive praeses sit provinciae sive quis alius, qui iure militari testari non potest.

${ }^{268}$ ) Einzelheiten bei Glück/Mühlenbruch (Fn. 265) 49f.

${ }^{269}$ ) Vgl. zu diesen Fragen v. a. C. Ad a m s, Supplying the Roman Army: O. Petrie 
Funktionieren des Militärs zentrale Funktion wird also honoriert, wenn sich die Gefahr realisiert. Dass $\S 34$ die in D. 37,13,1 pr. Ulp. 45 ad ed. zum Ausdruck kommenden besonderen Hürden für das Privileg nicht nennt, spricht nicht gegen die Identifizierung der àjò $\sigma \tau \rho \alpha \tau \varepsilon i ́ a \varsigma$ mit den das Heer begleitenden Nichtsoldaten ${ }^{270}$ ): Aus der für den Gnomon typischen Perspektive des Fiskus kann es ja ohnehin nur um die Wirksamkeit des Testaments nach dem Tod des Betroffenen gehen, das heißt wenn die besonderen Voraussetzungen für die Anwendung des ius militare vorliegen.

Mit dieser Grundannahme lassen sich auch die weiteren umstrittenen Fragen zu Inhalt und Umfang des in $§ 34$ erteilten Privilegs einer Lösung zu-

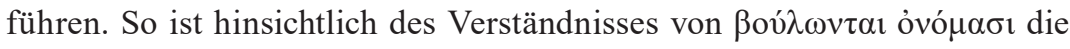
Meinung vorherrschend, der Begriff övo $\mu \alpha$ entspreche dem lateinischen verba (testamenti) ${ }^{271}$ ); man versteht also $\$ 34$ ganz im Sinne der bei Ulpian überlieferten Dienstanweisung: faciant igitur testamenta quo modo volent, faciant quo modo poterint (D. 29,1,1 pr. Ulp. 45 ad ed.) $)^{272}$ ). Gegen diese durch das lateinische Vorbild geleitete Interpretation ist allerdings daran zu erinnern, dass ővo $\mu \alpha$ vorrangig die Bedeutung von „Name“ hat $\left.{ }^{273}\right)$. Ohne ein entsprechendes Vorverständnis würde $\S 34$ also zunächst besagen, dass die Testatoren „die Namen brauchen, die sie wollen“. Diese Formulierung könnte auf die gerade für Ägypten gut belegte Praxis der doppelten Namensführung im Heer abzielen ${ }^{274}$ ): So ist bekannt, dass Rekruten der Auxiliartruppen, auch wenn der Eintritt in den Dienst gerade nicht mit der Bürgerrechtsverleihung verbunden war, regelmäßig einen römischen Namen annahmen ${ }^{275}$ ). Daher kann man annehmen, dass ihnen auch im Rechtsverkehr die Wahl zwischen

245, ZPE 109 (1995) 119-124; der s., Land Transport in Roman Egypt, Oxford 2007, 210-219, der die Bedeutung von zivilen Händlern betont.

${ }^{270}$ ) Die Idee der „Nichtkombattanten“ findet sich bereits bei Seidl (Fn. 4) $27 f$. allerdings ohne entsprechende Vertiefung.

271) Lenel/Partsch (Fn. 1) 26f.

${ }^{272}$ ) Vgl. auch Gai. 2,114 ... exceptis militibus, quibus propter nimiam imperitiam, ut diximus, quomodo velint vel quomodo possint permittitur testamentum facere.

$\left.{ }^{273}\right)$ LSJ (Fn. 121) s.v. ővo $\mu \alpha$ I.1 „name of a person or thing“.

${ }^{274}$ ) Allgemein zum Phänomen Y. Broux/S. Coussement, Double Names as Indicators of Social Stratification in Graeco-Roman Egypt, in: M. Depauw/ S. Coussement (Hgg.), Identifiers and Identification Methods in the Ancient World, Leuven 2014, 119-139 m.w. N. Im Zusammenhang mit dem Soldatentestament vgl. bereits die Überlegungen von D. Liebs, Das Testament des Antonius Silvanus, römischer Kavallerist in Alexandria bei Ägypten, aus dem Jahr 142 n. Chr., in: K. Märker (Hg.), Festschrift Fricke, 2000, 113-128, $118 \mathrm{f}$.

${ }^{275}$ ) Vgl. B. Saddington, The sorts of Names Used by Auxiliaries in the Early 
zwei Namen offenstand ${ }^{276}$ ). Kombiniert man diese Tatsache mit dem in $\S 34$ genannten Wahlrecht zwischen griechischem und römischem Testament ${ }^{277}$ ), lässt sich auf eine Korrelation zwischen Name und Rechtsform schließen: So ist vorstellbar, dass $\S 34$ den begünstigten Personen die Wahl eröffnete, entweder ihrer Herkunft entsprechend mittels griechischen Testaments und unter Verwendung ihres Ursprungsnamens zu testieren oder nach den Gepflogenheiten des römischen Testaments unter Verwendung des neuen lateinischen Namens ${ }^{278}$ ).

Für diese Deutung spricht auch, dass sie eine sinnvolle Erklärung des ebenfalls stark umstrittenen Begriffs der ó davon auszugehen, dass er nicht mit gens übersetzt werden kann ${ }^{279}$ ), da dann nicht plausibel wäre, warum $\S 35$ (zum Intestaterbrecht) das griechische Synonym $\gamma \varepsilon ́ v o \varsigma$ kennt, $\S 34$ aber ein anderes Wort verwendet. Unter Berücksichtigung dieser terminologischen Differenz kann die in literarischen Texten belegte Differenzierung von ó $\mu$ $\varphi v \lambda i ́ \alpha$ und $(\sigma v v) \gamma \varepsilon \dot{v \varepsilon ı \alpha}$ auch für $\S 34$ und $\S 35$ relevant sein: Während ( $\sigma v v) \gamma \varepsilon v \varepsilon 1 \alpha$ die familiäre, auf Abstammung gegründete Verwandtschaft („,family, kinship“) bezeichnet ${ }^{280}$ ), erfasst ó $\mu$ o $\varphi \nu i ́ \alpha$ eine kulturelle Nähebeziehung, die im Wesentlichen darauf beruht, dass die Parteien „being part of the same civic framework and speaking the same language “"281), was man in die Nähe der römischen civitas rücken $\mathrm{kann}^{282}$ ).

Principate, in: G. Alföldy et al. (Hgg.), Gedenkschrift Birley, 2000, 163-178, bes. 172; gleichsinnig Broux/Cous sement, Double Names (Fn. 274) 133.

${ }^{276}$ ) Dies tritt gerade in dem bei Broux/Coussement ebenda 131-133 geschilderten Archiv sehr klar hervor.

${ }^{277}$ ) Zu diesem vgl. zuletzt Strobel (Fn. 117) 77-79, der allerdings zu dem Schluss kommt, §34 gebe vollständige Formfreiheit.

${ }^{278)}$ Dazu stellt es keinen Widerspruch dar, wenn V. Arangio-Ruiz, L'origine del ,testamentum militis', BIDR 18 (1906) 5-44, 24-35, von einer Beeinflussung des Militärtestaments durch die ,freiere“ Form der griech. Diatheke ausgeht. Es sei erwähnt, dass sich auf diese Weise auch erklären ließe, warum die bekanntesten Soldatentestamente FIRA III,48 testamentum Antonii Silvani equites (142 n. Chr.) und BGU I,326 testamentum Gai Longini Castoris (194 n. Chr.) unter Wahrung der römischen Form verfasst wurden. Zu den bisherigen Deutungsversuchen, die meist auf die soziale Bedeutung der römischen Form rekurrieren, vgl. Strobel (Fn. 117) 65-109 und 110-150.

$\left.{ }^{279}\right)$ So aber Lenel/Partsch (Fn. 1) 26.

${ }^{280}$ ) F. Russ o, Kinship in Roman-Italian relationships: Diverse Traditions, Perspectives and Interpretations in Velleius Paterculus and Other Roman and Greek Historical Writers, Histos 6 (2012) 228-256, 229f.

${ }^{281)}$ Rus so ebenda 239.

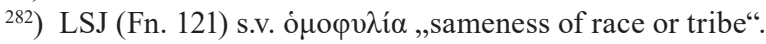


Wenn aber ó $\mu$ $\varphi \nu \lambda i ́ \alpha$ Voraussetzung für die Gültigkeit des entweder nach griechischer oder römischer Form errichteten Soldatentestaments ist, dann besagt der griechische Terminus, dass Testamentserbe und Legatar die gleiche civitas wie der Erblasser haben müssen. Dies aber ist nichts anderes als die bekannte Erfordernis der (beiderseitigen) testamenti factio ${ }^{283}$ ). Aus dieser Perspektive fügt sich die ó $о$ o $\nu \lambda i ́ \alpha$ zu der beobachteten vorsichtigen Flexibilisierung der Testamentsregeln, die nicht aufgehoben, sondern nur für das abweichende Regime des griechischen Testaments geöffnet werden ${ }^{284}$ ). $\mathrm{Zu}$ dieser Vorsicht fügt sich auch, dass nicht jede Person bedacht werden kann, sondern nur diejenigen, für die es gestattet ist (oĩ $\check{\varepsilon} \xi[\varepsilon \sigma]$ ț!y). Das in $\S 34$ niedergelegte Privileg soll also keineswegs die gesetzlichen Schranken der Testierfreiheit, wie sie sich auch aus den Juristenschriften ergeben, durchbrechen. Selbst wenn man den Eindruck gewinnen kann, dass letztere großzügiger sind und insbesondere offenbar orbi und caelibes als Erben und Legatare im Soldatentestament zulassen, gibt es auch nach der juristischen Überlieferung Personengruppen, vor allem Frauen, die auch im Soldatentestament nicht wirksam eingesetzt werden können ${ }^{285}$ ). Wie weit $\S 34$ derartige Verstöße gegen die lex Iulia et Papia zulässt, kann nicht entschieden werden; keinesfalls aber lässt sich aus der hier möglichen Abweichung zwischen Digesten und Gnomon ein Verdacht gegen die Authentizität der Vorschrift ableiten. Vielmehr wirft die genaue Regel des $\S 34$ umgekehrt die Frage auf, wieweit das in den Digesten überlieferte Privileg wirklich bedeutet, dass Soldaten ohne jegliche Form testieren konnten:

D. 29,1,1 pr. Ulp. 45 ad ed.: (...) Caput ex mandatis: „Cum in notitiam meam prolatum sit subinde testamenta a commilitonibus relicta proferri, quae possint in controversiam deduci, si ad diligentiam legum revocentur et observantiam: secutus animi mei integritudinem erga optimos fidelissimosque commilitones simpli-

$\left.{ }^{283}\right)$ Nicht im Widerspruch hierzu steht Gai. 2,110. Praeterea permissum est iis et peregrinos et Latinos instituere heredes vel iis legare; cum alioquin peregrini quidem ratione civili prohibeantur capere hereditatem legataque, Latini vero per legem Iuniam, da Gaius betont, dass die Peregrinen aufgrund des ius civile ausgeschlossen sind, was genau der Voraussetzung der testamenti factio entspricht.

${ }^{284}$ ) Die Verbindung unterschiedlicher Personen unterschiedlicher Herkunft und Sprache findet sich als Topos für das Heer des Hannibal bei Livius: Liv. 28,12,3-4 exercitu non suo civili sed mixto ex conluvione omnium gentium, quibus non lex, non mos, non lingua communis, alius habitus, alia vestis, alia arma, alii ritus, alia sacra, alii prope dii essent.

${ }^{285}$ ) Vgl. Gai. 2,111; Ausnahme: feminae famosae, probosae, stupro cognitae, vgl. D. 29,1,41,1 Tryph. 18 disp. und D. 34,9,14; C. 6,21,5, zu allen Kübler, Testament (Fn. 247) 1001. Verboten sind kaptatorische Verfügungen, vgl. D. 34,8,1 Iul. 78 dig., und Umgehungen der lex Iulia de fundi dotali, vgl. D. 29,1,16 Paul. 43 ad ed. 
citati eorum consulendum existimavi, ut quoquomodo testati fuissent, rata esset eorum voluntas. Faciant igitur testamenta quo modo volent, faciant quo modo poterint sufficiatque ad bonorum suorum divisionem faciendam nuda voluntas testatoris".

Nach einem historischen Rückblick zitiert Ulpian aus einem liber mandatorum die Anweisung eines Kaisers ${ }^{286}$ ), welche zunächst Anlass (Kenntnis von Testamenten, deren Wirksamkeit zweifelhaft ist) und Grund für das Tätigwerden des Kaisers (Schutz und Fürsorge für die unkundigen und unerfahrenen Kommilitonen) nennt, bevor dieser anordnet, dass Kommilitonen ihre Testamente so errichten können, wie sie wollten und könnten, und dass es für die Verteilung des Vermögens allein auf den Willen des Erblassers ankommt. Offensichtlich wird der hier untechnisch verfügte Verzicht auf Testiervoraussetzungen erst in den Juristenschriften und weiteren Konstitutionen genauer konturiert ${ }^{287}$ ). Dabei fällt auf, dass die meisten Fragmente mit Abweichungen vom römischen Manzipationstestament und dessen Förmlichkeiten befasst sind ${ }^{288}$ ); nur in seltenen Fällen wird ein Testamentsentwurf für wirksam gehalten, etwa wenn der Testator nach dem Diktat verstorben ist ${ }^{289}$ ). Mündliche Testamente kommen auch als Soldatentestamente nur ganz

${ }^{286}$ ) Die meisten Kommentatoren gehen von Traian aus, vgl. zuletzt L ov ato, Testamentum militis (Fn. 247) 258f.

${ }^{287}$ ) Wie hier Arangio-Ruiz, L'origine (Fn. 278) 12-15; anders Lovato, Testamentum militis (Fn. 247) 261-263, der gerade die untechnischen Worte als Teil der Kommentierung Ulpians ansieht.

${ }^{288}$ ) Dies zeigt ein Gang durch den Digestentitel: D. 29,1,4 Ulp. 1 ad Sab. betrifft das Testament eines Tauben und Stummen (der keine Manzipation vornehmen kann); D. 29,1,6 Ulp. 5 ad Sab. betrifft die institutio ex certa re und die Möglichkeit, dass ein Soldat pro parte testatus, pro parte intestatus versterben kann; D. 29,1,7-9 Ulp. 9 ad Sab. handeln von der fehlenden Enterbung eines postumus oder gleichgestellter Personen; D. 29,1,13 Ulp. 55 ad ed. erörtert Fälle der unwirksamen Erbeinsetzung (von Strafsklaven etc.); D. 29,1,15,1 Ulp. 55 ad ed. hält fest, dass die Aufhebung des Testaments durch nuda voluntas geschehen kann (also ebenfalls nicht die Form der Manzipation benötigt); D. 29,1,15,4 Ulp. 55 ad ed. und D. 29,1,41 pr. Tryph. 18 disp. halten die Erbeinsetzung auf Zeit für wirksam; D. 29,1,15,5 Ulp. 55 ad ed. auch die Erbeinsetzung des filius; ein zweites Testament hebt das erste nicht auf: D. 29,1,19 pr. Ulp. 4 disp.; Wirksamkeit eines Kodizills mit Erbeinsetzung: D. 29,1,36 pr. Pap. 6 resp.; ein Überblick über die einzelnen Ausnahmen zuletzt auch bei St a g1, Testamentum militare (Fn. 247) 131-142.

${ }^{289}$ ) Vgl. D. 29,1,35 Pap. 19 quaest. betrifft einen (schriftlichen) Testamentsentwurf; vgl. auch D. 29,1,40 pr. Paul. 11 resp., wo der Testator nach dem Diktat verstorben ist. Auch wenn man Gai. 2,109 unbefangen liest, sagt Gaius nicht, dass die Testamente komplett formfrei sind; er weist nur daraufhin, dass die diligens observatio des Rituals wie der Beiziehung von Zeugen nicht verlangt wird und dass auch 
ausnahmsweise ${ }^{290}$ ) vor und werden deshalb für wirksam gehalten, weil auch (römische) Zivilpersonen im Rahmen der Manzipation ein mündliches Testament errichten könnten ${ }^{291}$ ). Auch wenn also immer wieder betont wird, dass beim Soldatentestament nur die voluntas maßgeblich sei, ist damit nicht ein vollständiger Verzicht auf irgendeine Form gemeint, sondern vorrangig das Absehen von römischen Formalitäten zu verstehen ${ }^{292}$ ); genau diese indulgentia findet sich auch in $\S 34$, der diese Nachsicht für den lokalen Kontext als Wahlrecht zwischen römischer und griechischer Form konkretisiert.

2. Das Intestaterbrecht $(\S 35)$ :

Auch für die gesetzliche Erbfolge der Soldaten gelten besondere Regeln:

BGU V,1210, 99-100

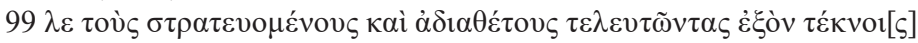

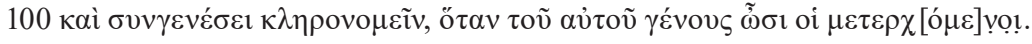

§35: Die, welche im Heere stehen und ohne Testament sterben, dürfen Kinder und Verwandte beerben, wenn die Beantragenden desselben Geschlechts (= verwandt) sind.

Das Intestaterbrecht nach einem Soldaten steht nach $\S 35$ den Kindern und Verwandten zu, die dem gleichen $\gamma \varepsilon ́ v o \varsigma$ wie der Erblasser angehören, womit nach dem soeben ausgeführten (VII.1) die Blutsverwandschaft (cognatio) gemeint sein muss $\left.{ }^{293}\right)$. Da $\S 35$ ausdrücklich von einem Antrag ausgeht (oi $\mu \varepsilon \tau \varepsilon \rho \chi[o ́ \mu \varepsilon]$ yọ ), wird hier offenbar nur die bonorum possessio, geregelt. Auch insoweit entspricht der Text daher der in BGU I 140 mitgeteilten epistula Hadriani ${ }^{294}$ ), mit der Hadrian den während der Dienst-

Peregrine eingesetzt werden können. Diese Beschreibung entspricht - bereinigt um die lokalen Besonderheiten - der in $§ 34$ erkennbaren Rechtslage.

${ }^{290}$ ) Kein Beispiel für ein fiktives Testament bildet D. 29,1,32 Mod. 9 reg., so aber Stag1, Testamentum militare (Fn. 247) 134.

${ }^{291}$ ) Vgl. D. 29,1,24 Florent. 10 inst. Divus Traianus Statilio Severo ita rescripsit: Id privilegium, quod militantibus datum est, ut quoquo modo facta ab his testamenta rata sint, sic intellegi debet, ut utique prius constare debeat testamentum factum esse, quod et sine scriptura et a non militantibus fieri potest. Si ergo miles, de cuius bonis apud te quaeritur, convocatis ad hoc hominibus, ut voluntatem suam testaretur, ita locutus est, ut declararet, quem vellet sibi esse heredem et cui libertatem tribuere: potest videri sine scripto hoc modo esse testatus et voluntas eius rata habenda est. (...).

${ }^{292}$ ) So bereits zutreffend D. Liebs, Zur Geschichte der Volksrechte im Römischen Reich, in: Studi Martini II, Mailand 2009, 449-472, bes. 470f., der die Anlehnung an nichtrömische Bräuche betont.

${ }^{293}$ ) Vgl. auch GENOS ( $\gamma \varepsilon \dot{v}$ o $\varsigma$ ), in: W. Smith/W. Wayte/G.E. Marindin (Hgg.), A Dictionary of Greek and Roman Antiquities, London 1890.

294) Vgl. BGU I,140; L. Mitteis/U. Wilcken, Grundzüge und Chrestomathie 
zeit geborenen Soldatenkindern die bonorum possessio unde cognati zuerkennt $\left.{ }^{295}\right)$. Gegenüber dieser epistula stellt der Gnomon nur insoweit eine Erweiterung dar, als nicht nur die Kinder, sondern auch die sonstigen Blutsverwandten antragsberechtigt sind ${ }^{296}$ ). $\S 35$ illustriert damit die auch in den Juristenschriften hervorgehobene Neuerung des prätorischen Rechts, welches erstmalig die kognatische Verwandtschaft als erbberechtigt anerkannte ${ }^{297}$ ), während das ius civile an der überkommenen agnatischen Verwandtschaftskonzeption festhielt. Während sich diese Neuerung nach den Juristenschriften auf die Erbberechtigung emanzipierter Kinder und von Frauen abstammenden Kindern beschränkt ${ }^{298}$ ), belegt $\S 35$, dass auch peregrine Verwandtschaftsverhältnisse den Schutz der bonorum possessio in Anspruch nehmen konnten, jedenfalls soweit es um Soldaten ging. Dass dies den Digesten nicht widerspricht, zeigt die ausführliche Diskussion der cognatio als ius naturale bei dem griechischstämmigen Juristen Modestinus ${ }^{299}$ ).

der Papyrusurkunde, II: Juristischer Teil, 2. Hälfte: Chrestomathie, Leipzig 1912 [M Chr] II 2 Nr. 373; dazu R. Taubenschlag, Die kaiserlichen Privilegien im Recht der Papyri, ZRG RA 70 (1953) 277-289; G. Schiemann, Zur Rechtsstellung der Soldatenkinder in vor-severischer Zeit, in: H.-P. Benöhr/K. Hackl/ R. Knütel/A. Wacke (Hgg.), Iuris professio. Festgabe für Max Kaser zum 80., Wien, Köln, Weimar 1986, 233-244; zuletzt S.E. Phang, Marriage of Roman Soldiers (13 BC-AD 235), Leiden 2001, bes. 38-40, 402f.; González Roldán (Fn. 229) 243-246.

${ }^{295}$ ) Nach Taubenschlag (Fn. 294) 285 gilt dies nur für Kinder, die in einer vor Dienstantritt geschlossenen Ehe (matrimonium iustum) gezeugt wurden. Im Wortlaut der Bestimmung ist dies nicht ersichtlich; vgl. auch Übersetzung in FIRA I, 428-430. Gleichsinnig aber Kreller (Fn. 103) 165f., der in der Tat festhält, dass nicht jede „geschlechtliche Verbindung“" ausgereicht haben dürfte; weniger apodiktisch $\mathrm{Ph}$ h $\mathrm{ng}$ (Fn. 294) 317-320.

${ }^{296}$ ) Damit ist freilich nicht gesagt, dass $\S 35$ von BGU I,140 abhänge, wie vor allem P.Oxy XLII 3014 gezeigt hat, vgl. Mélèze-Modrzejewski, Gnomon (Fn. 1) 522; weiterführend E. Volterra, Rez. zu The Oxyrhynchus Papyri, vol. XLII edited with Translations and Notes by P.J. Parsons, London 1974, Iura 26 (1975) 182-194, $187 f$.

${ }^{297}$ ) Knapper Überblick bei Babusiaux, Erbrecht (Fn. 37) 61-67.

${ }^{298}$ ) Vgl. Gai. 3,26-27; Gai. 3,29-30 sowie D. 38,8,1 Ulp. 46 ad ed.

${ }^{299}$ ) Vgl. D. 38,10,4,2 Mod. 12 pandect. Cognationis substantia bifariam apud Romanos intellegitur: nam quaedam cognationes iure civili, quaedam naturali conectuntur, nonnumquam utroque iure concurrente et naturali et civili copulatur cognatio. Et quidem naturalis cognatio per se sine civili cognatione intellegitur quae per feminas descendit, quae vulgo liberos peperit. civilis autem per se, quae etiam legitima dicitur, sine iure naturali cognatio consistit per adoptionem. (...). Zur Legitimation durch griechische Etymologien vgl. U. Babusiaux, Quod Graeci ... 
Der Gnomon enthält insoweit das Anschauungsmaterial, das die praktische Relevanz dieser Ausführungen vor Augen führt ${ }^{300}$ ).

\section{Fazit:}

Die in $\S 34$ und $\S 35$ enthaltenen Regelungen für das Soldatenerbrecht bieten erneut eine wertvolle Ergänzung der juristischen Überlieferung, indem sie Details des Testierprivilegs erkennen lassen und auch die Voraussetzungen der bonorum possessio ab intestato im Fall des Soldaten belegen. Vor allem aber schärfen sie den Blick für die harmonisierende Arbeit der Kompilatoren, welche die in D. 29,1,1 pr. Ulp. 45 ad ed. durchaus angesprochene Entwicklungsgeschichte des Privilegs kaum noch erkennen lässt.

\section{Ergebnisse und Ausblick}

Nach diesem Durchgang durch die erbrechtlichen Bestimmungen des BGU V,1210 ist der römischrechtliche Charakter der in diesen Abschnitten des Gnomon dokumentierten Regelungen ( $\S 1,2,4,7,8,18,24-35)$ nicht zu bezweifeln. Zur Bewertung dieses Ergebnisses sind zunächst die Resultate zu den einzelnen Themenkomplexen aufzuführen, bevor abschließend Implikationen für das römische Erbrecht in der justinianischen Überlieferung zu skizzieren sind.

1. Zusammenfassung der wesentlichen Ergebnisse:

Im Detail sind folgende Ergebnisse zu Einzelfragen des römischen Erbrechts festzuhalten:

(1) Die in $\S 2$ behandelten Veräußerungsverbote belegen den Nutzen von Fideikommissen bei der fiskalischen Beschlagnahme von Vermögen. Dabei tritt deutlich hervor, dass den Familienfideikommissen aufgrund des Verbotes, ad incertas personas zu verfügen, nur temporale Wirkung zukommt, was eine bedeutende Einschränkung gegenüber der lokalen Praxis dauerhafter Verfügungsverbote bedeutet. Die Funktion des Fideikommisses als Umgehungsinstrument gegenüber dem Fiskus wird besonders am Beispiel der Grabbauten und Grabumgebungen in $\S 1$ eindeutig belegt.

(2) Das in $\S 4$ ersichtliche Heimfallrecht für erbenlose Nachlässe bestätigt die Rechtslage, wie sie sich auch aus der juristischen Überlieferung ergibt; gleichzeitig bietet $\S 4$ einen klaren Beleg für die durch die literarische, juris-

vocant - Emblematischer Codewechsel in den Juristenschriften, in: J. Hallebeek et al. (Hgg.), Essays Sirks, 2014, 46-48.

$\left.{ }^{300}\right)$ P.Oxy. XLII 3014 enthält gegenüber BGU V,1210 zudem die früheste Bezeu-

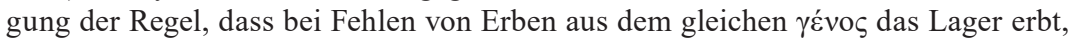
vgl. P.J. Pars on s (Hg.), The Oxyrhynchus Papyri, vol. XLII, London 1974, 51. 
tische und inschriftliche Überlieferung gespeiste Annahme einer Fiskalisierung des aerarium.

(3) Die in $\S 7$ vorgeschriebenen Förmlichkeiten der Testamentserrichtung können auch auf das römische Testament bezogen werden und geben damit Anlass, den überkommenen Topos der gleichsam, außergesetzlichen‘ Testierfreiheit in Rom zu hinterfragen. Die hier vorgeschlagene Interpretation des $\S 7$ wird gestützt durch $\S 8$, der Umgehungsversuche des förmlichen römischen Testaments durch das Kodizillarrecht ausschließt. Gleichzeitig bietet $\S 8$ einen einsichtigen Anwendungsfall der in der justinianischen Überlieferung eher theoretisch scheinenden Differenzierung zwischen Kodizill und Testament.

(4) Die fehlende testamenti factio zwischen Personen verschiedener Bürgerschaft bildet den Hintergrund von § 18, der Erbschaftsfideikommisse zwischen Römern und Griechen verbietet. Dabei legt der Gnomon nahe, dass neben der Regelung der Erbschaftsfideikommisse durch das SC Pegasianum und dem Verbot von Einzelfideikommissen an Peregrine unter Hadrian, weitere kaiserliche Maßnahmen (namentlich unter Vespasian) ergangen sein müssen, um die bürgerschaftlichen Grenzen des Erbrechts zu wahren. Andernfalls hätte gerade das Erbschaftsfideikommiss zu Zuwendungen über die Bürgerschaft hinaus verwendet werden können.

(5) Besonders wichtige Details vermittelt der Gnomon für die vielfältigen und in der sonstigen Überlieferung nur schemenhaft erkennbaren Rechtsfolgen der lex Iulia et Papia. Neben Einzelfragen ist vor allem die unterschiedliche Behandlung der Geschlechter hervorzuheben, die sich vorrangig in einer abweichenden Regelung der capacitas zeigt: Während für Männer zwischen caelibatus und orbitas unterschieden wird, werden Frauen mit der vollen incapacitas bestraft, unabhängig davon, ob sie unverheiratet oder verheiratet und kinderlos sind. Entscheidend ist für Frauen allein das ius liberorum. Dieses Privileg, das nach der bisherigen Überlieferung vor allem von der Geschlechtsvormundschaft befreite, ist nach der hier vorgeschlagenen Interpretation des $\S 30$ auch für die durch die lex Papia Poppaea erfolgte Anpassung der lex Voconia maßgeblich.

(6) Die (aktive) Testierfreiheit der Frau betreffend bietet $\S 33$ Anlass, die ohnehin wenig durchsichtige Überlieferung zum Verzicht auf die coëmptio zur Erlangung der Testierfähigkeit zu hinterfragen. Möglich scheint nach der hier vertretenen Deutung, dass auch nach der Reform durch Hadrian nicht alle Frauen automatisch testierfähig waren, sondern möglicherweise erst nach einem Verfahren zur Befreiung von der coëmptio. Vor allem aber zeigt $\S 33$, dass die Pupillarsubstitution Frauen verschlossen bleibt, sodass 
Legate, die auf den Erbfall ihres (unmündigen) Kindes ausgesetzt sind, eingezogen werden.

(7) Für das Sonderrecht der Soldaten belegen $\S 34$ und 35, dass die Rechtslage in den Digesten vereinfacht dargestellt wird. So offenbart $§ 34$ eine interessante Zwischenstufe des in den Digesten überlieferten Testierprivilegs, indem Soldaten und Trosspersonen ein Wahlrecht zwischen der römischen und griechischen Testamentsform zugestanden wird. §35 zum Intestaterbrecht schließlich zeigt eine in der juristischen Überlieferung nur erahnbare Komponente der im prätorischen Erbrecht vollzogenen Akzeptanz der Blutsverwandtschaft (cognatio): Auch Kinder und Verwandte von Peregrinen sind - soweit es um Soldaten geht - antragsberechtigt.

2. Weitergehende Folgerungen für das römische Erbrecht:

Aus der Gesamtperspektive des römischen Erbrechts sind drei Aspekte der hier beschriebenen Einzelbeobachtungen zusammenfassend hervorzuheben.

Die erste Beobachtung betrifft die Fiskalisierung des Erbrechts, die sich darin zeigt, dass dem Fiskus im Erbfall weitreichende Zugriffsmöglichkeiten eröffnet werden. Diese beschränken sich nicht nur auf die confiscatio im Fall der bona damnatorum, sondern erfassen gerade auch die Einforderung von bona vacantia und bona caduca im Wege der vindicatio bonorum. Nicht nur der Gnomon, sondern auch die Ulpiani Epitome belegen, dass der Begriff des caducum nicht auf Erbschaften und Legate von erwerbsunfähigen Personen beschränkt war, sondern jegliches Scheitern der erblasserischen Planung erfasste: Hierzu zählen etwa der Tod des eingesetzten Erben, der Bedingungsausfall sowie Fälle der Unwirksamkeit der letztwilligen Verfügung, die sowohl aus formellen als auch materiellen Gründen eintreten kann (vgl. oben II.3). Dieser im Gnomon offensichtliche Fiskalismus ist nicht als Sonderentwicklung im römischen Ägypten (vgl. oben I.), sondern als generelle Tendenz des kaiserzeitlichen Erbrechts anzusehen. Dafür spricht zum einen, dass die meisten der auch im Gnomon zitierten Vorschriften aus römischen Gesetzen, Senatsbeschlüssen und Kaiserkonstitutionen stammen und keineswegs lokalen Ursprungs sind; zum andern geben auch die justinianischen Quellen, namentlich die Reformkonstitution zur Beseitigung der Kadukargesetzgebung (vgl. oben V.), zu erkennen, dass die Zugriffsrechte des Fiskus in der römischen Kaiserzeit über das hinausgehen, was Digesten und Codex mitteilen. Der Gnomon schließt damit eine Überlieferungslücke und lässt erahnen, welche Dimension die fiskalische Ausbeute von Erbschaften gerade auch in Rom selbst gehabt haben dürfte. 
Der administrative Zugriff auf das Erbrecht - so die zweite Lektion aus der Betrachtung des Gnomon - ist aber keineswegs auf die fiskalischen Interessen beschränkt. Wie $\S 7$ (s. o. IV.1) und $§ 4$ (s. o. III.) belegen, liegen erbrechtliche Fragen - von der Behandlung herrenlosen Gutes bis zur Testamentsform - offenbar im Interesse des Gemeinwesens. Dies erklärt, warum das Testament nur dann wirksam errichtet ist, wenn die gesetzlichen, ediktalen und kaiserrechtlichen Vorgaben und Begrenzungen eingehalten wurden (vgl. oben IV.1). Die Mehrzahl der im Gnomon zu beachtenden Regeln wird auch in der justinianischen Kompilation überliefert; erst die auf Anwendung ausgelegte Darstellung im Gnomon hebt aber die praktische Relevanz und die Durchsetzungsfolgen der Nichtigkeitsanordnungen hervor.

Der dritte Aspekt, der sich für das römische Erbrecht aus der Betrachtung des Gnomon ergibt, betrifft das Verhältnis zwischen Provinzialrecht und römischer Rechtsentwicklung, das ganz unterschiedliche Facetten aufweist. So sind zunächst Situationen erkennbar, in denen eine Praxis des lokalen Rechts inzident mit einem römischen Prinzip verglichen wird, um sodann die römische Regelung einzuschärfen; hier ist vor allem an die für römische Bürger geltende temporale Schranke von Veräußerungsverboten (§2), an das Verbot der Umgehung der römischen Testamentsform (\$7) sowie an die Grenzen der Testierfreiheit der römischen Frau (§33) zu erinnern: In allen drei Vorschriften wird die Besonderheit der römischen Regel fortgeschrieben, obgleich das lokale Recht eine abweichende Lösung bereithielte. Eine weitere, unter dem Stichwort „Provinzialrecht“ einzuordnende Erscheinung betrifft den Rechtskontakt von Römern und Nichtrömern. Hier steht weniger die Kollision von Rechtsanschauungen, als vielmehr die Möglichkeit, auch über die eigene Herkunftszugehörigkeit hinweg erbrechtlich zu verfügen, im Vordergrund. Wie insbesondere das in $\S 18$ angeordnete Verbot von Universalfideikommissen zwischen Römern und Griechen zeigt, besteht wenig Bereitschaft der römischen Behörden, Verfügungen zwischen den verschiedenen Bevölkerungsgruppen zuzulassen ${ }^{301}$ ): Obwohl also Fideikommisse prinzipiell formlos ausgesetzt werden können, wird am Erfordernis der testamenti factio festgehalten. Erst an dritter Stelle sind unter dem Stichwort „Provinzialrecht" vereinzelt Fälle zu beobachten, in denen eine dem römischen Recht widersprechende lokale Praxis ausnahmsweise doch mit Wirkungen ausgestattet wird. Die besten Beispiele für diese Tendenz sind die Vorschriften

${ }^{301}$ ) So bereits der allgemeine Befund von H.J. Wolff, Das Problem der Konkurrenz von Rechtsordnungen in der Antike, 1979, 66-72; weitere Nachweise bei W. Kais er, s.v. Volksrecht, in: DNP 12.2, 2003, Sp. 303-306. 
zum Erbrecht der Soldaten (§§34-35); die hier ersichtlichen Zugeständnisse sind aber einerseits weniger weitreichend, als es die justinianische Überlieferung glauben lässt; andererseits sind sie auf diese für Rom wichtige Gruppe beschränkt und keineswegs verallgemeinerbar (vgl. oben VIII.).

Aus alldem ergibt sich, dass das römische Erbrecht vielfältigen Einflüssen und widersprüchlichen gesellschaftlichen Anforderungen ausgesetzt ist, die auf die kautelarjuristische Gestaltung ebenso wirken wie auf die Gesetzgebung und kaiserliche Rechtssetzung. Durch die Berücksichtigung dieser Faktoren wird die bereits in der justinianischen Kompilation zum Ausdruck kommende Komplexität des Erbrechts noch gesteigert; gleichzeitig aber ergeben sich neue Erklärungsansätze für die nicht immer nachvollziehbare Fülle erbrechtlicher Regeln, Vorgaben und Gestaltungsmöglichkeiten in der römischen Kaiserzeit. Daher erscheint es notwendig, die aus dem Gnomon ablesbaren Tendenzen der Fiskalisierung, der öffentlichrechtlichen Prägung und der Provinzialisierung des römischen Erbrechts auch bei der Untersuchung der juristischen Überlieferung stärker als bisher zu berücksichtigen.

\section{Ausblick:}

Ausgangspunkt dieser Untersuchung war die Frage, inwieweit der Gnomon als Quelle des römischen Erbrechts herangezogen werden kann. Der hierzu angestellte Vergleich mit der juristischen Überlieferung hat für viele erbrechtliche Institute neue Details geliefert und neue Fragen aufgeworfen und ist geeignet, die Bewertung des römischen Erbrechts insgesamt zu beeinflussen. Der Hauptertrag der romanistischen Befassung mit dem Gnomon aber liegt offensichtlich darin, den Blick des Interpreten für den evolutionären Charakter des römischen Erbrechts zu schärfen und die durch die justinianische Kompilation hervorgerufene Verengung der Perspektive zu vermeiden $^{302}$ ).

${ }^{302}$ ) Dies entspricht dem Programm von L. Wenger, Der heutige Stand der römischen Rechtswissenschaft, 1927, 5-11: „Das feste Datum der justinianischen Gesetzgebung hat nun aber eine eigenartige bedenkliche Folgeerscheinung. Dem Juristen war das Corpus Iuris Civilis, wie das Mittelalter Justinians Gesetzgebung genannt hat, ,das römische Recht' schlechthin geworden. Diese, wenn auch noch so bedeutsame Entwicklungsphase, dieser Querschnitt durch die römische Rechtsentwicklung zu Justinians Zeit, ließ nämlich alles Vorher und Nachher versinken.“ 